\title{
Uptake, Trapping, and Release of Organometallic Cations by Redox-Active Cationic Hosts
}

\author{
Iram F. Mansoor," Kaitlyn G. Dutton," Daniel A. Rothschild, Richard C. Remsing, and Mark C. Lipke* \\ Department of Chemistry and Chemical Biology, Rutgers The State University of New Jersey \\ 123 Bevier Road, Piscataway NJ 08854 \\ \# These authors contributed equally to this work. \\ *Email:
}

\section{Supporting Information}

$\underline{\text { Table of Contents: }}$

1. General Considerations. .52

2. Preparation of $\mathrm{Cp}_{2} * \mathrm{Co}^{+} @ 1 a^{12+}$ and $\mathrm{Cp}_{2} \mathrm{Co}^{+} @ 1 \mathbf{b}^{12+}$ .53

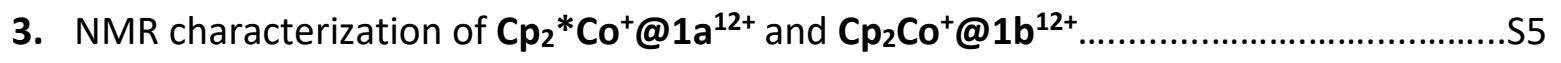

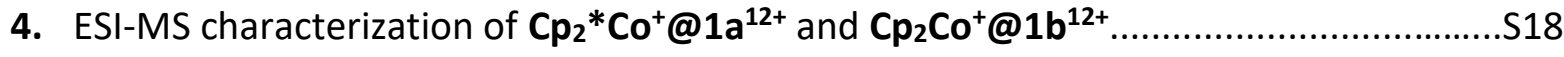

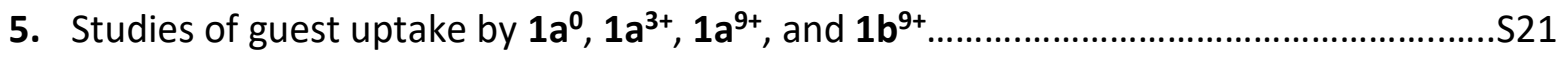

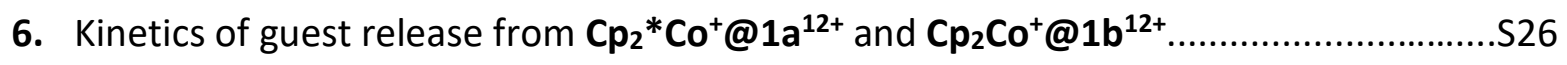

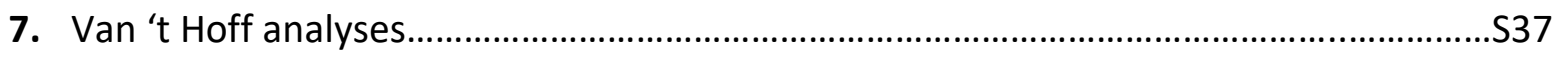

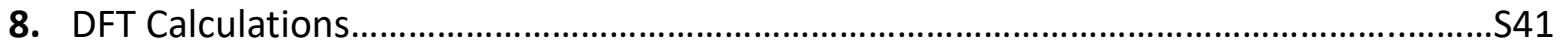

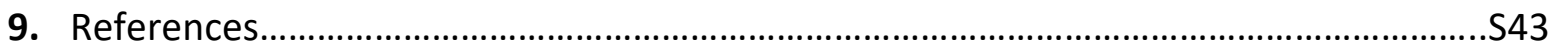




\section{General Considerations}

Sources: Unless otherwise specified, commercially available chemicals and solvents were used as received from (1) Fisher: acetonitrile; (2) Acros Organics: tetrabutylammonium hexafluorophosphate, silver(I) hexafluorophosphate; (3) Alfa-Aesar: ferrocene ( $F c$ ); (4) Cambridge Isotopes: acetonitrile- $\mathrm{d}_{3}$ (D-99.8\%) and benzene- $d_{6}$ (D-99.5\%); (5) Sigma Aldrich: ferrocenium hexafluorophosphate ([Fc]PF 6 ), cobaltocene $\left(\mathrm{Cp}_{2} \mathrm{Co}\right)$, and decamethylcobaltocene $\left(\mathrm{Cp}_{2}{ }_{2} \mathrm{Co}\right) ;(6)$ Strem Chemicals: silver(I)

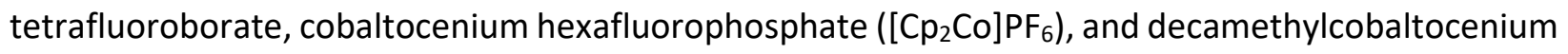
hexafluorophosphate $\left(\left[\mathrm{Cp}^{*}{ }_{2} \mathrm{Co}_{\mathrm{P}} \mathrm{PF}_{6}\right)\right.$; (7) Oakwood Chemical: fluorobenzene. Nanocages $\mathbf{1 a} \cdot \mathbf{1 2 X}$ and $\mathbf{1 b} \cdot \mathbf{1 2 X}\left(\mathrm{X}^{-}=\mathrm{PF}_{6}{ }^{-}, \mathrm{BF}_{4}{ }^{-}\right)$were prepared as previously described. ${ }^{1}$

Purification: Solvents for NMR spectroscopy were dried over a suitable drying agent $\left(\mathrm{CaH}_{2}\right.$ for $\mathrm{CD}_{3} \mathrm{CN}$; NaK alloy for $\mathrm{C}_{6} \mathrm{D}_{6}$ ), subjected to three freeze-pump-thaw cycles, distilled by vacuum transfer, and then stored in an $\mathrm{N}_{2}$ atmosphere glovebox prior to use. Ferrocene was sublimated under static vacuum prior to use. Cobaltocene $\left(\mathrm{Cp}_{2} \mathrm{Co}\right)$ and decamethylcobaltocene $\left(\mathrm{Cp} *{ }_{2} \mathrm{Co}\right)$ were sublimated under dynamic vacuum and stored at $-25{ }^{\circ} \mathrm{C}$ in an $\mathrm{N}_{2}$ atmosphere glovebox prior to use. Tetrabutylammonium hexafluorophosphate $\left(\mathrm{TBAPF}_{6}\right)$ was recrystallized three times from absolute ethanol, dried at $125{ }^{\circ} \mathrm{C}$ under dynamic vacuum for $\geq 12$ hours, and stored in an $\mathrm{N}_{2}$ atmosphere glovebox prior to use.

Air-Sensitive Procedures: All reduction and reoxidation experiments were carried out in an MBraun Unilab inert atmosphere $\left(\mathrm{N}_{2}\right)$ glovebox. Solids were weighed inside the glovebox using a Sartorius Secura 225D-1S semimicro analytical balance accompanied by an electronic ionizer to eliminate static. Liquids were measured and transferred using Hamilton microliter syringes. Spectra were acquired on samples that were sealed under $\mathrm{N}_{2}$, either in PTFE-valved NMR tubes or by wrapping the cap of traditional NMR tubes tightly with PTFE tape.

Physical Measurements: NMR spectra were recorded at $25{ }^{\circ} \mathrm{C}$ unless otherwise stated, using a Bruker AVANCE Neo $500 \mathrm{MHz}$ spectrometer or a Varian VNMRS $500 \mathrm{MHz}$ spectrometer. Spectra were referenced using the residual proteo signal of the solvent for ${ }^{1} \mathrm{H}$ NMR data and a sealed capillary of fluorobenzene in $\mathrm{CD}_{3} \mathrm{CN}$ for ${ }^{19} \mathrm{~F}$ NMR data. High resolution mass spectra were obtained via direct infusion of acetonitrile solutions of the analyte into a Waters Xevo G2-XS QTof mass spectrometer. Additional details of physical measurements are provided below in their respective sections. 


\section{Preparation of $\mathrm{Cp}_{2} * \mathrm{Co}^{+} @ 1 a^{12+}$ and $\mathrm{Cp}_{2} \mathrm{Co}^{+} @ 1 b^{12+}$}

\section{2.a. $\mathrm{Cp}_{2} * \mathrm{Co}^{+} @ 1 \mathrm{a}^{12+}$}

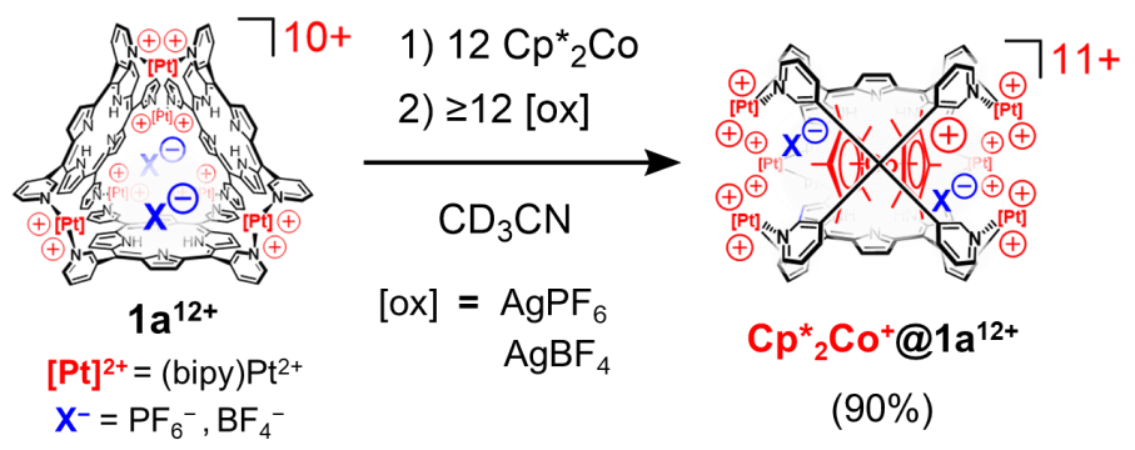

General Procedure: $\mathrm{Cp}^{*}{ }_{2} \mathrm{Co}^{+} @ 1 \mathrm{a}^{12+}$ was generated in situ by addition of 12 equiv of $\mathrm{Cp}^{*}{ }_{2} \mathrm{Co}$ as a stock solution in $\mathrm{C}_{6} \mathrm{D}_{6}$ to a solution of $\mathbf{1 a} \cdot \mathbf{1 2}^{2} \mathrm{PF}_{6}$ or $\mathbf{1 a} \cdot \mathbf{1 2} \mathrm{BF}_{4}$ in $\mathrm{CD}_{3} \mathrm{CN}$, followed by reoxidation after 30 min with 12.1 to 12.5 equiv of $\mathrm{AgPF}_{6}$ or $\mathrm{AgBF}_{4}$ added as stock solutions in $\mathrm{CD}_{3} \mathrm{CN}$. After reoxidation, the ratio of $\mathrm{Cp}_{2}{ }_{2} \mathrm{Co}^{+} @ 1 \mathrm{a}^{12+}$ to unconverted $1 \mathrm{a}^{12+}$ was determined by integration of the ${ }^{1} \mathrm{H}$ NMR resonances of the pyridyl 6-position $\mathrm{CH}$ bonds, which were the sharpest and best separated resonances of the host-guest complex vs. the free host. All stock solutions were prepared in an $\mathrm{N}_{2}$ atmosphere glovebox containing < $0.5 \mathrm{ppm}$ of $\mathrm{O}_{2}$ and $\mathrm{H}_{2} \mathrm{O}$. Solids were weighed directly in tared vials on a semi-micro balance before the appropriate amount of solvent was transferred into the vial using a microliter syringe. Microliter syringes were also used for subsequently measuring and transferring stock solutions to prepare $\mathrm{Cp}^{*}{ }_{2} \mathrm{Co}^{+} @ 1 \mathbf{a}^{12+}$.

Representative Procedure 1 (single sample): In an $\mathrm{N}_{2}$ atmosphere glovebox, $0.600 \mathrm{~mL}$ of a $1.34 \mathrm{mM}$ solution of $1 \mathrm{a} \cdot 12 \mathrm{PF}_{6}(0.80 \mu \mathrm{mol})$ in $\mathrm{CD}_{3} \mathrm{CN}$ was transferred into a J-Young style air-free NMR tube containing a sealed capillary of ferrocene in $\mathrm{CD}_{3} \mathrm{CN}$. The NMR sample was sealed with a PTFE stopper and its ${ }^{1} \mathrm{H}$ NMR spectrum was acquired. After returning the sample to the glovebox, $58 \mu \mathrm{L}$ of a $0.166 \mathrm{M}$ solution of $\mathrm{Cp}^{*}{ }_{2} \mathrm{Co}\left(9.6 \mu \mathrm{mol}, 12\right.$ equiv) in $\mathrm{C}_{6} \mathrm{D}_{6}$ was added. The tube was resealed and then turned over repeatedly to mix the solutions, resulting in an immediate change of appearance from a clear, dark red-purple color to an opaque green color with a voluminous yellow-brown precipitate. The tube was sealed again, and the ${ }^{1} \mathrm{H}$ NMR spectrum of the sample was acquired, showing the disappearance of all resonances of $1 \mathrm{a}^{12+}$. Integration of the $\mathrm{Cp}_{2}{ }_{2} \mathrm{Co}^{+}$resonance against the resonance of the ferrocene standard confirmed that the appropriate amount of $\mathrm{Cp}_{2}{ }_{2} \mathrm{Co}$ had been added. The sample was returned to the glovebox, and after a total of $30 \mathrm{~min}$ in the reduced state, $19.5 \mu \mathrm{L}$ of a $0.50 \mathrm{M}$ solution of $\mathrm{AgPF}_{6}\left(9.8 \mu \mathrm{mol}, 12.2\right.$ equiv) in $\mathrm{CD}_{3} \mathrm{CN}$ was added. The tube was sealed and turned over repeatedly to mix the solutions, resulting in an immediate color change to brownish red with a fine precipitate of $\mathrm{Ag}^{0}$ evident. The ${ }^{1} \mathrm{H}$ NMR spectrum of the sample was acquired and integration against the ferrocene standard confirmed that $\geq 95 \%$ of the cage was observable as $\mathrm{Cp}_{2}{ }_{2} \mathrm{Co}^{+} @ 1 \mathbf{a}^{12+}$ or unconverted $1 \mathbf{a}^{12+}$ in an approximately 9:1 ratio.

Representative Procedure 2 (batch preparation): In an $\mathrm{N}_{2}$ atmosphere glovebox, $221.5 \mu \mathrm{L}$ of a $0.18 \mathrm{M}$ solution of $\mathrm{Cp} *{ }_{2} \mathrm{Co}\left(39.9 \mu \mathrm{mol}, 12\right.$ equiv) in $\mathrm{C}_{6} \mathrm{D}_{6}$ was added to $2.550 \mathrm{~mL}$ of a $1.33 \mathrm{mM}$ solution of $1 \mathrm{a} \cdot 12 \mathrm{PF}_{6}$ (39.9 $\mu \mathrm{mol})$ in $\mathrm{CD}_{3} \mathrm{CN}$ in a scintillation vial. The vial was capped and swirled for several seconds, resulting 
in an immediate change in appearance of the solution from a clear, dark red-purple color to an opaque green color with a voluminous yellow-brown precipitate. The sample was left for 30 min without a significant change in appearance before $82.0 \mu \mathrm{L}$ of a $0.50 \mathrm{M}$ solution of $\mathrm{AgPF}_{6}$ (41 mmol, 12.3 equiv) in $\mathrm{CD}_{3} \mathrm{CN}$ was added. The vial was capped and swirled for several seconds, resulting in an immediate color change to brownish red with a fine precipitate of $\mathrm{Ag}^{0}$ evident. The final combined concentration of $\mathrm{Cp}^{*}{ }_{2} \mathrm{Co}^{+} @ 1 \mathrm{a}^{12+}$ and unconverted $1 \mathrm{a}^{12+}$ was $1.19 \mathrm{mM}$. The ${ }^{1} \mathrm{H}$ NMR spectrum of the sample was acquired, finding an approximately 9:1 ratio of $\mathrm{Cp}^{*}{ }_{2} \mathrm{Co}^{+} @ 1 \mathbf{a}^{12+}$ to unconverted $1 \mathbf{a}^{12+}$.

\section{2.b. $\mathrm{Cp}_{2} \mathrm{Co}^{+} @ 1 b^{12+}$}

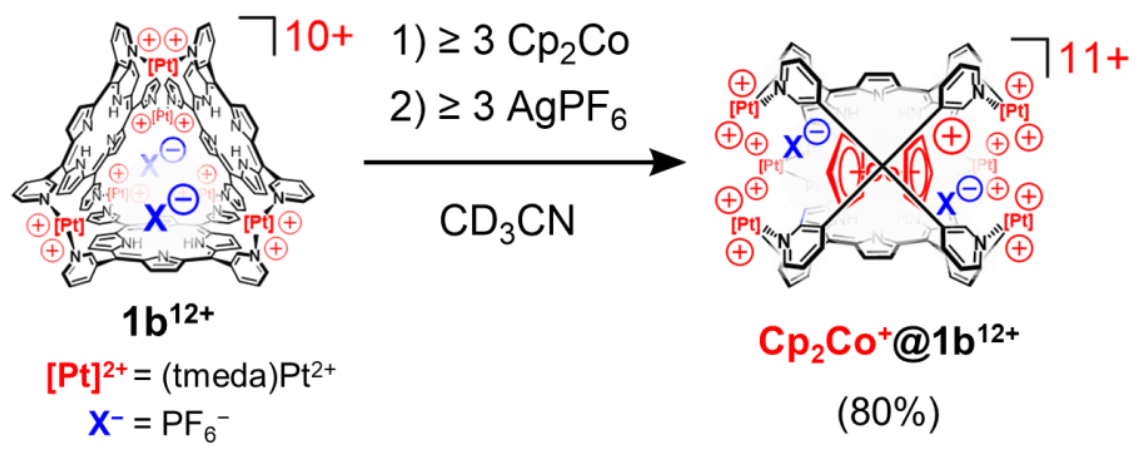

General Procedure: $\mathbf{C p}_{2} \mathbf{C o}^{+} @ \mathbf{1} \mathbf{b}^{12+}$ was prepared in a manner similar to that described above for the single-sample preparation of $\mathbf{C p}_{2}{ }_{2} \mathrm{Co}^{+} @ 1 a^{12+}$ (Procedure 1), except that an excess of $\mathrm{Cp}_{2} \mathrm{Co}$ (3.5- 6 equiv) was typically employed to reduce $\mathbf{1 b}^{\mathbf{1 2 +}}$ since reduction past the $\mathbf{1 b}^{\mathbf{9 +}}$ state is not possible using $\mathrm{Cp}_{2} \mathrm{Co}$. After reoxidation, the ratio of $\mathbf{C p}_{2} \mathbf{C o}^{+} @ \mathbf{1} \mathbf{b}^{\mathbf{1 2 +}}$ to unconverted $\mathbf{1} \mathbf{b}^{\mathbf{1 2 +}}$ was determined by integration of the ${ }^{1} \mathrm{H}$ NMR resonances of the porphyrin NH bonds, which were the sharpest and best separated resonances of the host-guest complex vs. the free host. Conversion to $\mathbf{C p}_{\mathbf{2}} \mathbf{C o}^{+} @ \mathbf{1} \mathbf{b}^{\mathbf{1 2 +}}$ did not vary noticeably for samples reduced with 3, 3.5, or 6 equiv of $\mathrm{Cp}_{2} \mathrm{Co}$.

Representative Procedure: In an $\mathrm{N}_{2}$ atmosphere glovebox, $0.660 \mathrm{~mL}$ of a $1.22 \mathrm{mM}$ solution of $\mathbf{1 b} \cdot \mathbf{1 2} \mathrm{PF}_{\mathbf{6}}$ $(0.80 \mu \mathrm{mol})$ in $\mathrm{CD}_{3} \mathrm{CN}$ was transferred into an air-free NMR tube containing a sealed capillary of ferrocene in $\mathrm{CD}_{3} \mathrm{CN}$. The NMR sample was sealed with a polyethylene cap, secured with PTFE tape, and the ${ }^{1} \mathrm{H} N M R$ spectrum was acquired. After returning the sample to the glovebox, $9.5 \mu \mathrm{L}$ of a $0.30 \mathrm{M}$ solution of $\mathrm{Cp}_{2} \mathrm{Co}$ ( $2.9 \mu \mathrm{mol}, 3.6$ equiv) in $\mathrm{C}_{6} \mathrm{D}_{6}$ was added. The tube was sealed with a polyethylene cap and then turned over repeatedly to mix the solutions, resulting in an immediate change of appearance from a clear dark red color to a dark green color. The tube was sealed again with PTFE tape, and the ${ }^{1} \mathrm{H}$ NMR spectrum of the sample was acquired, showing the disappearance of all resonances of $\mathbf{1}^{\mathbf{1 2 +}}$. The sample was returned to the glovebox, and after a total of $30 \mathrm{~min}$ in the reduced state, $6.5 \mu \mathrm{L}$ of a $0.46 \mathrm{M}$ solution of $\mathrm{AgPF}_{6}$ (3.0 $\mu$ mol, 3.7 equiv) in $\mathrm{CD}_{3} \mathrm{CN}$ was added. The tube was sealed and turned over repeatedly to mix the solutions, resulting in an immediate color change to brownish red with a fine precipitate of $\mathrm{Ag}^{0} \mathrm{evident.}$ The ${ }^{1} \mathrm{H}$ NMR spectrum of the sample was acquired, finding an approximately 8:2 ratio of $\mathbf{C p}^{*}{ }_{2} \mathrm{Co}^{+} @ \mathbf{1 b}^{\mathbf{1 2 +}}$ to unconverted $\mathbf{1} \mathbf{b}^{\mathbf{1 2 +}}$. 


\section{NMR characterization of $\mathrm{Cp}_{2}{ }^{*} \mathrm{Co}^{+} @ 1 \mathrm{a}^{12+}$ and $\mathrm{Cp}_{2} \mathrm{Co}^{+} @ 1 b^{12+}$}

Instrumentation: Nuclear magnetic resonance (NMR) spectra were measured using a Bruker AVANCE Neo spectrometer or a Varian VNMR spectrometer, both with a $500 \mathrm{MHz}$ working frequency for ${ }^{1} \mathrm{H}$ nuclei and a $470 \mathrm{MHz}$ working frequency for ${ }^{19} \mathrm{~F}$ nuclei. All spectra were recorded at $298 \mathrm{~K}$ unless otherwise noted. Chemical shifts of ${ }^{1} \mathrm{H}$ NMR spectra were referenced to the residual proteo signal of the solvent $\left({ }^{1} \mathrm{H} \delta 1.94\right.$ ppm for $\mathrm{CD}_{2} \mathrm{HCN}$ in $\mathrm{CD}_{3} \mathrm{CN}$ ), and ${ }^{19} \mathrm{~F}$ NMR spectra were referenced to a capillary standard of $1 \mathrm{M}$ fluorobenzene in $\mathrm{CD}_{3} \mathrm{CN}\left({ }^{19} \mathrm{~F} \delta-114.26 \mathrm{ppm}\right)$. The signal of fluorobenzene in $\mathrm{CD}_{3} \mathrm{CN}$ was calibrated against a capillary standard of neat fluorobenzene $\left({ }^{19} \mathrm{~F} \delta-113.5 \mathrm{ppm}\right.$ relative to $\mathrm{CFCl}_{3} @ 0$ ppm). ${ }^{2}$ Internal standards consisting of $\mathrm{CD}_{3} \mathrm{CN}$ solutions of ferrocene $(\mathrm{Fc})$ sealed in glass capillaries were used to track ${ }^{1} \mathrm{H}$ NMR integrations across multiple spectra.

\section{3.a. $\mathrm{Cp}_{2}{ }^{*} \mathrm{Co}^{+} @ 1 a^{12+}$ with $\mathrm{BF}_{4}^{-}$counteranions, formed using $\mathrm{AgBF}_{4}$.}

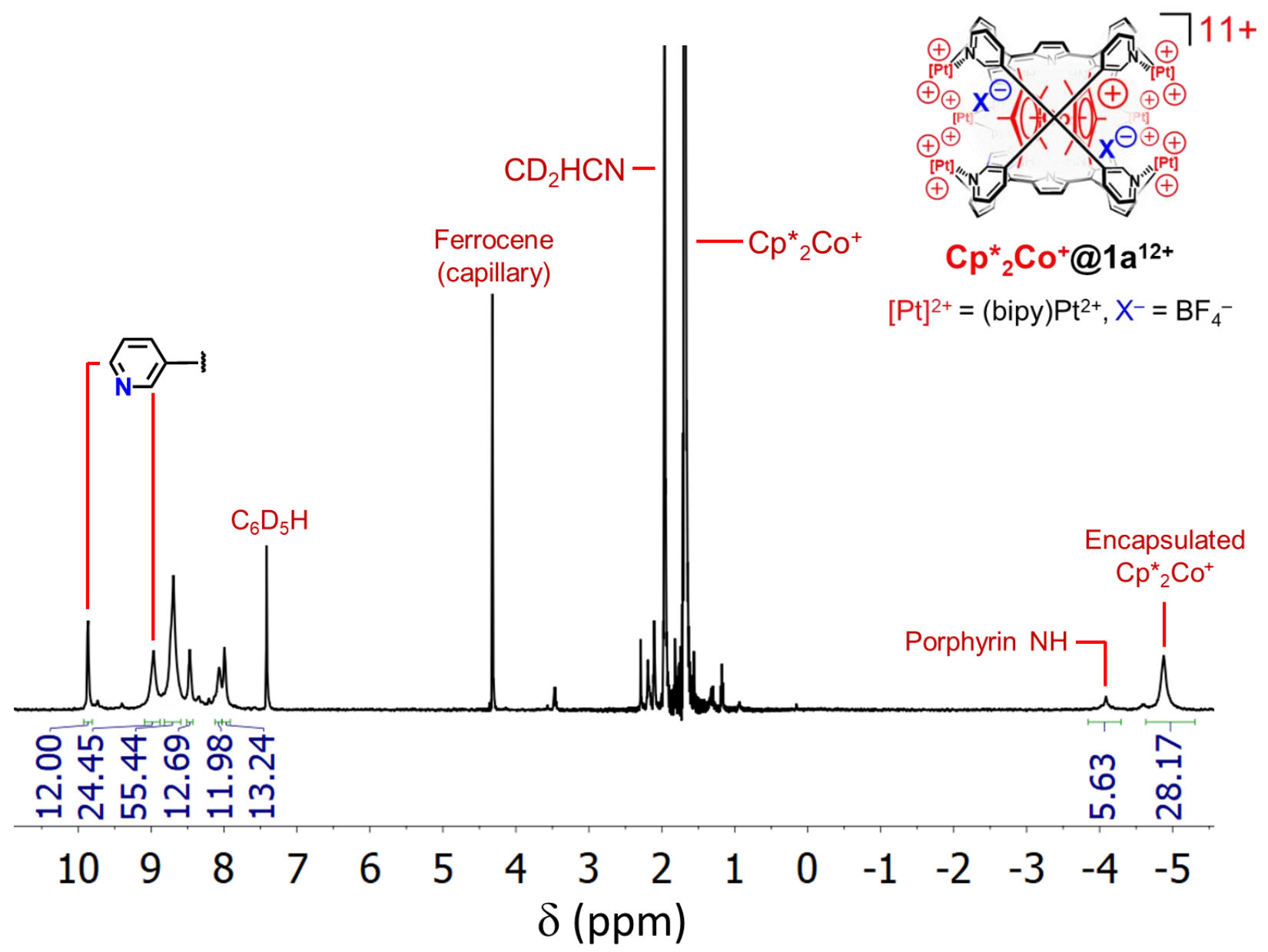

Figure S1. Full ${ }^{1} \mathrm{H}$ NMR spectrum of a $1.2 \mathrm{mM}$ solution of $\mathrm{Cp}^{*}{ }_{2} \mathrm{Co}^{+} @ 1 \mathrm{a}^{12+}$ with $\mathrm{BF}_{4}{ }^{-}$anions $(29 \mathrm{mM})$ in $\mathrm{CD}_{3} \mathrm{CN}$. Select resonances of the host-guest complex are labeled along with any major resonances that do not arise from the host-guest complex. 


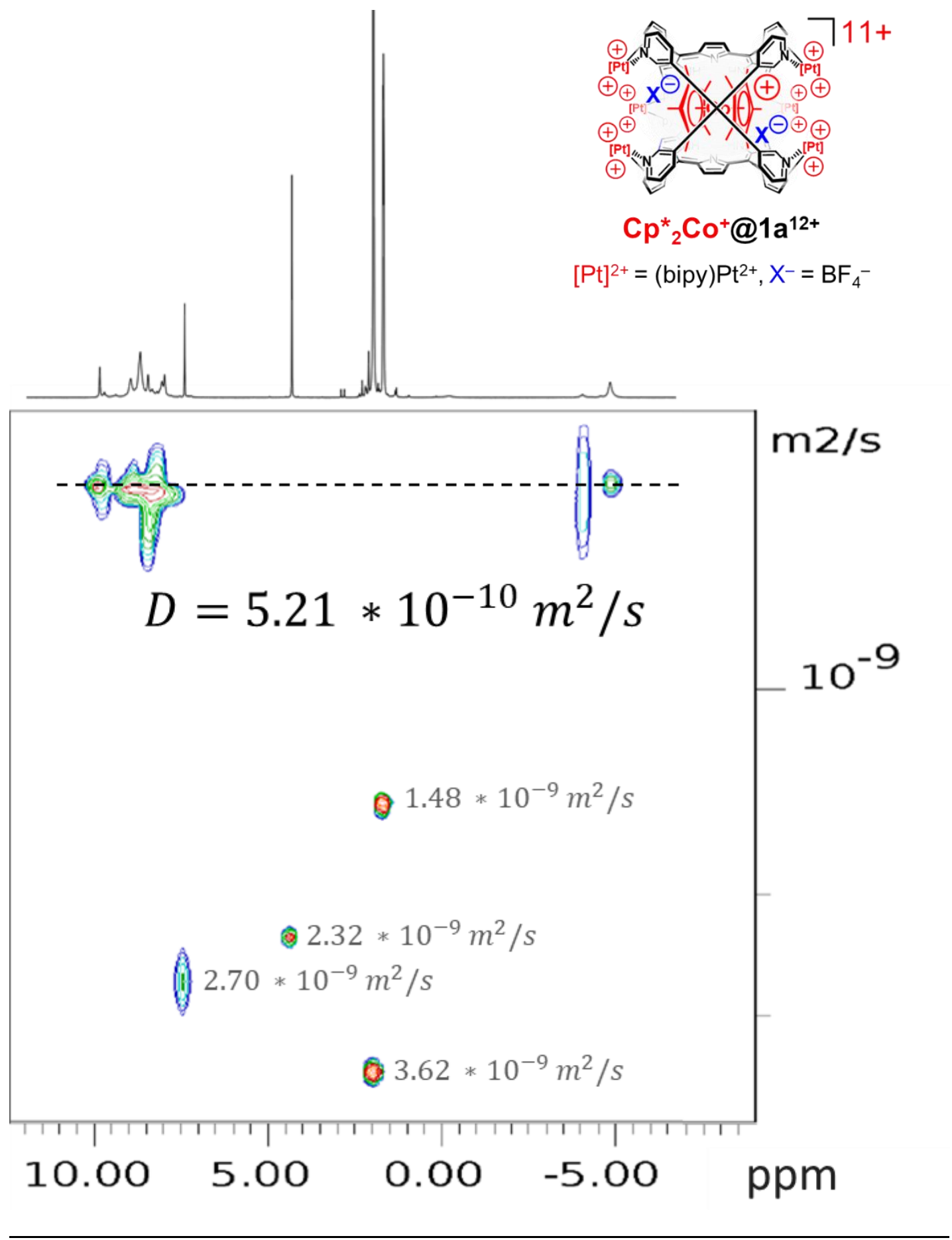

Figure S2. Diffusion ordered (DOSY) ${ }^{1} \mathrm{H}$ NMR spectrum of a $1.2 \mathrm{mM}$ solution of $\mathrm{Cp}^{*}{ }_{2} \mathrm{Co}^{+} @ 1 \mathrm{a}^{12+}$ with $\mathrm{BF}_{4}{ }^{-}$ anions (29 mM) in $\mathrm{CD}_{3} \mathrm{CN}$. The experimental diffusion constant corresponds to a spherical hydrodynamic radius $^{3}$ of $12.5 \AA$., which is similar to that reported for $1 a^{12+}$. 

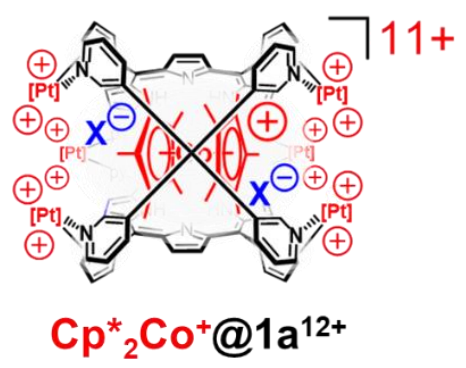

$[\mathrm{Pt}]^{2+}=($ bipy $) \mathrm{Pt}^{2+}, \mathrm{X}^{-}=\mathrm{BF}_{4}^{-}$

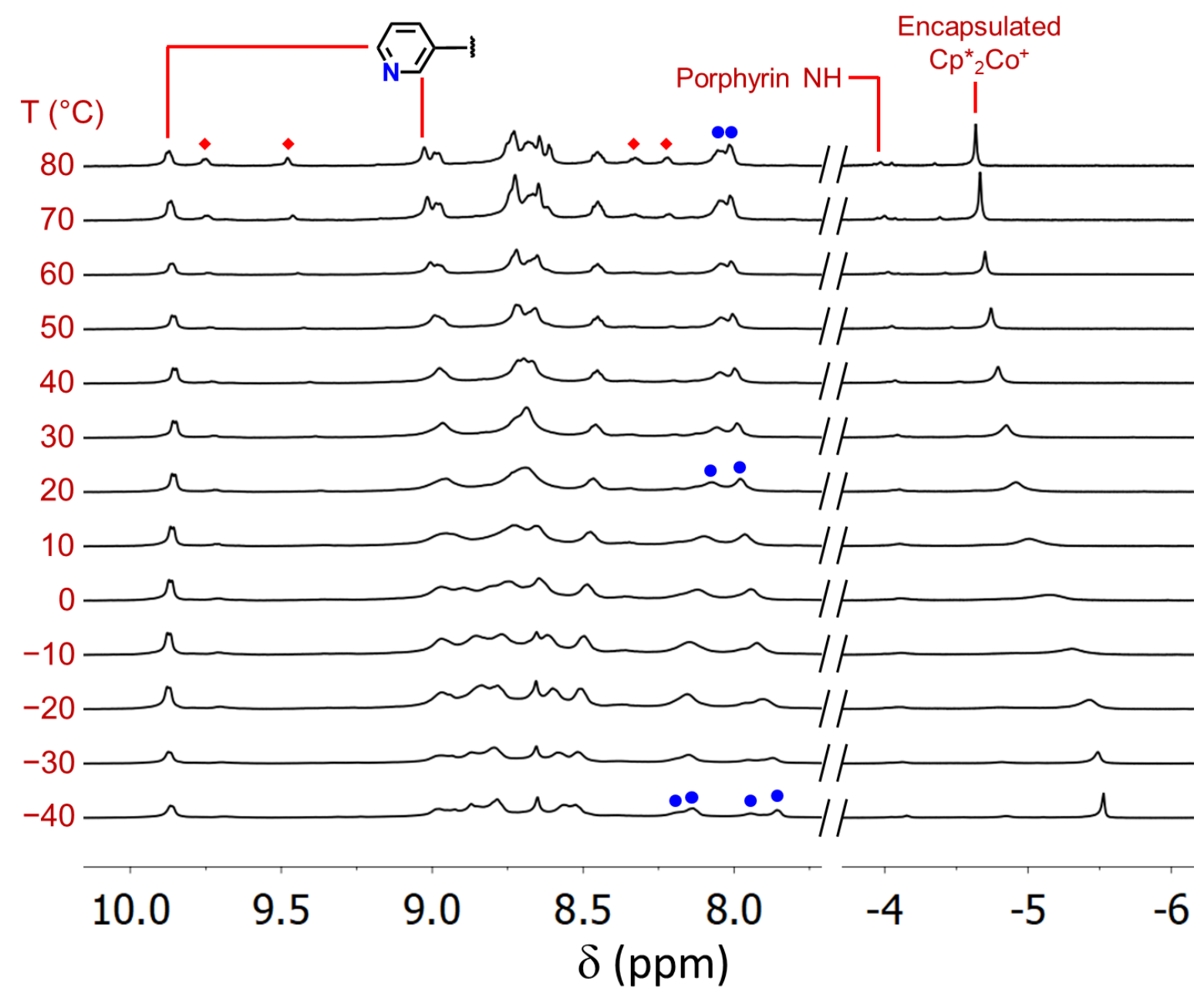

Figure S3. ${ }^{1} \mathrm{H}$ NMR spectra recorded from $-40{ }^{\circ} \mathrm{C}$ to $80{ }^{\circ} \mathrm{C}$ on a $1.2 \mathrm{mM}$ solution of $\mathrm{Cp}^{*}{ }_{2} \mathrm{Co}^{+} @ 1 \mathrm{a}^{12+}$ with $\mathrm{BF}_{4}{ }^{-}$anions $(29 \mathrm{mM})$ in $\mathrm{CD}_{3} \mathrm{CN}$. Select resonances of the host-guest complex are labeled. Red diamonds mark resonances that arise from $1 \mathbf{a}^{12+}$ that forms at elevated temperatures due to the increased rate of guest escape from $\mathbf{C p}{ }_{2} \mathrm{Co}^{+} @ 1 \mathbf{a}^{12+}$. Blue circles mark signals of $\mathbf{C p}_{2}{ }_{2} \mathrm{Co}^{+} @ 1 \mathbf{a}^{12+}$ that become split at lower temperatures, indicating that the static symmetry of the host has lower than the $D_{3 h}$ symmetry of an ideal equilateral triangular prism. The resonance corresponding to encapsulated $\mathrm{Cp}_{2}{ }_{2} \mathrm{Co}^{+}$is observed as a single sharp signal at $-40^{\circ} \mathrm{C}$, indicating that the guest or its individual $\mathrm{Cp}^{*}$ rings can rotate freely about its 5 -fold axis even at low temperatures. Thus, the movement of this resonance from $-5.53 \mathrm{ppm}$ at $-40{ }^{\circ} \mathrm{C}$ to -4.63 ppm at $80{ }^{\circ} \mathrm{C}$, with significant broadening observed at $0{ }^{\circ} \mathrm{C}$, is attributed to temperature dependent conformational changes of the host that appear to occur slowly on the NMR timescale below $0{ }^{\circ} \mathrm{C}$. 


\section{3.b. $\mathrm{Cp}_{2}{ }^{*} \mathrm{Co}^{+} @ 1 \mathrm{a}^{12+}$ with $\mathrm{PF}_{6}{ }^{-}$counteranions, formed using $\mathrm{AgPF}_{6}$.}

A

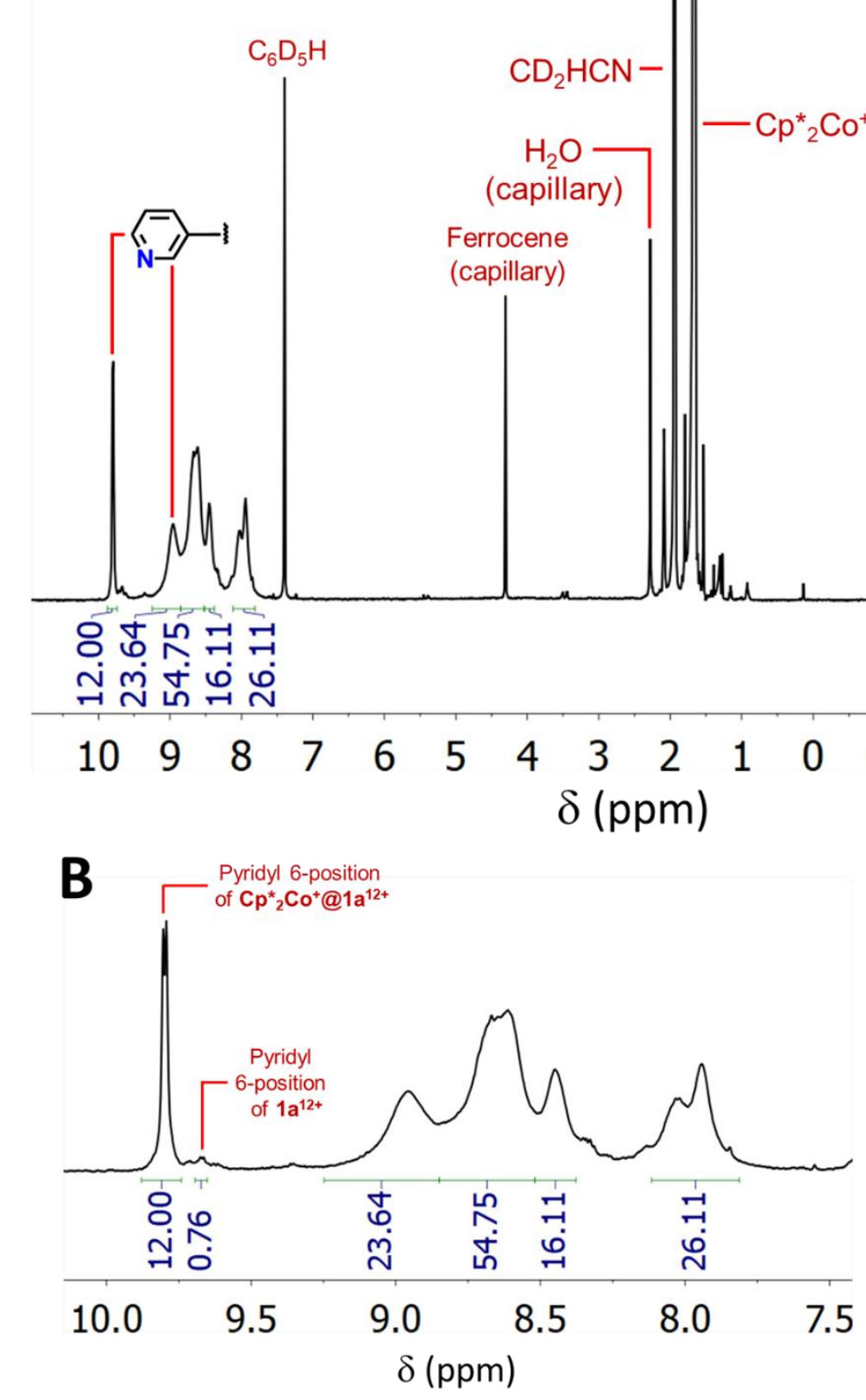

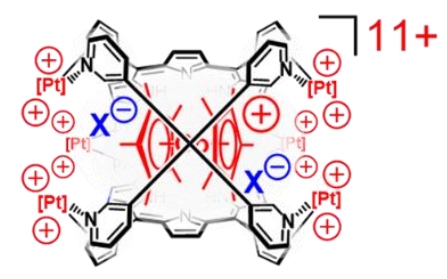

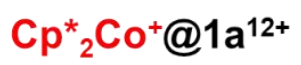

$[\mathrm{Pt}]^{2+}=($ bipy $) \mathrm{Pt}^{2+}, \mathrm{X}^{-}=\mathrm{PF}_{6}^{-}$

\section{Encapsulated \\ $\mathrm{Cp}^{*}{ }_{2} \mathrm{Co}^{+}$}

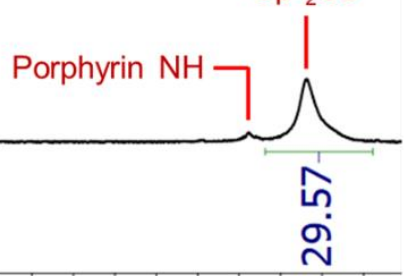

$\begin{array}{lllll}-1 & -2 & -3 & -4 & -5\end{array}$

C

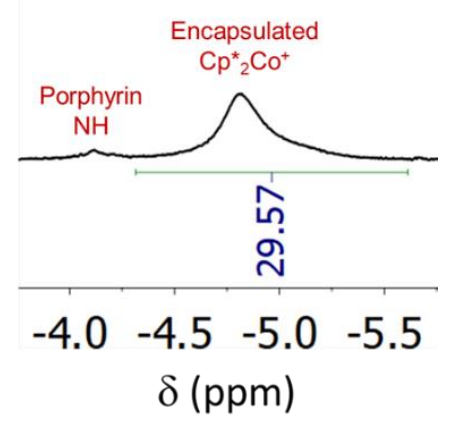

Figure S4. ${ }^{1} \mathrm{H}$ NMR spectrum of a $1.2 \mathrm{mM}$ solution of $\mathrm{Cp}^{*}{ }_{2} \mathrm{Co}^{+} @ 1 \mathbf{a}^{12+}$ with $\mathrm{PF}_{6}{ }^{-}$anions $(29 \mathrm{mM})$ in $\mathrm{CD}_{3} \mathrm{CN}$. (A) Full spectrum. Select resonances of the host-guest complex are labeled along with any major resonances that do not arise from the host-guest complex. (B) Aromatic region. The pyridyl 6-position $\mathrm{CH}$ resonances of $\mathbf{C p}^{*}{ }_{2} \mathrm{Co}^{+} @ 1 \mathbf{a}^{12+}$ and $1 \mathbf{a}^{12+}$ are indicated. Comparison of these resonances was used to determine a $94: 6$ ratio of the host-guest complex to the unconverted host, representing the best conversion to the host-guest complex that was observed. (C) Upfield region. The broad resonance corresponding to encapsulated $\mathrm{Cp}_{2}{ }_{2} \mathrm{Co}^{+}$is indicated. 


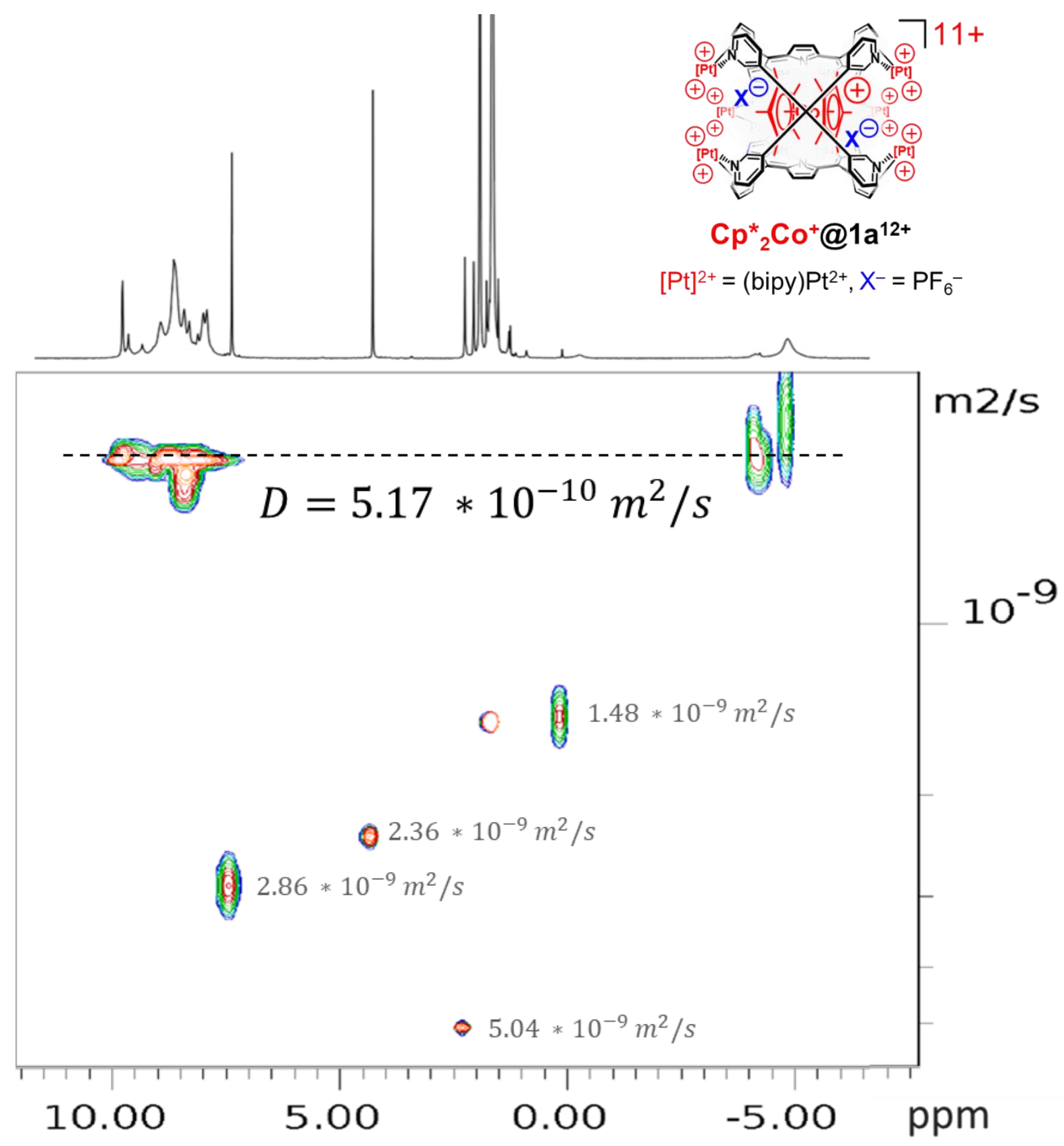

Figure S5. Diffusion ordered (DOSY) ${ }^{1} \mathrm{H}$ NMR spectrum of a $1.2 \mathrm{mM}$ solution of $\mathrm{Cp}^{*}{ }_{2} \mathrm{Co}^{+} @ 1 \mathrm{a}^{12+}$ with $\mathrm{PF}_{6}{ }^{-}$ anions ( $29 \mathrm{mM}$ ) in $\mathrm{CD}_{3} \mathrm{CN}$. The experimental diffusion constant corresponds to a spherical hydrodynamic radius $^{3} 12.6 \AA$., which is similar to that of $1 \mathrm{a}^{12+}$. $^{1}$ 


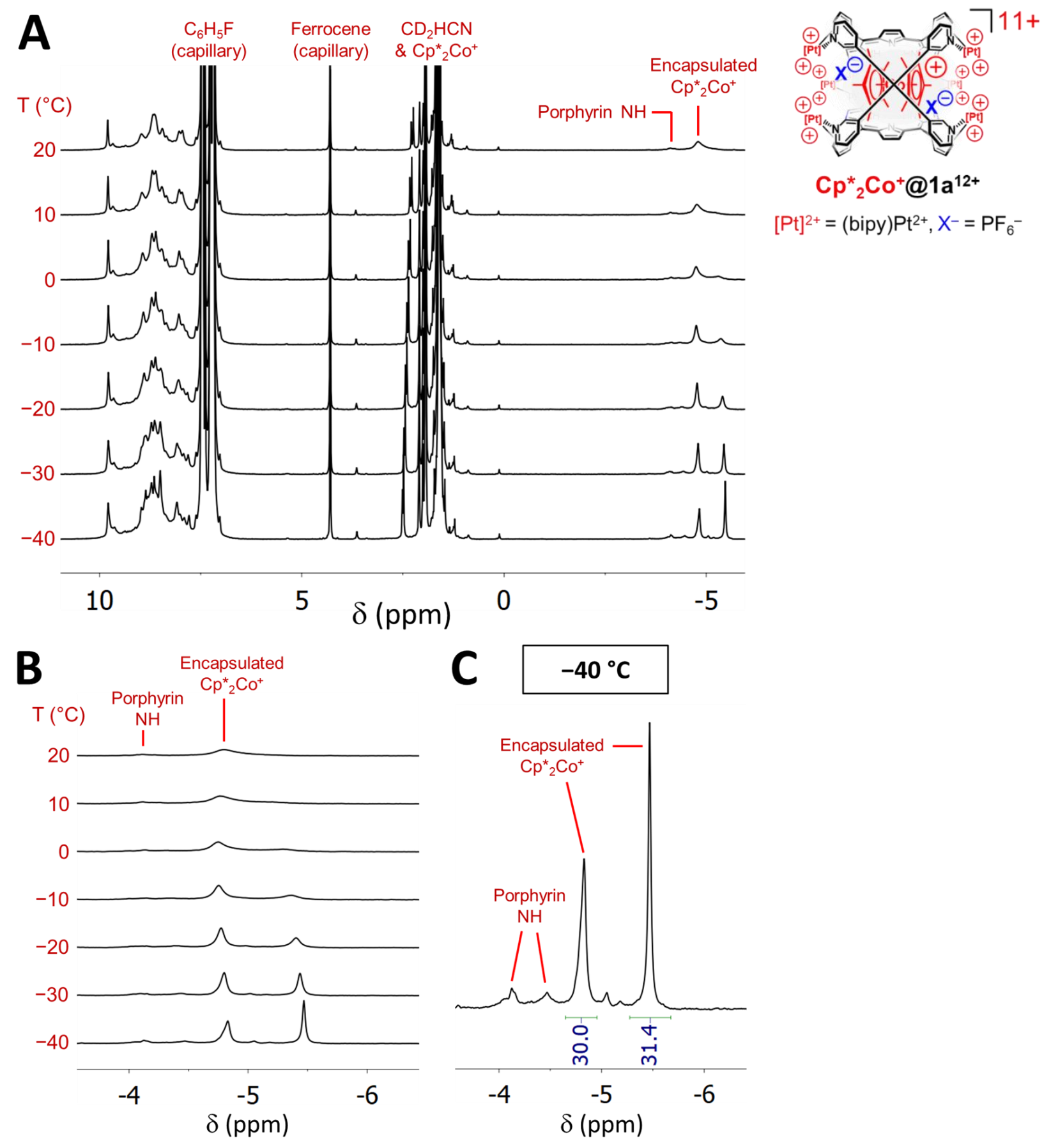

Figure S6. ${ }^{1} \mathrm{H}$ NMR spectra recorded from $-40{ }^{\circ} \mathrm{C}$ to $20{ }^{\circ} \mathrm{C}$ on a $1.2 \mathrm{mM}$ solution of $\mathrm{Cp}^{*}{ }_{2} \mathrm{Co}^{+} @ 1 \mathrm{a}^{12+}$ with $\mathrm{PF}_{6}{ }^{-}$anions $(29 \mathrm{mM})$ in $\mathrm{CD}_{3} \mathrm{CN}$. (A) Full ${ }^{1} \mathrm{H}$ NMR spectra. (B) Upfield region showing temperaturedependent changes to the resonance arising from the encapsulated $\mathrm{Cp}_{2}{ }_{2} \mathrm{Co}^{+}$guest. At $20^{\circ} \mathrm{C}$ this resonance is observed as a broad signal at $-4.79 \mathrm{ppm}$, which sharpens at decreased temperatures as an additional signal grows in $\sim 0.5 \mathrm{ppm}$ upfield. (C) Both signals are well-defined at $-40{ }^{\circ} \mathrm{C}$, appearing at -4.83 and -5.47 ppm in an approximately 1:1 ratio. As described for $\mathrm{BF}_{4}{ }^{-}$solutions of $\mathrm{Cp}_{2}{ }_{2} \mathrm{Co}^{+} @ 1 a^{12+}$ (see Figure S3), these observations are attributed to temperature dependent conformational changes of the host. Since greater conversion to the low temperature conformation is observed in $\mathrm{BF}_{4}{ }^{-}$solutions, it can be concluded that the anions influence the conformational changes. 


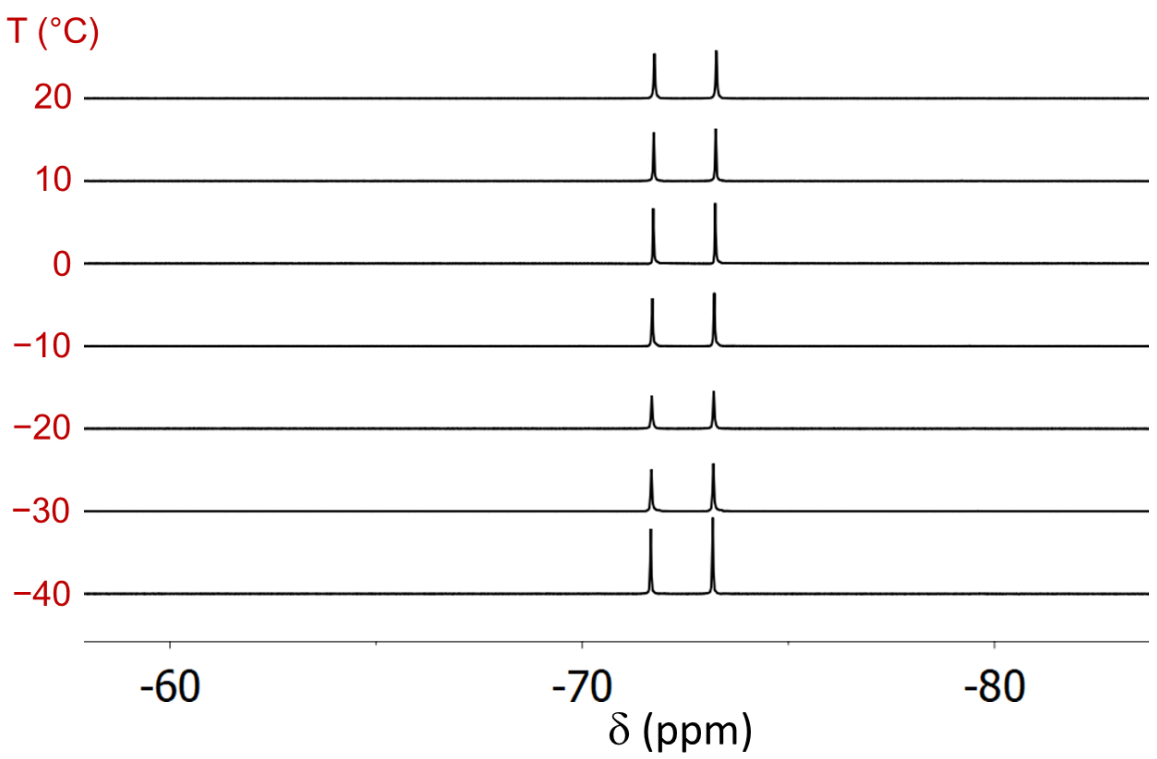

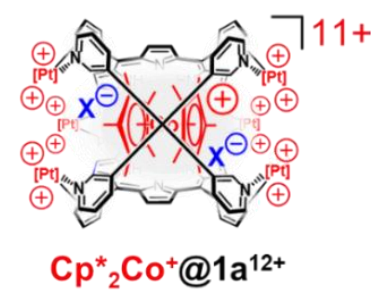

$[\mathrm{Pt}]^{2+}=($ bipy $) \mathrm{Pt}^{2+}, \mathrm{X}^{-}=\mathrm{PF}_{6}^{-}$

Figure S7. ${ }^{19} \mathrm{~F}$ NMR spectra recorded from $-40{ }^{\circ} \mathrm{C}$ to $20{ }^{\circ} \mathrm{C}$ on a $1.2 \mathrm{mM}$ solution of $\mathrm{Cp}_{2}{ }_{2} \mathrm{Co}^{+} @ 1 \mathrm{a}^{12+}$ with $\mathrm{PF}_{6}{ }^{-}$anions $(29 \mathrm{mM})$ in $\mathrm{CD}_{3} \mathrm{CN}$. Since a single ${ }^{19} \mathrm{~F}$ resonance $\left(J_{\mathrm{PF}}=706 \mathrm{~Hz}\right)$ is observed at all temperatures, the $\mathrm{PF}_{6}{ }^{-}$anions bound inside the host must exchange quickly on the NMR timescale with those in bulk solution. This observation demonstrates that the different conformations of $\mathbf{C p}_{2}{ }_{2} \mathrm{Co}^{+} @ 1 \mathbf{a}^{12+}$ observed in the ${ }^{1} \mathrm{H}$ NMR spectra at reduced temperatures (see Figure $\mathrm{S} 6$ above) do not correspond solely to different numbers of $\mathrm{PF}_{6}{ }^{-}$anions bound in the host-guest complex.
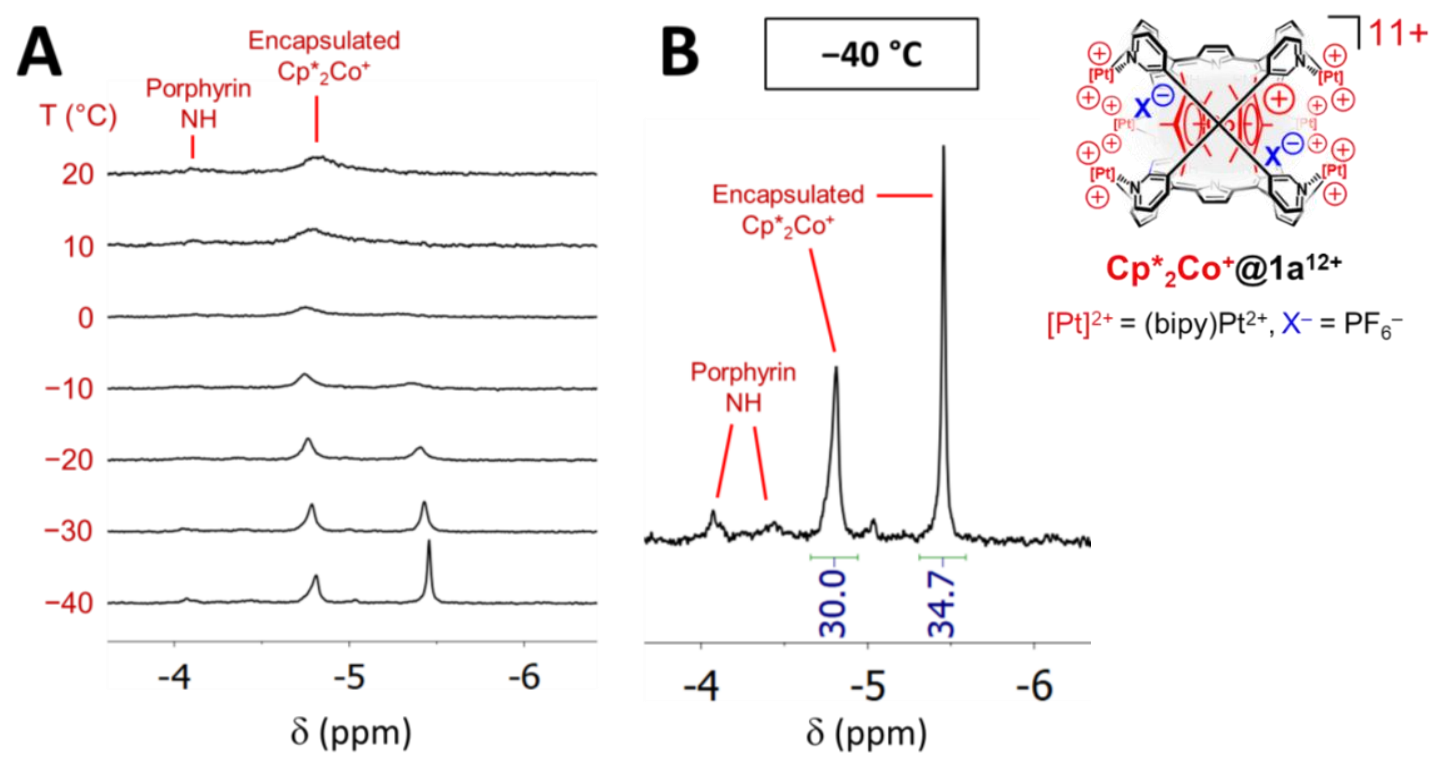

Figure S8. Upfield region of ${ }^{1} \mathrm{H}$ NMR spectra recorded from $-40{ }^{\circ} \mathrm{C}$ to $20{ }^{\circ} \mathrm{C}$ on a $0.3 \mathrm{mM}$ solution of Cp* ${ }_{2} \mathrm{Co}^{+} @ 1 \mathrm{a}^{12+}$ with $\mathrm{PF}_{6}{ }^{-}$anions $(7.2 \mathrm{mM})$ in $\mathrm{CD}_{3} \mathrm{CN}$. (A) As seen for higher concentration samples, the resonance of the encapsulated $\mathrm{Cp}_{2}{ }_{2} \mathrm{Co}^{+}$guest is observed as a broad signal at $20{ }^{\circ} \mathrm{C}$, with an additional signal growing in $\sim 0.5 \mathrm{ppm}$ upfield at lower temperatures. (B) The signals appear in an approximately 6:7 ratio at $-40{ }^{\circ} \mathrm{C}$. Since concentration only slightly influences the ratio of these signals (see Figure S6), it can be concluded that anion dissociation is not a major influence on the observed conformational changes. 

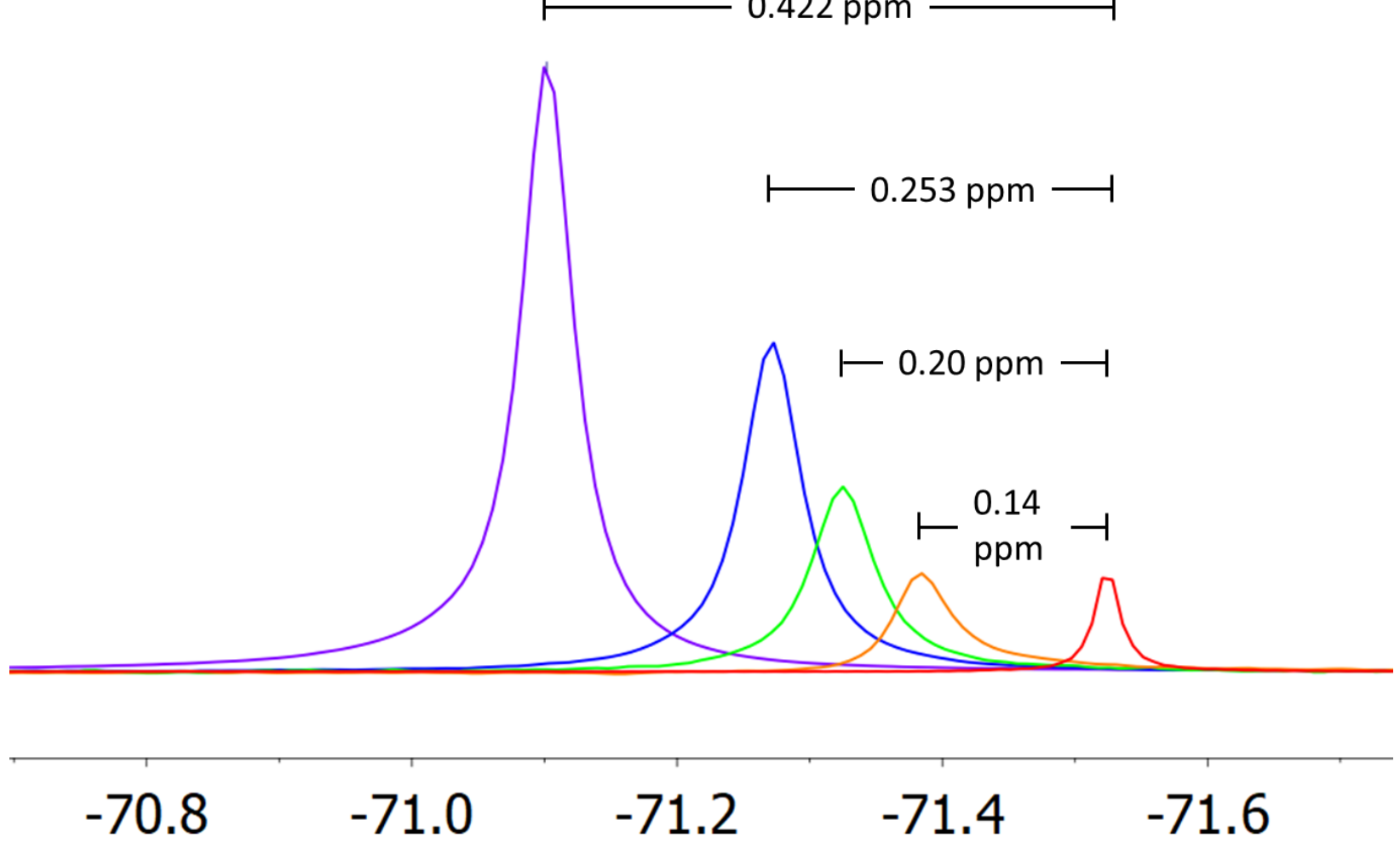

$-71.2$

$-71.4$

$-71.6$

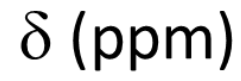

Figure S9. Overlaid partial ${ }^{19} \mathrm{~F}$ NMR spectra of solutions of TBAPF 6 (34.4 mM, red) and $\mathrm{Cp}_{2}{ }_{2} \mathrm{Co}^{+} @ 1 \mathbf{a}^{12+}\left(\mathrm{PF}_{6}{ }^{-}\right.$ counteranions) at concentrations of $5.0 \mathrm{mM}$ (purple), $1.0 \mathrm{mM}$ (blue), $0.2 \mathrm{mM}$ (green), and $0.04 \mathrm{mM}$ (orange) in $\mathrm{CD}_{3} \mathrm{CN}$. Spectra were recorded at $298 \mathrm{~K}$ and only the more upfield half of the doublet resulting from $J_{\mathrm{PF}}$ coupling in the $\mathrm{PF}_{6}{ }^{-}$anions is shown. Dilution of the host-guest solutions from 1.0 to $0.04 \mathrm{mM}$ concentration causes a similar pattern in the changes of the ${ }^{19} \mathrm{~F}$ chemical shift as seen for dilution of samples of $1 \mathbf{1 a} \mathbf{1 2}^{-\mathrm{PF}_{6}}$ (see Figure S45 in section 7.b.). However, while the ${ }^{19} \mathrm{~F}$ NMR signal of solutions of $1 \mathbf{1 a} \mathbf{1 2 P F}_{6}$ appears to approach a maximum value as concentration is increased, the samples of $\mathrm{Cp}_{2}{ }_{2} \mathrm{Co}^{+} @ 1 \mathrm{a}^{12+}$ show more irregular behavior in which a large change of the ${ }^{19} \mathrm{~F}$ NMR chemical shift is seen between the $1.0 \mathrm{mM}$ and $5.0 \mathrm{mM}$ samples, breaking the trend established at lower concentrations. This observation could be due to the $\mathrm{PF}_{6}{ }^{-}$anions engaging in additional interactions at higher concentrations, such as with the external faces of the host-guest complex or with the excess of $\mathrm{Cp}_{2}{ }_{2} \mathrm{Co}^{+}$present in samples after formation of $\mathrm{Cp}_{2}{ }_{2} \mathrm{Co}^{+} @ 1 \mathbf{a}^{12+}$. 


\section{3.c. $\mathrm{Cp}_{2}{ }^{*} \mathrm{Co}^{+} @ 1 \mathrm{a}^{12+}$ with $\mathrm{PF}_{6}{ }^{-}$counteranions, generated using $[\mathrm{Fc}] \mathrm{PF}_{6}$.}

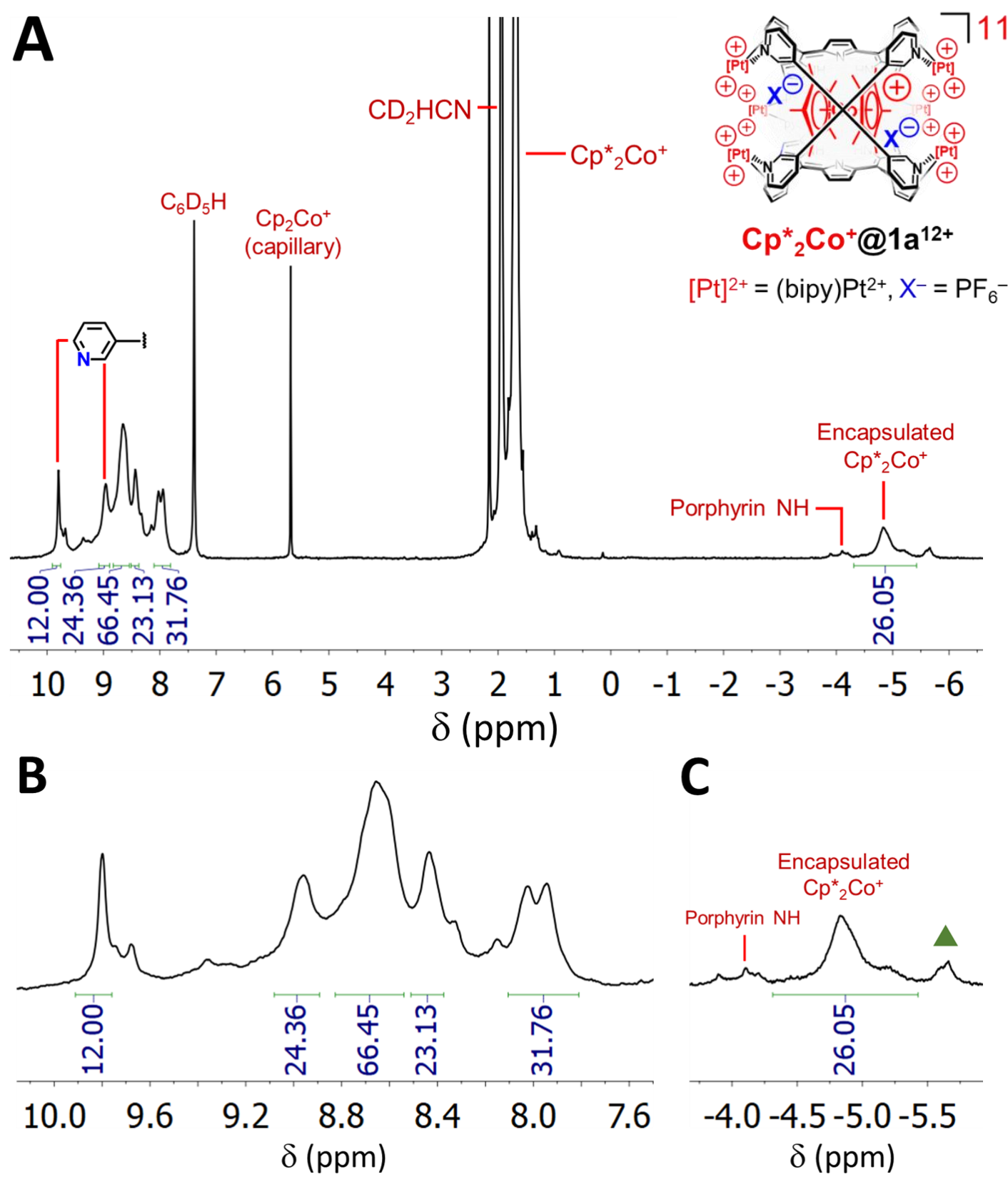

Figure S10. ${ }^{1} \mathrm{H}$ NMR spectrum of a $1.2 \mathrm{mM}$ solution of $\mathrm{Cp}^{*}{ }_{2} \mathrm{Co}^{+} @ 1 \mathrm{a}^{12+}$ in $\mathrm{CD}_{3} \mathrm{CN}$ prepared by reducing $1 \mathrm{a} \cdot 12 \mathrm{PF}_{6}{ }^{-}$with 12 equiv $\mathrm{Cp}_{2}{ }_{2} \mathrm{Co}$ and then reoxidizing after 30 min using 22 equiv of [Fc]PF 6 . (A) Full spectrum. Select resonances of the host-guest complex are labeled along with any major resonances that do not arise from the host-guest complex. Note that the resonance of $\mathrm{Fc}$ formed upon reduction of $\mathrm{Fc}^{+}$is not observed due to fast electron self-exchange with the large excess of paramagnetic $\mathrm{Fc}^{+}$remaining in solution. (B) Aromatic region. (C) Upfield region. The broad resonance corresponding to encapsulated $\mathrm{Cp}_{2}{ }_{2} \mathrm{Co}^{+}$is labeled, and a green triangle is used to indicate an additional resonance at $-5.64 \mathrm{ppm}$ that was observed in samples of $\mathbf{C p}_{2}{ }_{2} \mathbf{C o}^{+} @ 1 \mathbf{a}^{12+}$ prepared with or containing $[\mathrm{Fc}] \mathrm{PF}_{6}$. 


\section{3.d. Comparison of $\mathrm{Cp}_{2}{ }^{*} \mathrm{Co}^{+} @ 1 \mathbf{a}^{12+}$ formed with different oxidants}

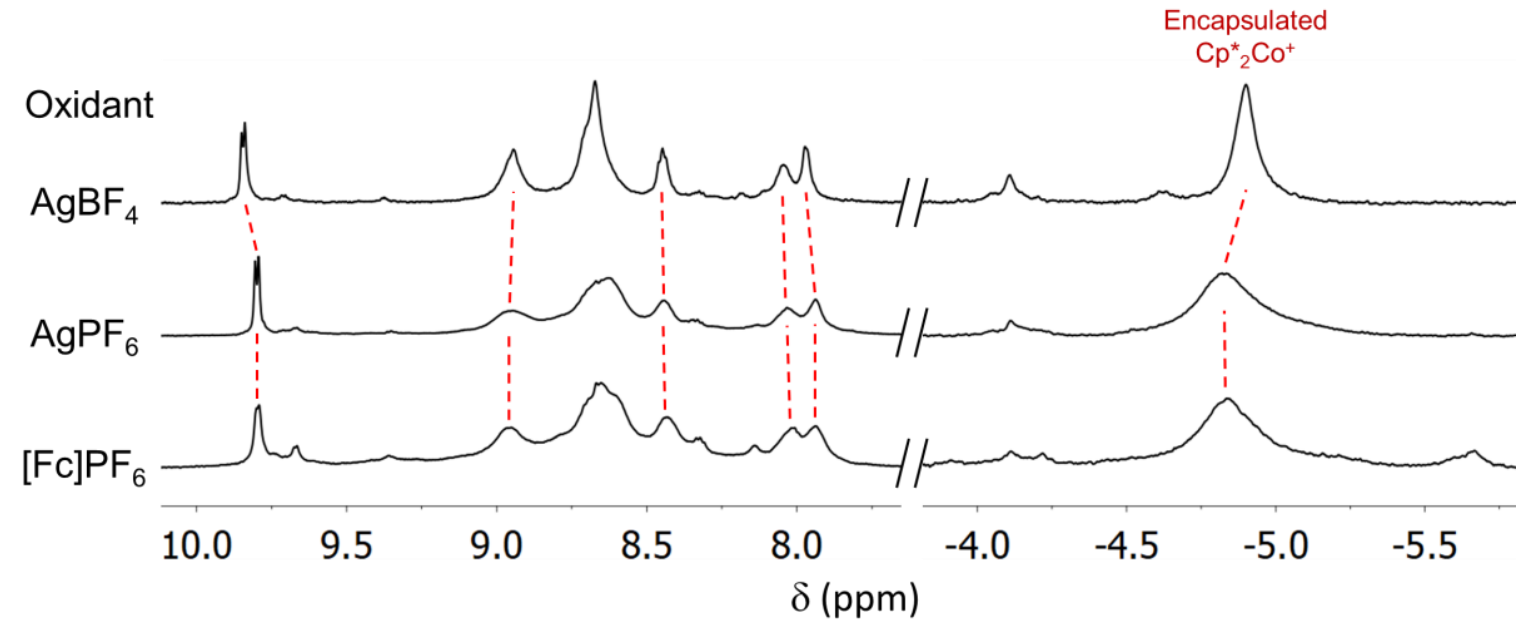

Figure S11. Truncated ${ }^{1} \mathrm{H}$ NMR spectra of $1.2 \mathrm{mM}$ solutions of $\mathrm{Cp}^{*}{ }_{2} \mathrm{Co}^{+} @ 1 \mathbf{a}^{12+}$ in $\mathrm{CD}_{3} \mathrm{CN}_{\text {generated using }}$ different oxidants $\left(\mathrm{AgBF}_{4}, \mathrm{AgPF}_{6}\right.$, and $\left.\left[\mathrm{Fc}_{\mathrm{P}}\right] \mathrm{PF}_{6}\right)$. The salts of the host $\left(\mathbf{1} \mathbf{a} \bullet \mathbf{1 2 B F}_{4}\right.$ or $\left.\mathbf{1} \mathbf{a} \bullet \mathbf{1 2} \mathrm{PF}_{6}\right)$ were chosen to match the counteranions of the oxidant. Red dotted lines are used to indicate corresponding resonances between the three spectra, showing much greater differences between the resonances of $\mathrm{Cp}_{2}{ }_{2} \mathrm{Co}^{+} @ 1 \mathrm{a}^{12+}$ in samples containing $\mathrm{BF}_{4}{ }^{-} \mathrm{vs} \mathrm{PF}_{6}{ }^{-}$anions than between samples prepared with $\mathrm{AgPF}_{6} \mathrm{vs}$. $\left[\mathrm{Fc}_{\mathrm{P}} \mathrm{PF}_{6}\right.$. Slight differences between the latter two spectra can be attributed to the presence of higher amounts of the empty host $1 \mathbf{a}^{12+}$ along with some additional, unidentified species in the sample prepared with [Fc]PF $F_{6}$. Together, these observations show that (i) anions have substantial interactions with the hostguest complex, (ii) neither $\mathrm{Ag}^{+}$nor $\mathrm{Ag}^{0}$ nanoparticles appear to interact with the host-guest complex, and (iii) additional species are formed in samples containing $\mathrm{Fc}^{+}$. 


\section{3.e. $\mathrm{Cp}_{2} \mathrm{Co}^{+} @ 1 b^{12+}$}

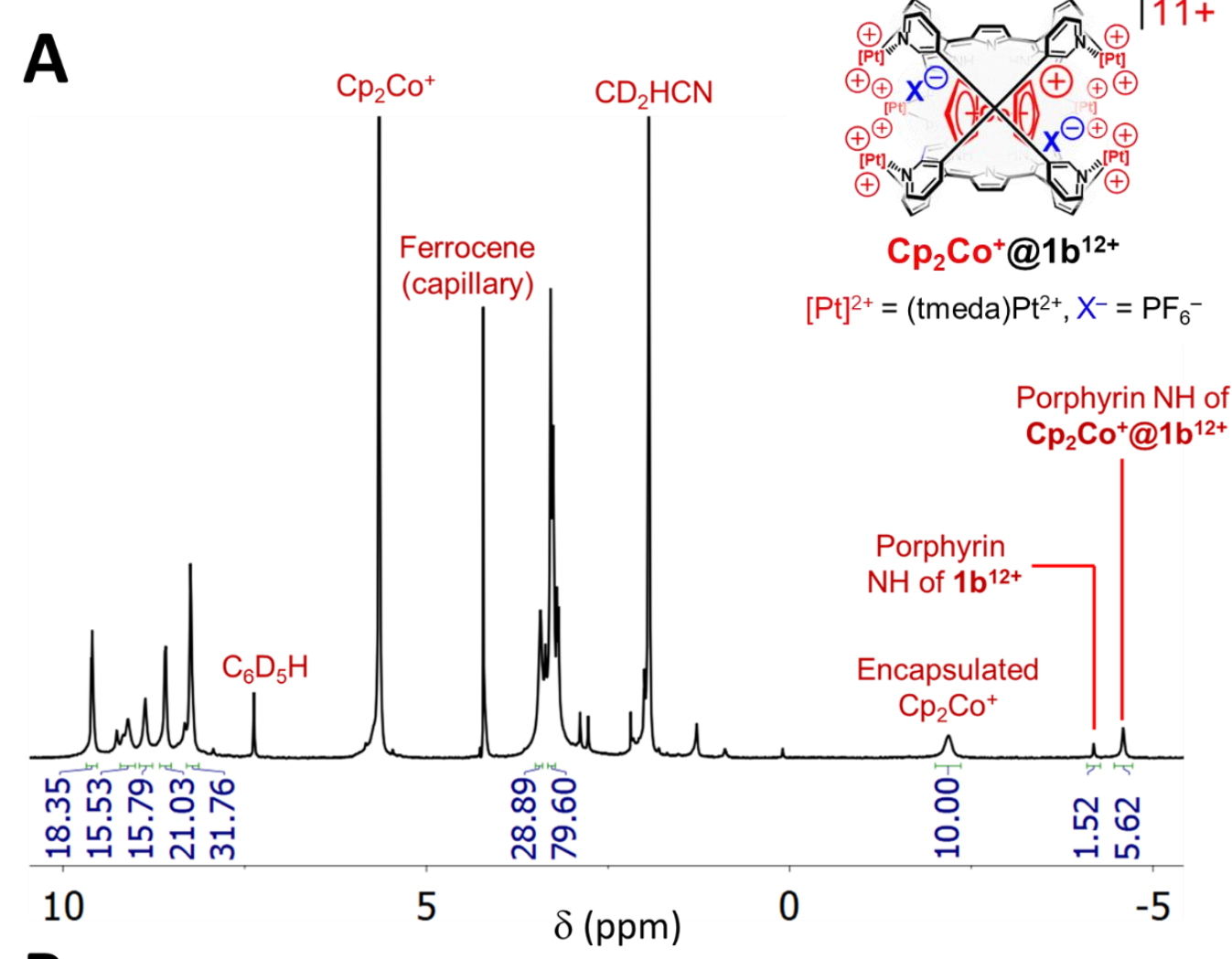

B

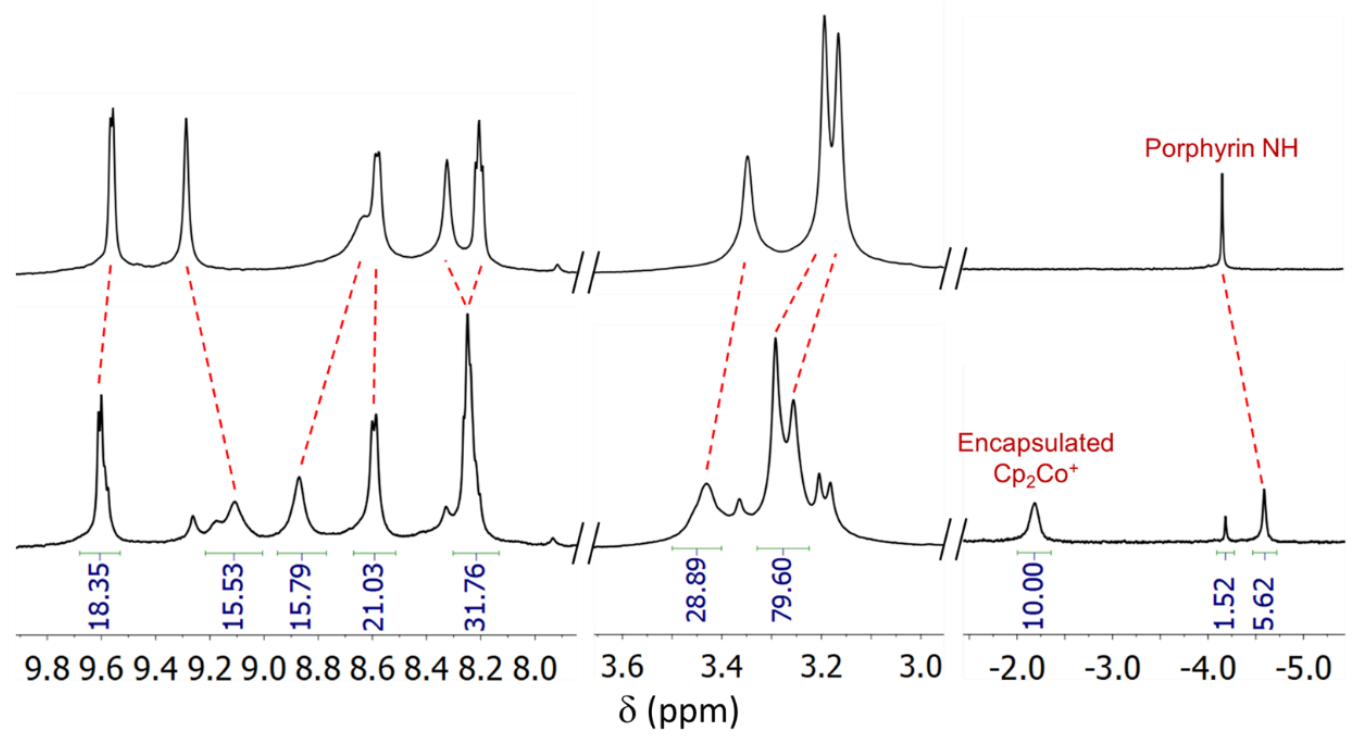

Figure S12. ${ }^{1} \mathrm{H}$ NMR spectrum of a solution of $\mathrm{Cp}_{2} \mathrm{Co}^{+} @ 1 \mathbf{b}^{12+}$ in $\mathrm{CD}_{3} \mathrm{CN}$ generated by reducing a $1.2 \mathrm{mM}$ solution of $\mathbf{1 b} \cdot \mathbf{1 2} \mathbf{P F}_{6}$ with 3.5 equiv $\mathrm{Cp}_{2} \mathrm{Co}$ and reoxidizing after 30 minutes with 3.6 equiv $\mathrm{AgPF}_{6}$. (A) Full spectrum. Select resonances of the host-guest complex and unconverted $\mathbf{1 \mathbf { b } ^ { \mathbf { 1 2 + } }}$ are labeled along with any major resonances that do not arise from either the host-guest complex or the free host. (B) Truncated spectra before (top) and after (bottom) conversion of $\mathbf{1 b}^{\mathbf{1 2 +}}$ to $\mathbf{C p}_{2} \mathbf{C o}^{+} @ \mathbf{1} \mathbf{b}^{\mathbf{1 2 +}}$. Changes to the resonances of the host caused by binding $\mathrm{Cp}_{2} \mathrm{Co}^{+}$are tracked with red dotted lines. 

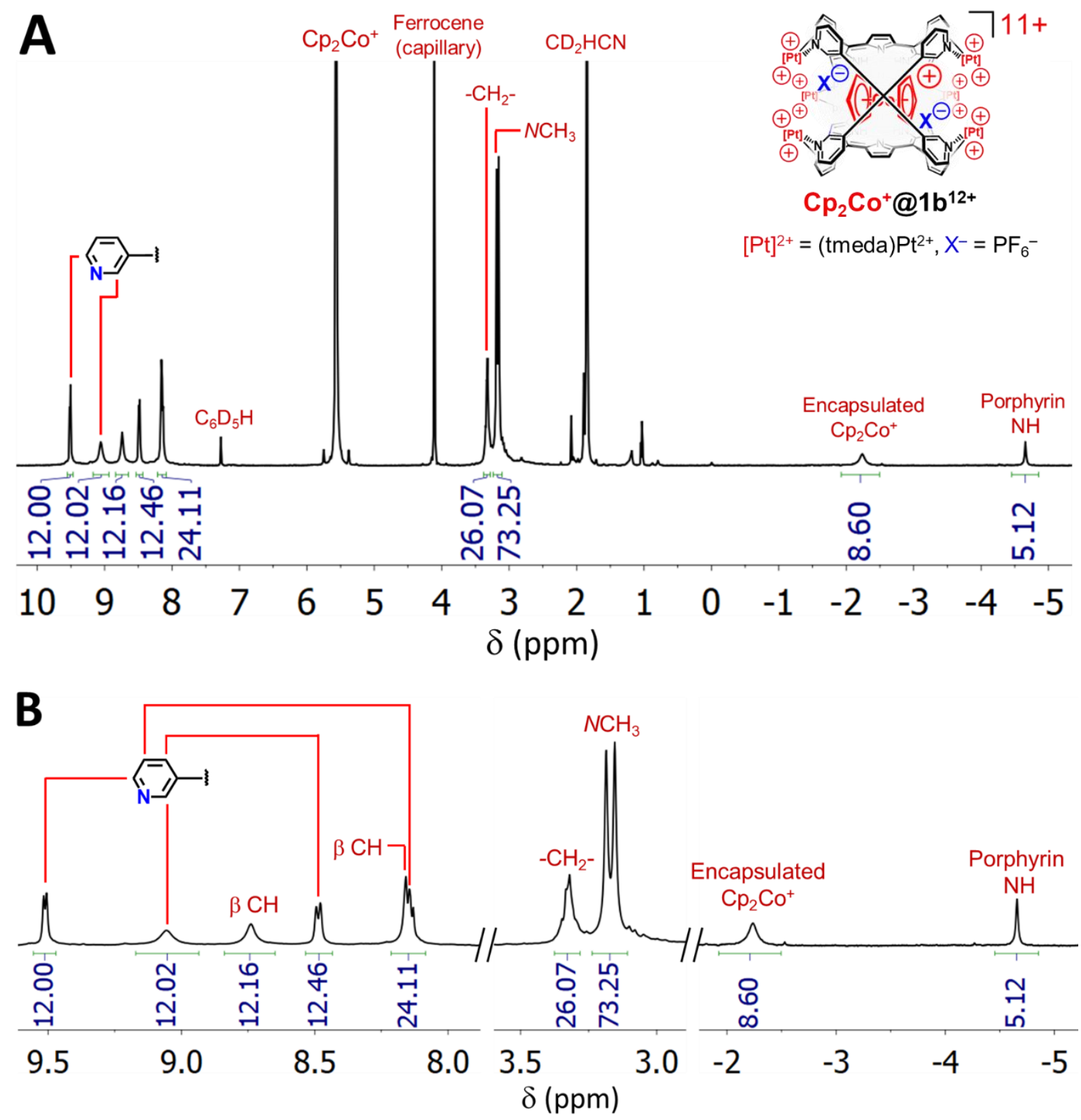

Figure S13. ${ }^{1} \mathrm{H}$ NMR spectrum of a $1.2 \mathrm{mM}$ solution of $\mathbf{C p}_{2} \mathbf{C o}^{+} @ 1 \mathbf{b}^{12+}$ in $\mathrm{CD}_{3} \mathrm{CN}$ generated by reducing $\mathbf{1 b} \bullet \mathbf{1 2 P F}_{6}$ with 3.5 equiv of $\mathrm{Cp}_{2} \mathrm{Co}$ in the presence of 18 equiv of $\left[\mathrm{Cp}_{2} \mathrm{Co}\right] \mathrm{PF}_{6}$ and then reoxidizing after 30 min with 3.6 equiv $\mathrm{AgPF}_{6}$. These conditions provided $>95 \%$ conversion of $\mathbf{1 b}^{\mathbf{1 2 +}}$ to $\mathbf{C p}_{2} \mathbf{C o}^{+} @ \mathbf{1} \mathbf{b}^{\mathbf{1 2 +}}$, allowing clear identification of all signals of the host-guest complex. (A) Full spectrum. Select resonances of the host-guest complex are labeled along with any major resonances that do not arise from the host-guest complex. (B) Truncated spectrum. All signals of $\mathbf{C p}_{2} \mathbf{C o}^{+} @ 1 \mathbf{b}^{12+}$ are assigned. $\beta \mathrm{CH}$ refers to the pyrrolic $\mathrm{CH}$ resonances of the porphyrin walls of the host, which are split into two distinct signals for the positions facing the triangular faces vs. the long edges of the prism. Likewise, the $\mathrm{NCH}_{3}$ resonances are two distinct singlets that correspond to $\mathrm{NCH}_{3}$ groups facing the interior vs. exterior of the host. 


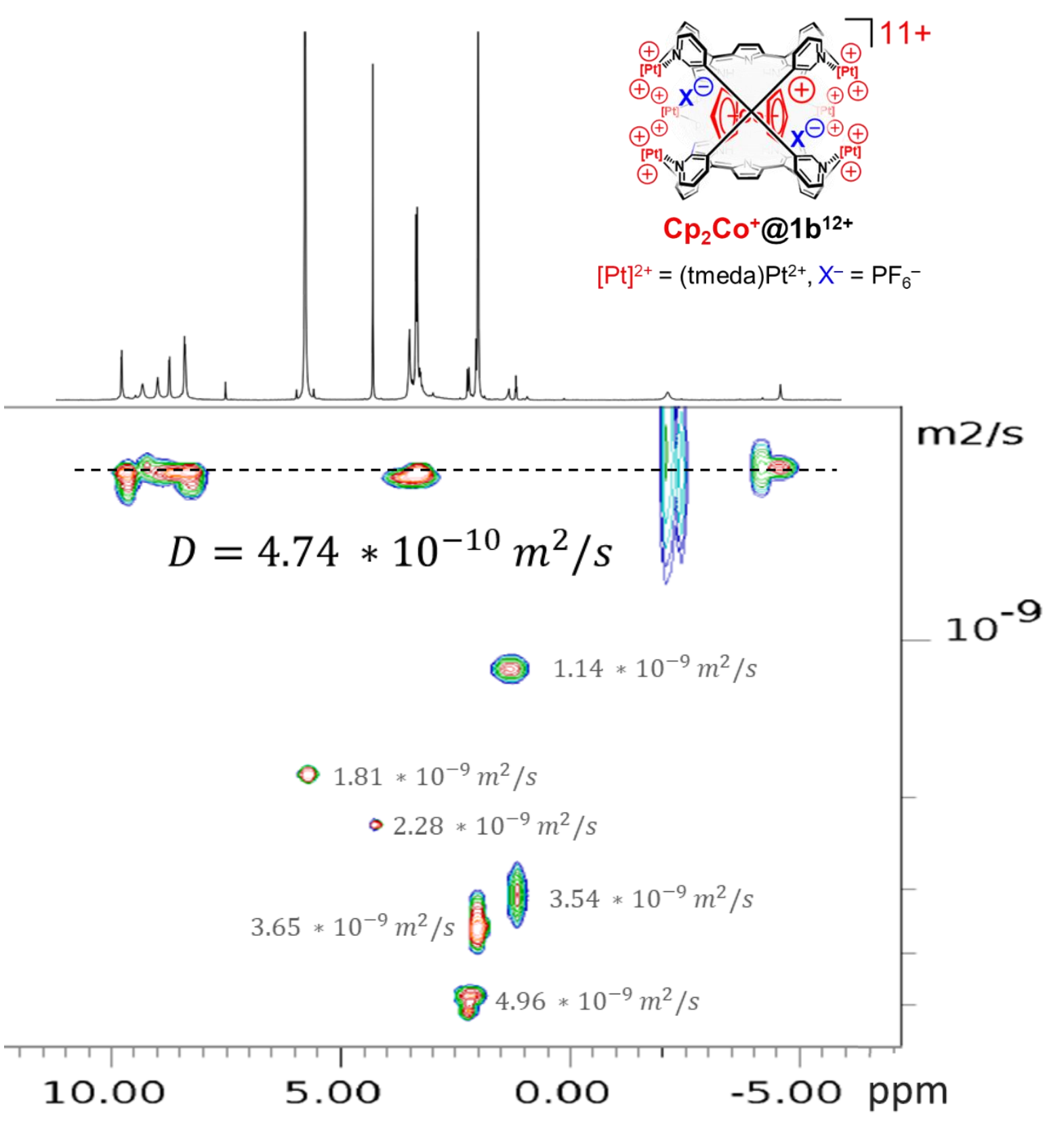

Figure S14. Diffusion ordered (DOSY) ${ }^{1} \mathrm{H}$ NMR spectrum of a $1.2 \mathrm{mM}$ solution of $\mathrm{Cp}^{*}{ }_{2} \mathrm{Co}^{+} @ 1 \mathbf{b}^{12+}$ with $\mathrm{PF}_{6}{ }^{-}$ anions (40 mM) in $\mathrm{CD}_{3} \mathrm{CN}$. This sample was generated in the presence of excess $\mathrm{Cp}_{2} \mathrm{Co}^{+}$(see Figure $\mathrm{S} 13$ above), so signals corresponding to the free host $\mathbf{1}^{\mathbf{1 2 +}}$ are not observed. The experimental diffusion constant corresponds to a spherical hydrodynamic radius ${ }^{3}$ of $13.8 \AA$., which is similar to that of $\mathbf{1 b}^{\mathbf{1 2 +}}$. ${ }^{1}$ Note that a small signal at $-2.5 \mathrm{ppm}$ is observed to arise from a species with a comparable diffusion coefficient to that of the host-guest complex. The identity of this minor species could not be determined. A comparison of the ${ }^{1} \mathrm{H}$ NMR spectra in Figures $\mathrm{S} 13$ and $\mathrm{S} 12$ show that this signal was not always observed in samples of $\mathrm{Cp}^{*}{ }_{2} \mathrm{Co}^{+} @ 1 \mathbf{b}^{12+}$. 


\section{ESI-MS characterization of $\mathrm{Cp}_{2}{ }^{*} \mathrm{Co}^{+} @ 1 a^{12+}$ and $\mathrm{Cp}_{2} \mathrm{Co}^{+} @ 1 b^{12+}$}

High resolution mass spectra were obtained using a Waters Xevo G2-XS QTof mass spectrometer using an ESI source and positive ion detection. Samples of the host-guest complexes in MeCN were introduced by direct infusion ( $5 \mu \mathrm{L} / \mathrm{min}$ ). A standard of Leu-Enkephalin (Waters, Milford, MA) was injected in tandem with the sample for in-process calibration.

\section{a. $\mathrm{Cp}_{2}{ }^{*} \mathrm{Co}^{+} @ 1 \mathrm{a}^{12+}$ with $\mathrm{PF}_{6}{ }^{-}$counteranions}

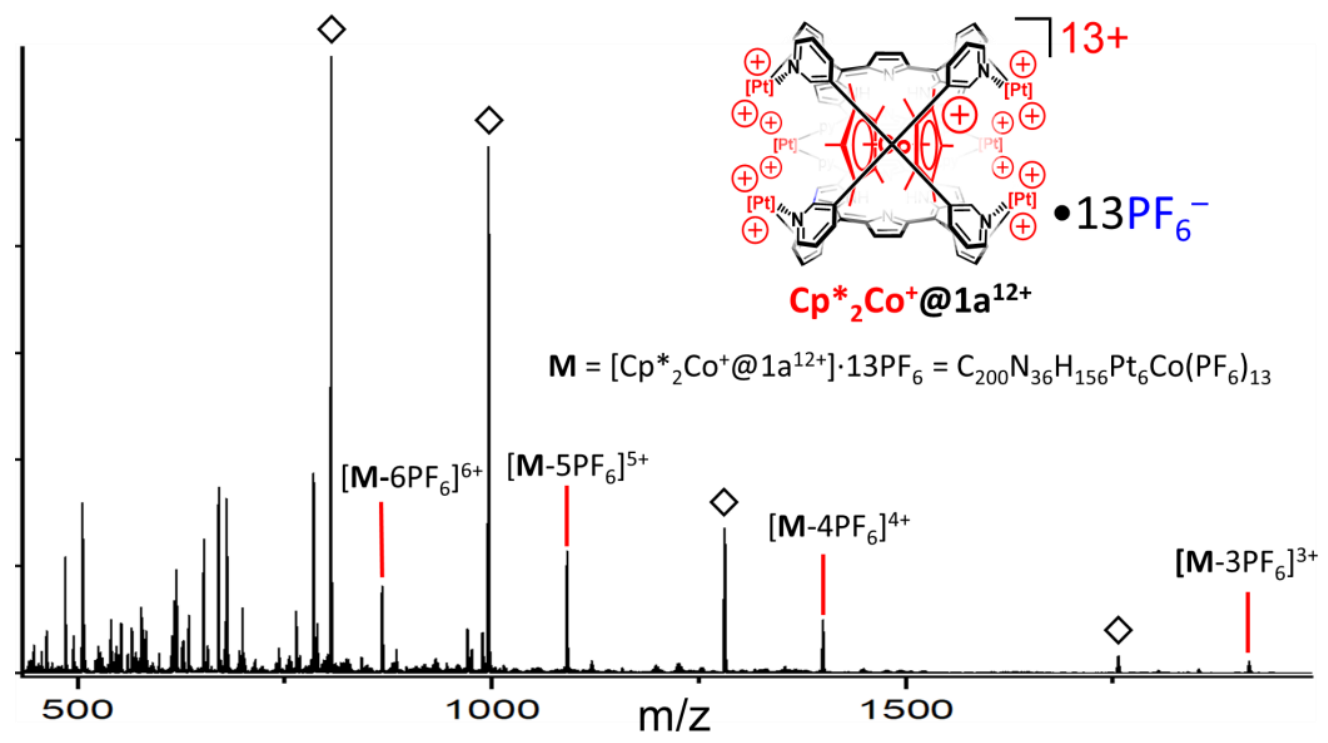

Figure S15. ESI(+)-MS spectrum of $\mathrm{Cp}^{*}{ }_{2} \mathrm{Co}^{+} @ 1 a^{12+}$ in $\mathrm{CH}_{3} \mathrm{CN}$ showing successive loss of $\mathrm{PF}_{6}{ }^{-}$from the hostguest complex. Peaks corresponding to the empty host $1 \mathrm{a}^{12+}$ are marked with diamonds.

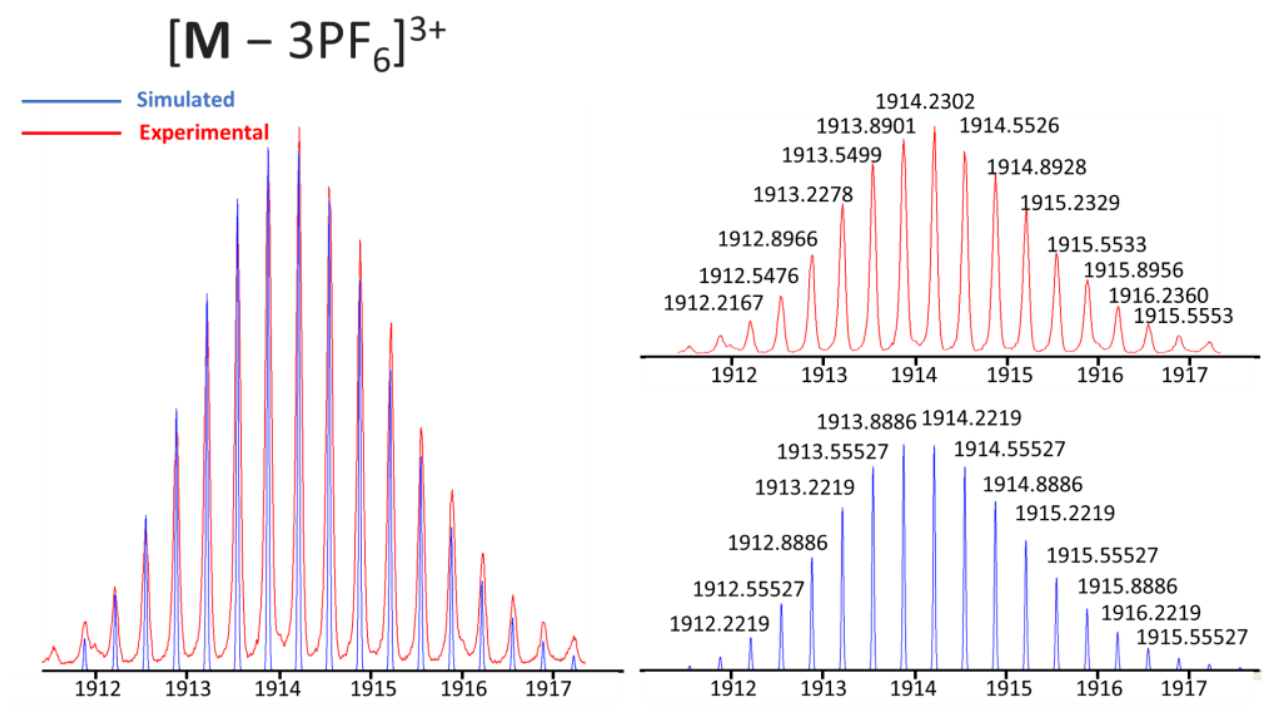

Figure S16. Comparison of the experimental (red) and simulated (blue) isotope patterns of the $\left[\mathrm{M}-3 \mathrm{PF}_{6}\right]^{3+}$ mass peak for the $\mathrm{Cp}_{2}{ }_{2} \mathrm{Co}^{+} @ 1 \mathbf{a}^{12+}$ host-guest complex. Overlaying the experimental and simulated isotope pattern shows good agreement. 

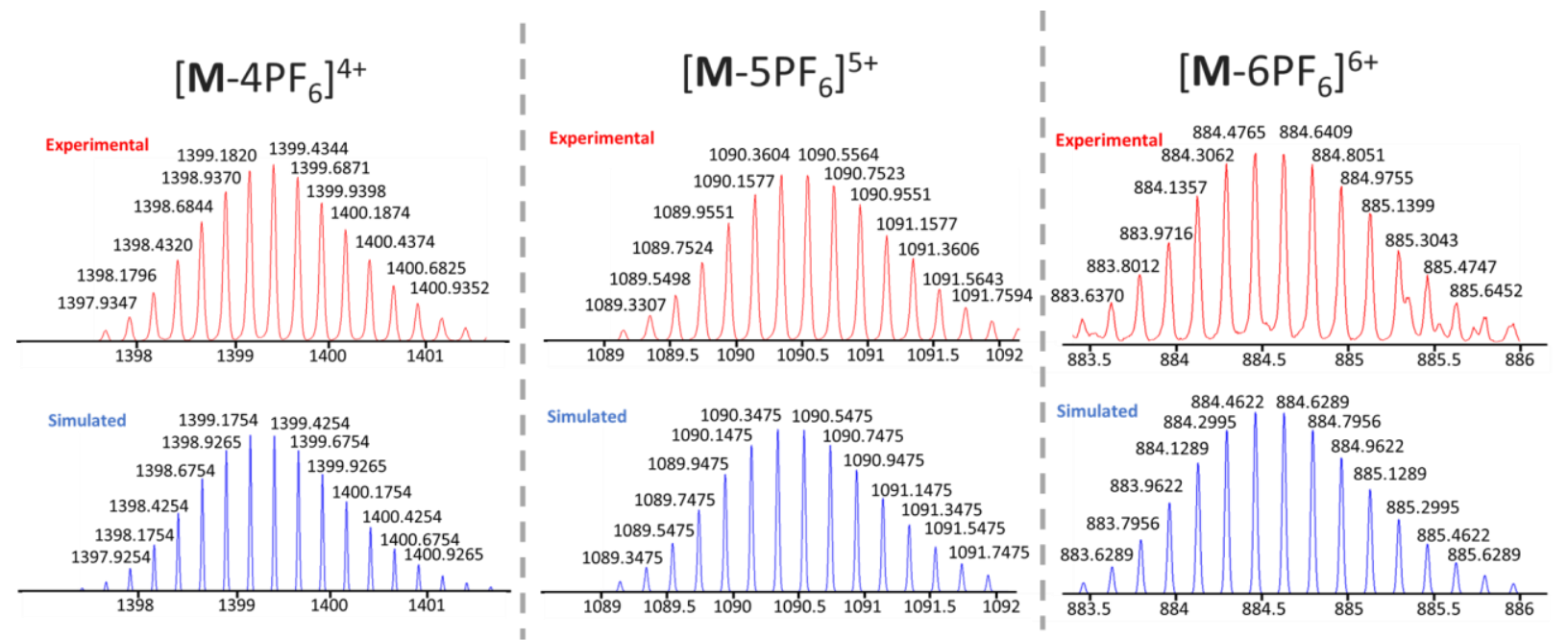

Figure S17. Comparison of the experimental (red) and simulated (blue) isotope patterns of the $\left[\mathrm{M}-n \mathrm{PF} \mathrm{F}_{6}\right]^{\mathrm{n+}}(\mathrm{n}=4,5,6)$ mass peaks for the $\mathrm{Cp}_{2}{ }_{2} \mathrm{Co}^{+} @ 1 \mathbf{a}^{12+}$ host-guest complex.

\section{b. $\mathrm{Cp}_{2} \mathrm{Co}^{+} @ 1 \mathbf{b}^{12+}$ with $\mathrm{PF}_{6}{ }^{-}$counteranions}

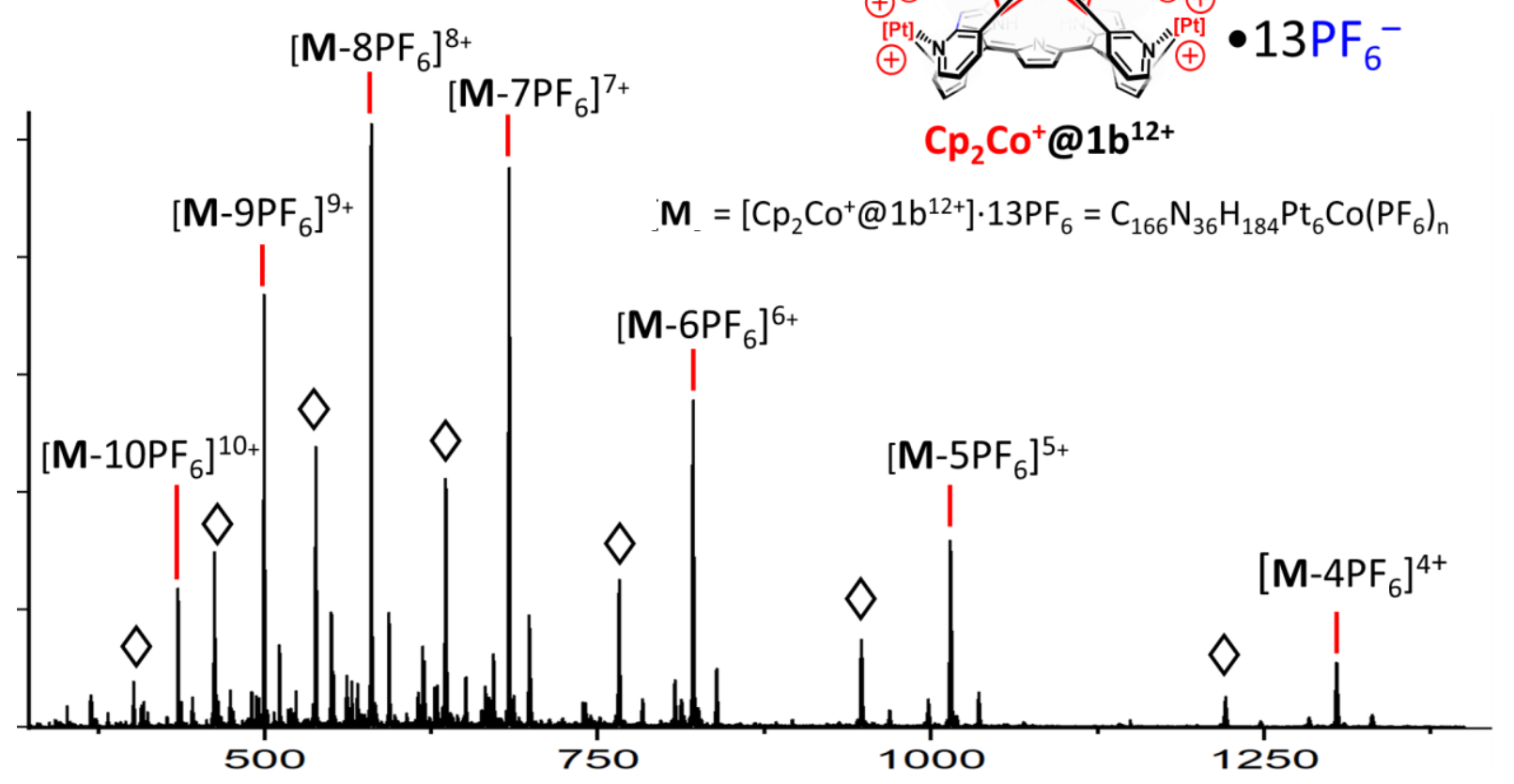

Figure S18. ESI(+)-MS spectrum of $\mathrm{Cp}_{2} \mathrm{Co}^{+} @ 1 \mathbf{b}^{12+}$ in $\mathrm{CH}_{3} \mathrm{CN}$ showing successive loss of $\mathrm{PF}_{6}{ }^{-}$from the hostguest complex. Peaks corresponding to the empty host $\mathbf{1 b}^{\mathbf{1 2 +}}$ are marked with diamonds. 
$\left[\mathrm{M}-4 \mathrm{PF}_{6}\right]^{4+}$

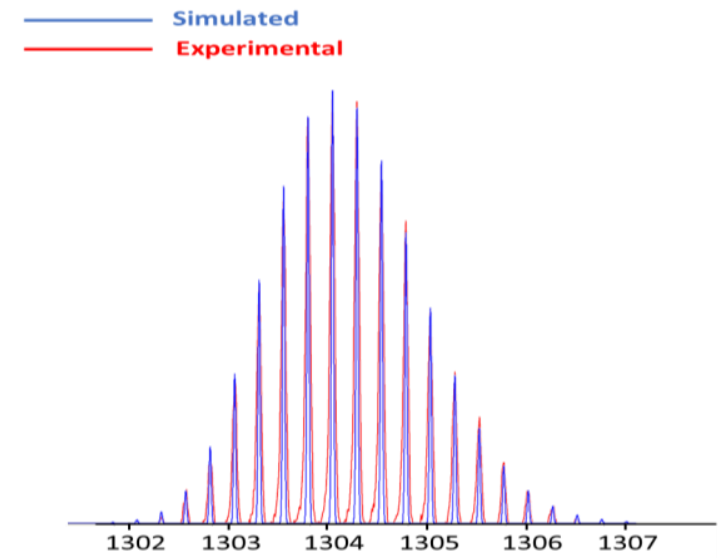

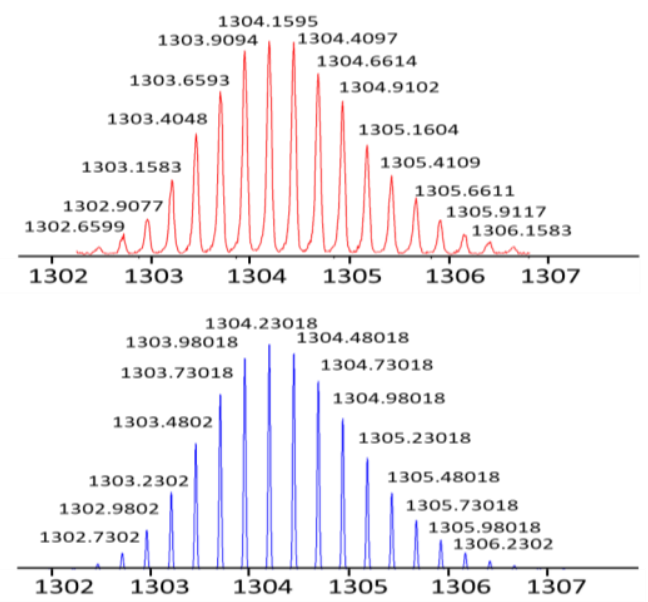

Figure S19. Comparison of the experimental (red) and simulated (blue) isotope patterns of the $\left[\mathrm{M}-4 \mathrm{PF}_{6}\right]^{3+}$ mass peak for the $\mathbf{C p}_{2} \mathbf{C o}^{+} @ \mathbf{1} \mathbf{b}^{\mathbf{1 2 +}}$ host-guest complex. Overlaying the experimental and simulated isotope pattern shows good agreement.
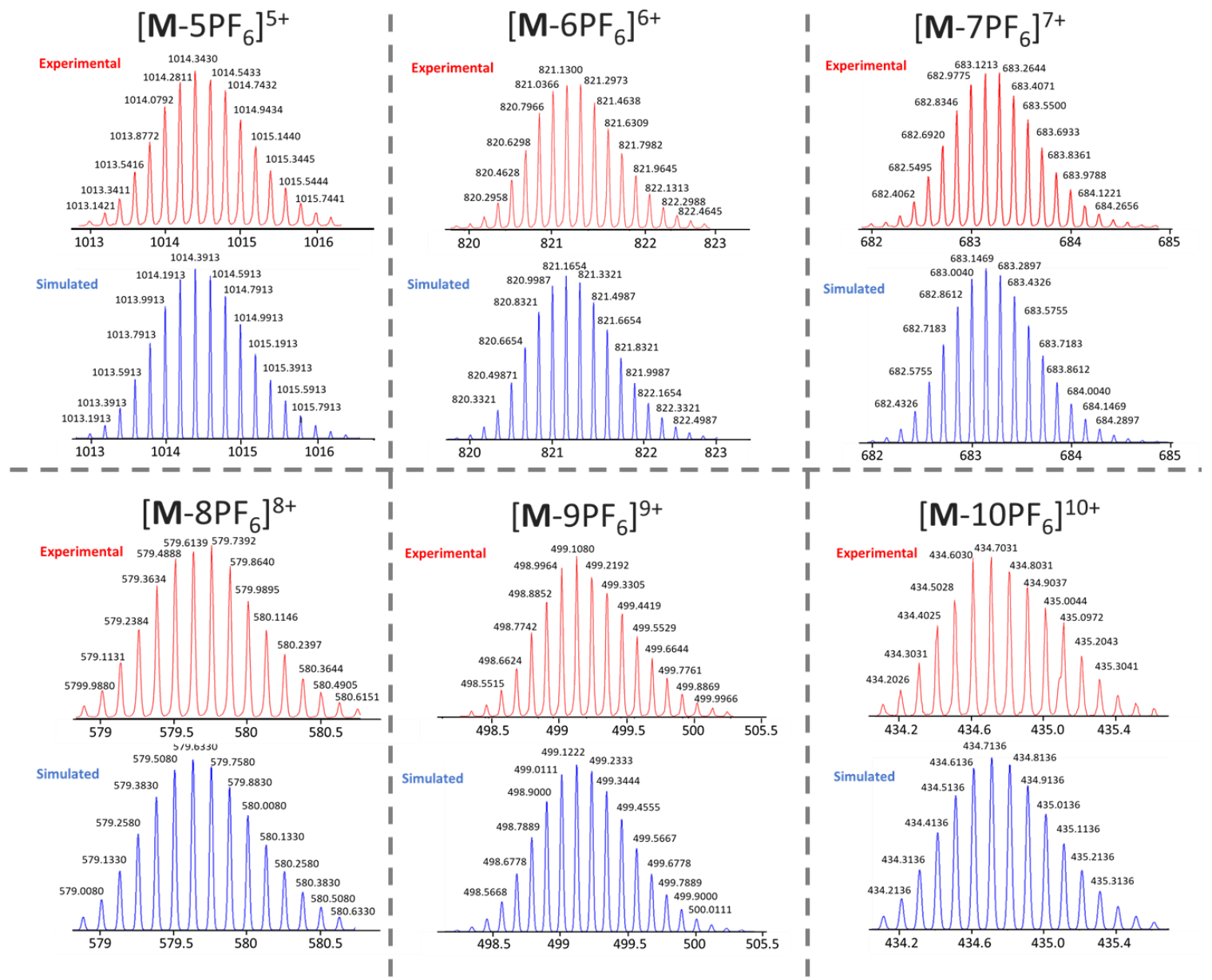

Figure S20. Comparison of the experimental (red) and simulated (blue) isotope patterns of the $\left[\mathrm{M}-\mathrm{nPF}_{6}\right]^{\mathrm{n+}}(\mathrm{n}=5,6,7,8,9,10)$ mass peaks for the $\mathrm{Cp}^{*}{ }_{2} \mathrm{Co}^{+} @ 1 \mathrm{a}^{12+}$ host-guest complex. 


\section{Studies of guest uptake by $1 a^{0}, 1 a^{3+}, 1 a^{9+}$, and $1 b^{9+}$}

\section{5.a. Uptake of $\mathrm{Cp}^{*}{ }_{2} \mathrm{Co}^{+}$by $1 \mathrm{a}^{0}$.}

General Procedure: Experiments to examine the rate of cation uptake by $1 a^{0}$ were performed by modifying the procedures described above for the preparation of samples of $\mathbf{C p}^{*}{ }_{2} \mathrm{Co}^{+} @ 1 \mathbf{a}^{12+}$. To accommodate very short times in the reduced state, a solution of $1 \mathrm{a} \cdot 12 \mathrm{PF}_{6}$ in $\mathrm{CD}_{3} \mathrm{CN}$ was treated with $\mathrm{Cp}_{2}{ }_{2} \mathrm{Co}$ with vigorous stirring and then immediately reoxidized by addition of $\mathrm{AgPF}_{6}$. For comparing times in the reduced state ranging from several seconds to several minutes, a single solution of $\mathbf{1 a} \cdot \mathbf{1 2} \mathbf{P F}_{6}$ was reduced with vigorous stirring and aliquots were removed and reoxidized at specified times.

Representative Procedure 1 (very short reduction times, < 5 s): In an $\mathrm{N}_{2}$ atmosphere glovebox, $0.350 \mathrm{~mL}$ of a $1.27 \mathrm{mM}$ solution of $1 \mathrm{a} \cdot 12 \mathrm{PF}_{6}(0.40 \mu \mathrm{mol})$ in $\mathrm{CD}_{3} \mathrm{CN}$ was added to a $4 \mathrm{~mL}$ vial that was charged with a PTFE-coated stir bar. The solution was stirred vigorously while $26.5 \mu \mathrm{L}$ of a $0.20 \mathrm{M}$ solution of $\mathrm{Cp}_{2}{ }_{2} \mathrm{Co}$ ( $5.3 \mu \mathrm{mol}, 12$ equiv) in $\mathrm{C}_{6} \mathrm{D}_{6}$ was quickly added by syringe, resulting in an immediate color change from red-purple to an opaque brownish green. After about $1 \mathrm{~s}$, as measured by an observer with a stopwatch, 13.5 $\mu \mathrm{L}$ of a $0.46 \mathrm{M}$ solution of $\mathrm{AgPF}_{6}$ ( $6.2 \mathrm{mmol}, 15.5$ equiv) in $\mathrm{CD}_{3} \mathrm{CN}$ was quickly added by syringe, resulting in an immediate color change to brownish red. The ${ }^{1} \mathrm{H}$ NMR spectrum of the sample was then acquired (see Figure S21A below).

Representative Procedure 2 (reduction times > 10 s): In an $\mathrm{N}_{2}$ atmosphere glovebox, $2.880 \mathrm{~mL}$ of a 1.36 $\mathrm{mM}$ solution of $1 \mathrm{a} \cdot 12 \mathrm{PF}_{6}(3.9 \mu \mathrm{mol})$ in $\mathrm{CD}_{3} \mathrm{CN}$ was added to a $20 \mathrm{~mL}$ vial that was charged with a PTFEcoated stir bar. The solution was stirred vigorously while $298 \mu \mathrm{L}$ of a $0.16 \mathrm{M}$ solution of $\mathrm{Cp} *{ }_{2} \mathrm{Co}(47.7 \mu \mathrm{mol}$, 12 equiv) in $\mathrm{C}_{6} \mathrm{D}_{6}$ was added quickly by syringe, resulting in an immediate color change from red-purple to an opaque brownish green. After $30 \mathrm{~s}$, a $0.4 \mathrm{~mL}$ aliquot of the reduced solution was removed by syringe and added to one of six NMR tubes that had each been charged with $14 \mu \mathrm{L}$ of a $0.50 \mathrm{M}$ solution of AgPF 6 (7 $\mu$ mol, 14 equiv) in $\mathrm{CD}_{3} \mathrm{CN}$. The tube was quickly sealed with a polyethylene cap and shaken vigorously for a few seconds, resulting in an immediate color change to an opaque brownish red. This procedure was repeated after $60 \mathrm{~s}, 5 \mathrm{~min}, 10 \mathrm{~min}, 20 \mathrm{mins}$, and $60 \mathrm{~min}$ in the reduced state. The samples were then sealed with PTFE tape, and ${ }^{1} \mathrm{H}$ NMR spectrum of each was acquired (see Figure S21B below). 


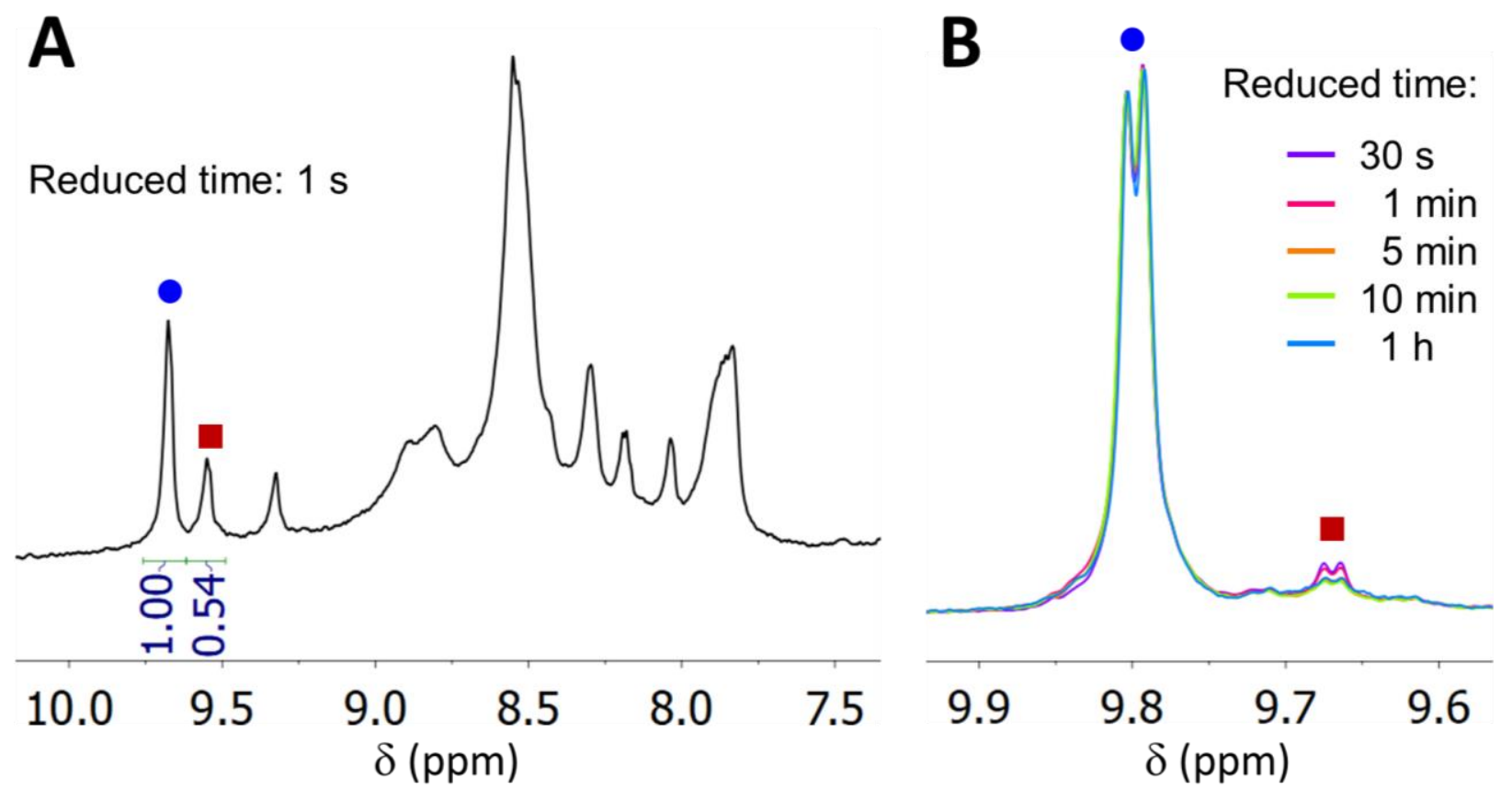

Figure S21. Aromatic region of the ${ }^{1} \mathrm{H}$ NMR spectra of solutions of $1 \mathbf{1 a} \cdot \mathbf{1 2 P F}_{6}$ (ca. $1.3 \mathrm{mM}$ ) in $\mathrm{CD}_{3} \mathrm{CN}_{\text {after }}$ being reduced with 12 equiv $\mathrm{Cp}_{2}{ }_{2} \mathrm{Co}$ and reoxidized with excess $\mathrm{AgPF}_{6}$ at the specified times. Blue circles and red squares are used to mark the respective pyridyl 6-position signals of $\mathrm{Cp}^{*}{ }_{2} \mathrm{Co}^{+} @ 1 \mathbf{a}^{12+}$ and unconverted $1 \mathrm{a}^{12+}$ that were compared to determine conversion to the host-guest complex. (A) Sample reoxidized after $1 \mathrm{~s}$, providing 65\% conversion to $\mathrm{Cp}_{2}{ }_{2} \mathrm{Co}^{+} @ 1 \mathbf{a}^{12+}$. (B) Samples reoxidized after $30 \mathrm{~s}, 60 \mathrm{~s}$, $5 \mathrm{~min}, 10 \mathrm{~min}$, and $1 \mathrm{~h}$. The spectra are overlayed and scaled so the host-guest signals are matched, providing a clear view of the slight decrease of the signal of the free host between $30 \mathrm{~s}, 60 \mathrm{~s}$, and $5 \mathrm{~min}$. Samples reoxidized after $\geq 5$ min showed no substantial differences in their spectra. The spectrum of an aliquot reoxidized after $20 \mathrm{~min}$ is not included here but can be seen above in Figure S1 and matches closely with the other spectra recorded after $\geq 5 \mathrm{~min}$.

\section{5.b. Uptake of $\mathrm{Cp}_{2}{ }_{2} \mathrm{Co}^{+}$by $1 \mathrm{a}^{3+}$.}

General Procedures: Experiments to examine the uptake of $\mathrm{Cp}_{2}{ }_{2} \mathrm{Co}^{+}$into $1 \mathrm{a}^{3+}$ were performed similarly to Representative Procedure 2 described above in section 5.b., but with 9 equiv of $\mathrm{Cp}_{2}{ }_{2} \mathrm{Co}$ used to reduce the cage. Samples were reoxidized after $10 \mathrm{~s}, 30 \mathrm{~s}, 1 \mathrm{~h}$, and $2 \mathrm{~h}$ (see Figure S22).

Experiments to examine the effect of $\left[\mathrm{Cp}^{*}{ }_{2} \mathrm{Co}\right] \mathrm{PF}_{6}$ on the uptake of $\mathrm{Cp}_{2}{ }_{2} \mathrm{Co}^{+}$into $1 \mathrm{a}^{3+}$ were performed similarly to Representative Procedure 1 in section 2.a., but with 10 equiv of the additional salt present prior to reduction with 40 equiv of $\mathrm{Cp}_{2} \mathrm{Co}$ (see Figure $\mathrm{S} 23$ ). 


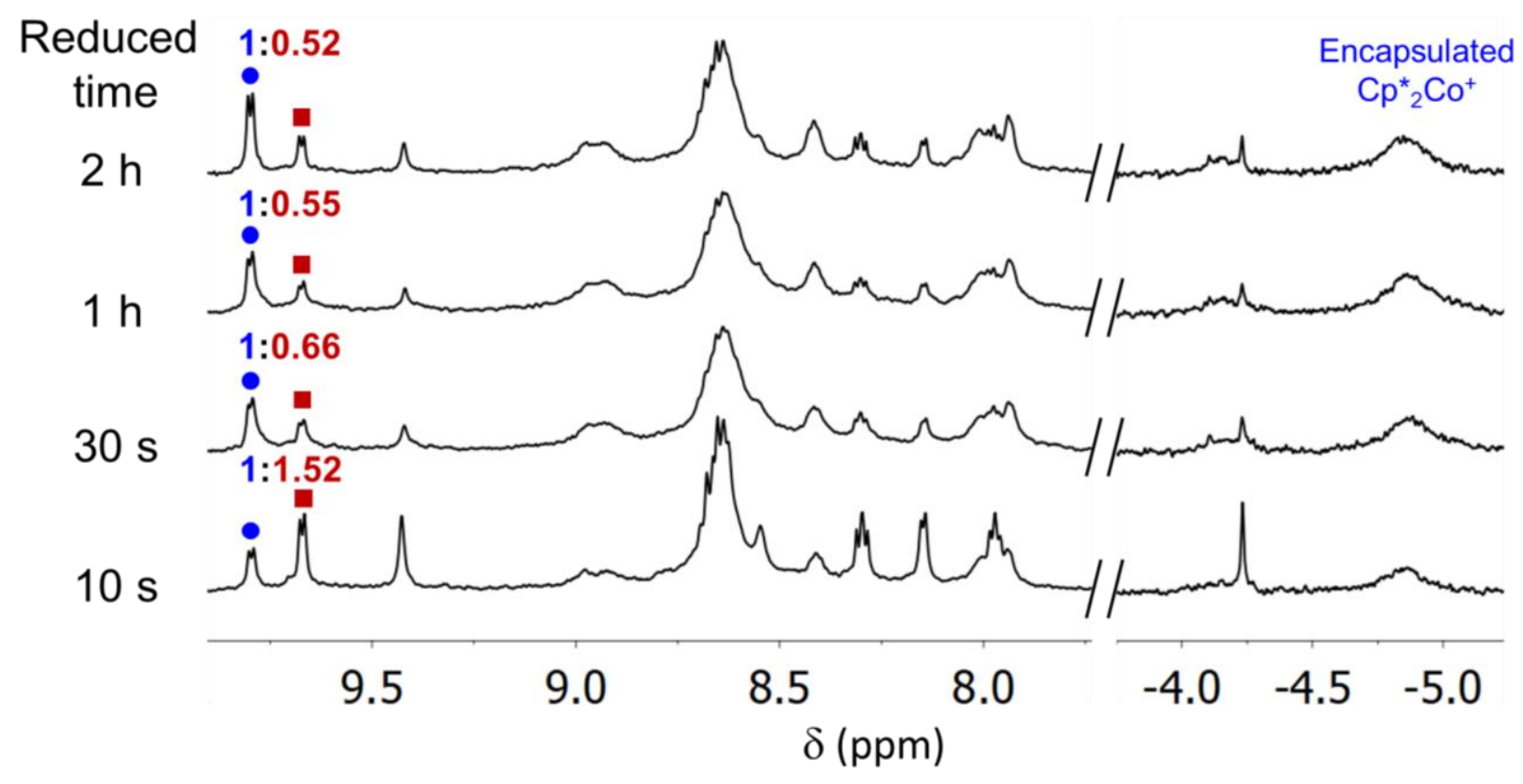

Figure S22. Aromatic and upfield regions of the ${ }^{1} \mathrm{H}$ NMR spectra of solutions of $1 \mathrm{a} \cdot \boldsymbol{1 2}^{2} \mathrm{PF}_{6}$ (ca. $1.3 \mathrm{mM}$ ) in $\mathrm{CD}_{3} \mathrm{CN}$ after being reduced with 9 equiv $\mathrm{Cp}_{2}{ }_{2} \mathrm{Co}$ and reoxidized with excess $\mathrm{AgPF}_{6}$ at the specified times. Blue circles and red squares are used to mark the respective pyridyl 6-position signals of $\mathbf{C p}_{2}{ }_{2} \mathrm{Co}^{+} @ 1 \mathbf{a}^{12+}$ and unconverted $1 \mathbf{a}^{12+}$.

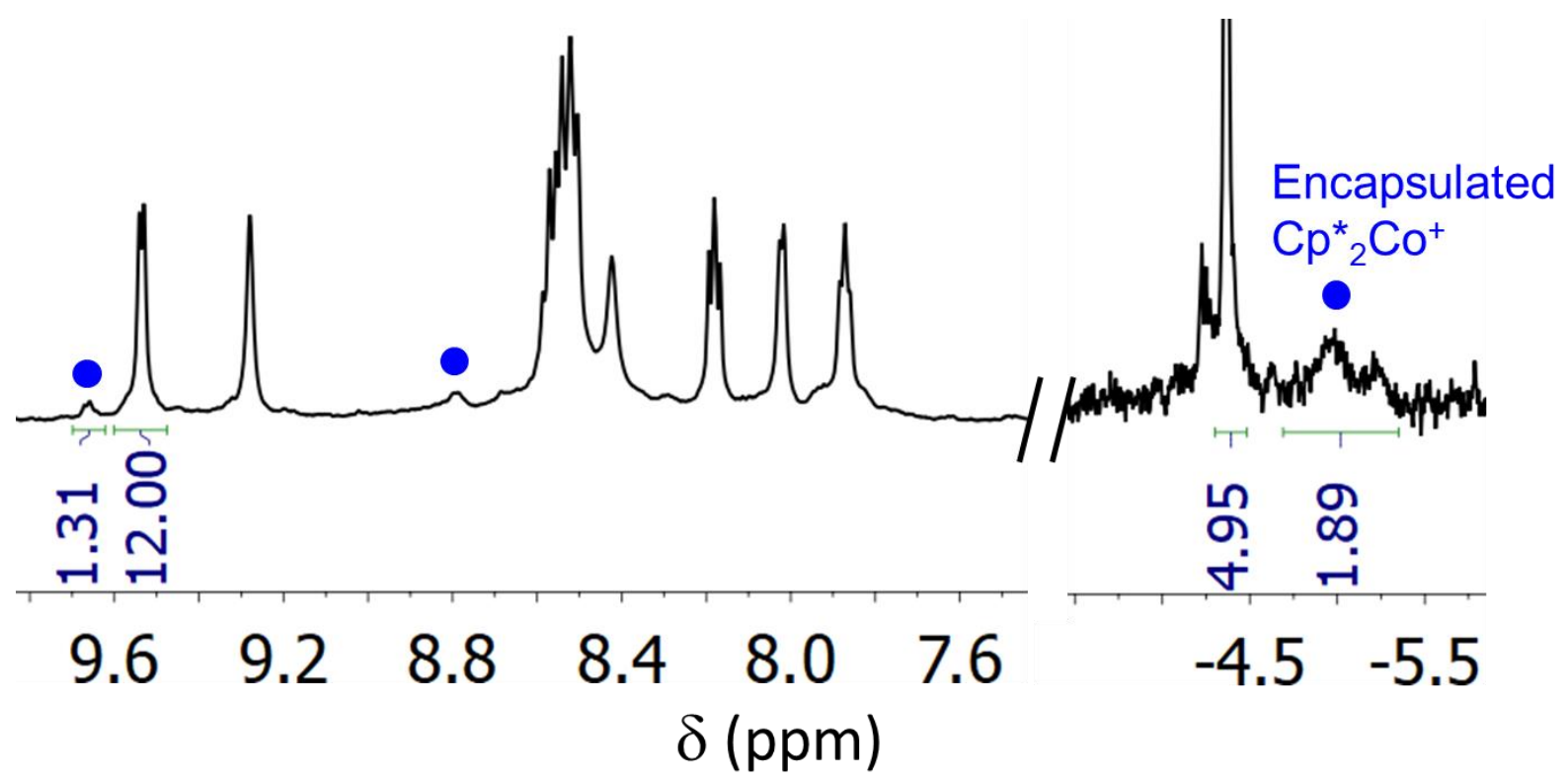

Figure S23. Aromatic and upfield regions of the ${ }^{1} \mathrm{H}$ NMR spectrum of a solution of $1 \mathrm{a} \cdot 12 \mathrm{PF}_{6}$ (ca. $1.3 \mathrm{mM}$ ) and $\left[\mathrm{Cp}_{2}{ }_{2} \mathrm{Co}\right] \mathrm{PF}_{6}$ (13 mmol, 10 equiv) in $\mathrm{CD}_{3} \mathrm{CN}$ after being reduced with 40 equiv $\mathrm{Cp}_{2} \mathrm{Co}$ and reoxidized 30 min later with excess $\mathrm{AgPF}_{6}$. Blue circles mark select signals of $\mathrm{Cp}_{2}{ }_{2} \mathrm{Co}^{+} @ 1 \mathbf{a}^{12+}$. The pyridyl 6-position signals of $\mathbf{C p}^{*}{ }_{2} \mathrm{Co}^{+} @ 1 \mathbf{a}^{12+}$ and $1 \mathbf{a}^{12+}$ were compared to reveal $10 \%$ conversion to the host-guest complex. 


\section{5.c. Uptake of $\mathrm{Cp}_{2}{ }_{2} \mathrm{Co}^{+}$by $1 \mathrm{a}^{9+}$.}

General Procedures: Experiments to examine the uptake of $\mathrm{Cp}^{*}{ }_{2} \mathrm{Co}^{+}$into $1 \mathrm{a}^{9+}$ were performed similarly to Representative Procedure 2 described above in section 5.b., but with 3 equiv of $\mathrm{Cp}_{2}{ }_{2} \mathrm{Co}$ used to reduce $\mathbf{1 a} \cdot \mathbf{1 2} \mathbf{P F}_{6}$. Samples were reoxidized after $1 \mathrm{~h}, 2 \mathrm{~h}$, and $4 \mathrm{~h}$, finding similar conversions to $\mathrm{Cp}_{2}{ }_{2} \mathrm{Co}^{+} @ 1 \mathrm{a}^{12+}$.

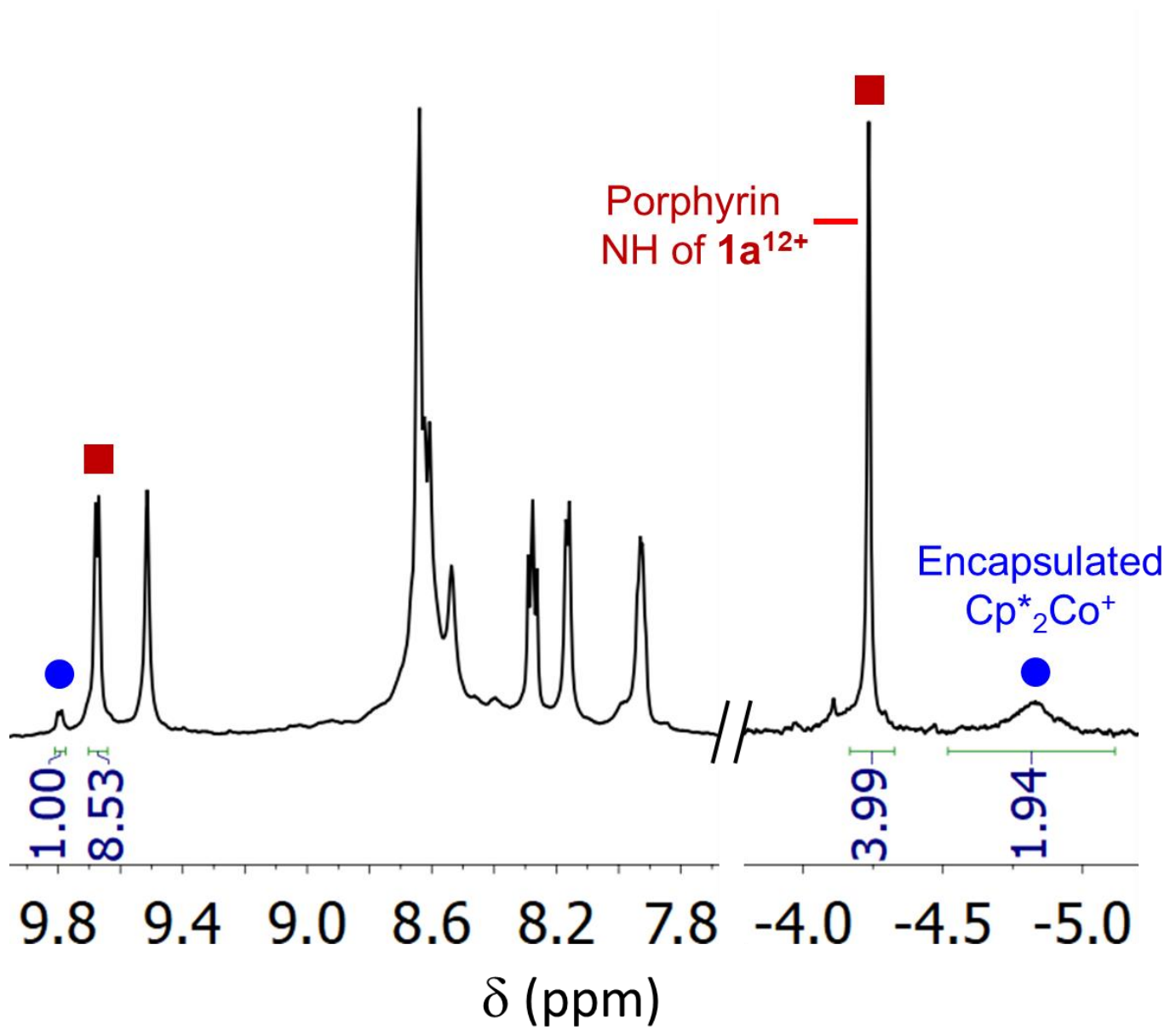

Figure S24. Aromatic and upfield regions of the ${ }^{1} \mathrm{H}$ NMR spectrum of a solution of $1 \mathrm{a} \cdot 12 \mathrm{PF}_{6}$ (ca. $1.3 \mathrm{mM}$ ) in $\mathrm{CD}_{3} \mathrm{CN}$ after being reduced with 3 equiv $\mathrm{Cp}^{*}{ }_{2} \mathrm{Co}$ and reoxidized with excess $\mathrm{AgPF}_{6}$ after $1 \mathrm{~h}$. Blue circles and red squares are used respectively to mark signals of $\mathrm{Cp}_{2}{ }_{2} \mathrm{Co}^{+} @ 1 \mathrm{a}^{12+}$ and unconverted $1 \mathrm{a}^{12+}$. The pyridyl 6-position signals were compared to assess conversion to the host-guest complex. 


\section{5.d. Uptake of $\mathrm{Cp}_{2} \mathrm{Co}^{+}$by $1 \mathrm{~b}^{9+}$.}

General Procedures: Experiments to examine the uptake of $\mathrm{Cp}_{2} \mathrm{Co}^{+}$into $\mathbf{1} \mathbf{b}^{\mathbf{9}}$ were performed similarly to Representative Procedures 1 and 2 described above in section 5.b., but with 3.5 equiv of $\mathrm{Cp}_{2} \mathrm{Co}$ used to reduce solutions of $\mathbf{1 b} \cdot \mathbf{1 2} \mathbf{P F}_{6}$. Reoxidation after $5 \mathrm{~s}$ revealed no conversion to the host-guest complex, with conversion increasing after longer times until reaching a plateau at $\geq 15 \mathrm{~min}$ (Figure S25).

An additional experiment to examine the influence of $\left[\mathrm{Cp}_{2} \mathrm{Co}\right] \mathrm{PF}_{6}$ on the uptake of $\mathrm{Cp}_{2} \mathrm{Co}^{+}$by $\mathbf{1 b}^{9+}$ was performed similarly to Representative Procedure 1 in section 2.a., but with excess $\left[\mathrm{Cp}_{2} \mathrm{Co}_{\mathrm{PF}}\right.$ (18 equiv) added to a solution of $\mathbf{1} \mathbf{b} \cdot \mathbf{1 2} \mathbf{P F}_{6}$ prior to reduction with 3.5 equiv $\mathrm{Cp}_{2} \mathrm{Co}$. The spectrum resulting after reoxidation with $\mathrm{AgPF}_{6}$ is presented above in Figure $\mathrm{S} 13$.

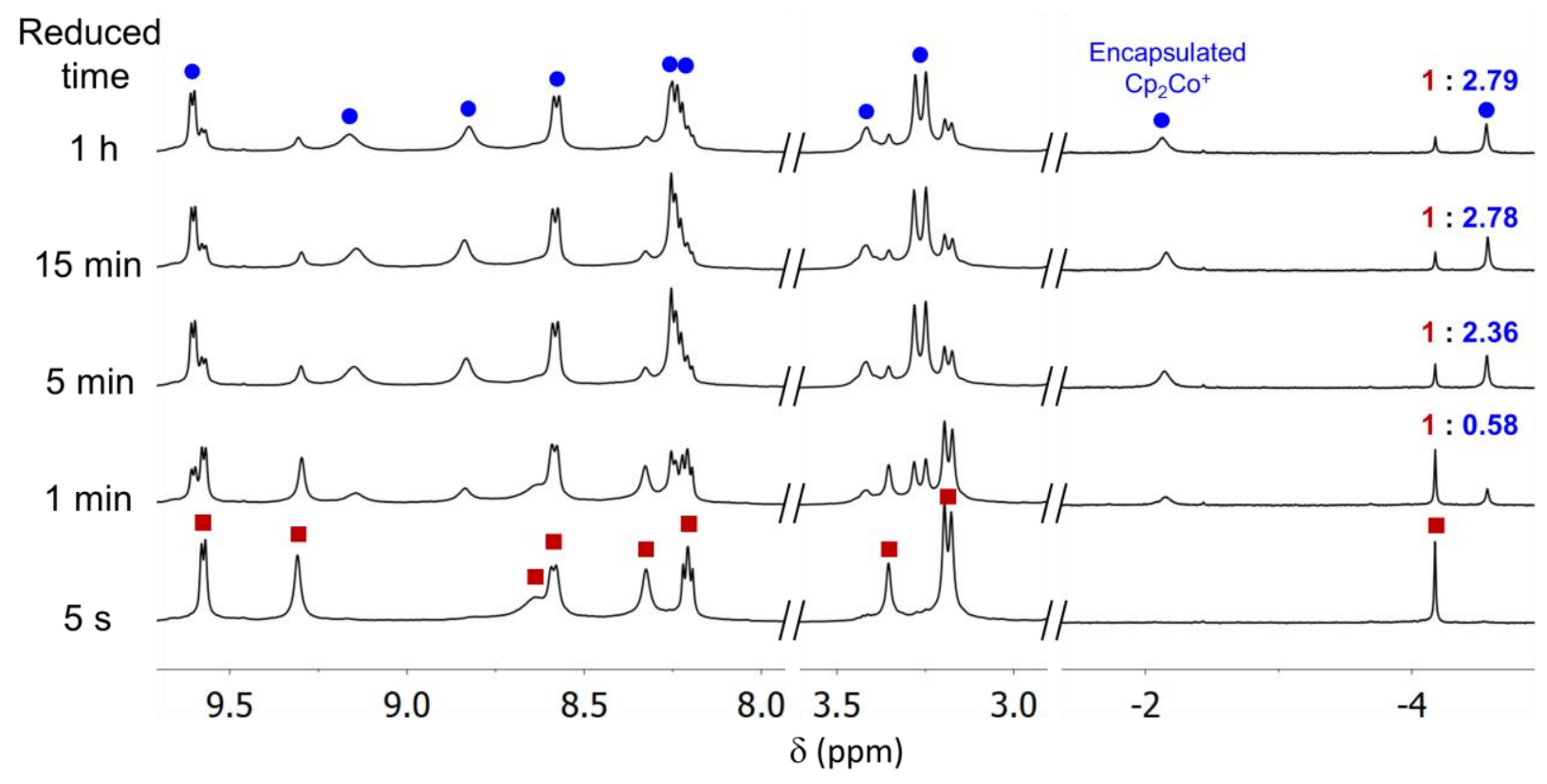

Figure S25. ${ }^{1} \mathrm{H}$ NMR spectra of solutions of $\mathbf{1 b} \cdot \mathbf{1 2} \mathrm{PF}_{6}$ (ca. $1.3 \mathrm{mM}$ ) in $\mathrm{CD}_{3} \mathrm{CN}$ after being reduced with 3.5 equiv $\mathrm{Cp}_{2} \mathrm{Co}$ and reoxidized with excess $\mathrm{AgPF}_{6}$ at the specified times. Blue circles and red squares are used respectively to mark signals of $\mathbf{C p}_{\mathbf{2}} \mathbf{C o}^{+} @ \mathbf{1} \mathbf{b}^{\mathbf{1 2 +}}$ and unconverted $\mathbf{1 b}^{\mathbf{1 2 +}}$. The porphyrin $\mathrm{NH}$ signals were compared to determine conversion to the host-guest complex, revealing no conversion after $5 \mathrm{~s}$ and nearly full conversion after 5 min. 


\section{Kinetics of guest release from $\mathrm{Cp}_{2}{ }^{*} \mathrm{Co}^{+} @ 1 a^{12+}$ and $\mathrm{Cp}_{2} \mathrm{Co}^{+} @ 1 b^{12+}$}

General Procedures. For monitoring the kinetics of $\mathrm{Cp}_{2}{ }_{2} \mathrm{Co}^{+}$escape from $\mathrm{Cp}_{2}{ }_{2} \mathrm{Co}^{+} @ 1 \mathbf{a}^{12+}$, samples of the host-guest complex were prepared in batches from $\mathbf{1} \mathbf{a} \cdot \mathbf{1 2} \mathbf{P F}_{6}$ or $\mathbf{1} \mathbf{a} \cdot \mathbf{1 2} \mathbf{B F}_{4}$ following Representative Procedure 2 in section 2.a. The solution of the host-guest complex was then divided into individual samples in NMR tubes containing sealed glass capillaries of ferrocene or $\left[\mathrm{Cp}_{2} \mathrm{Co}_{\mathrm{P}}\right] \mathrm{F}_{6}$ in $\mathrm{CD}_{3} \mathrm{CN}$ as internal standards. The samples were then used as-is, diluted with additional solvent, and/or treated with various additives as needed for specific experiments. Samples were monitored by ${ }^{1} \mathrm{H}$ NMR spectroscopy, with the decay of the host-guest complex $\mathbf{C p}_{2}{ }_{2} \mathrm{Co}^{+} @ 1 \mathbf{a}^{12+}$ tracked by integration of the resonance corresponding to the encapsulated $\mathrm{Cp}_{2}{ }_{2} \mathrm{Co}^{+}$guest, which was well-separated from resonances of the host $1 \mathrm{a}^{12+}$. For most experiments, the natural log of $\left[\mathbf{C p}_{2}{ }_{2} \mathrm{Co}^{+} @ 1 \mathbf{a}^{12+}\right] /\left[\mathrm{Cp}_{2}{ }_{2} \mathrm{Co}^{+} @ 1 \mathbf{a}^{12+}{ }_{\text {initial }}\right]$ showed a good linear dependence vs. time, from which first-order rate constants were obtained. For samples monitored over several weeks, spectra were acquired once per day, with occasional data points missed due to limited instrumentation availability or instrument malfunctions that could not be avoided over the course of multiple weeks. Additional details for testing specific variables are provided:

Procedure 1 (Parallel monitoring at $23^{\circ} \mathrm{C}$ ). A solution of $\mathrm{Cp}{ }_{2} \mathrm{Co}^{+} @ 1 \mathrm{a}^{12+}$ was divided equally into three NMR tubes, each containing a sealed capillary of ferrocene in $\mathrm{CD}_{3} \mathrm{CN}$ as an internal standard. The NMR samples were sealed with a polyethylene cap that was then wrapped generously with PTFE tape. The ${ }^{1} \mathrm{H}$ NMR spectrum of each sample was then recorded. Additional spectra were acquired once per day until $\mathrm{Cp}_{2}{ }_{2} \mathrm{Co}^{+} @ 1 \mathrm{a}^{12+}$ had decayed to $\leq 12.5 \%$ of its original concentration ( 3 half-lives) as determined by integration of the signal of encapsulated $\mathrm{Cp}_{2}{ }_{2} \mathrm{Co}^{+}$against the ferrocene standard. Between NMR acquisitions, the samples were covered with aluminum foil and stored together in a beaker along with a glass thermometer that consistently measured a temperature of $23^{\circ} \mathrm{C}+/-1^{\circ} \mathrm{C}$.

Procedure 2 (Temperature dependence). A solution of $\mathrm{Cp}_{2}{ }_{2} \mathrm{Co}^{+} @ 1 \mathbf{a}^{12+}$ was divided equally into six JYoung style air-free NMR tubes, each containing a sealed capillary of ferrocene in $\mathrm{CD}_{3} \mathrm{CN}$ as an internal standard. The NMR samples were sealed with a PTFE stopper and the ${ }^{1} \mathrm{H}$ NMR spectrum of each sample was recorded. The decay of $\mathbf{C p}_{2}{ }_{2} \mathrm{Co}^{+} @ 1 \mathbf{a}^{12+}$ was then monitored in one of three ways, as appropriate for the temperature being evaluated:

(a) Samples at ambient temperature $\left(23^{\circ} \mathrm{C}\right)$ were monitored as described immediately above in Procedure 1.

(b) Samples monitored at $<50^{\circ} \mathrm{C}$ were heated in a thermocouple-controlled oil bath set to maintain the desired temperature, which was confirmed by monitoring the oil bath with a partialimmersion thermometer. The samples were removed briefly from heating every $4-6 \mathrm{~h}$ to acquire the NMR spectrum at $25{ }^{\circ} \mathrm{C}$. When it was not possible to monitor the samples for an extended period of time, the samples were removed from heating and chilled to $\leq-10^{\circ} \mathrm{C}$ in a salt/ice bath in a vacuum dewar. ${ }^{1} \mathrm{H}$ NMR spectra were acquired before and after cooling to confirm that the host-guest complex decays negligibly when stored in this manner for several hours.

(c) Samples monitored at $\geq 50{ }^{\circ} \mathrm{C}$ were heated in the probe of a Bruker AVANCE Neo NMR spectrometer and spectra were acquired every $10 \mathrm{~min}$. Prior to heating each sample of $\mathrm{Cp}_{2}{ }_{2} \mathrm{Co}^{+} @ 1 \mathbf{a}^{12+}$, the temperature of the probe was measured by acquiring the spectrum of an external standard of neat ethylene glycol. Analysis of the $\mathrm{CH} / \mathrm{OH}$ peak separation indicated 
excellent agreement between the measured and set temperatures of the probe. For samples heated above $60^{\circ} \mathrm{C}$, guest escape was fast enough to monitor $\geq 3$ half-lives of decay, while for samples heated to $<60^{\circ} \mathrm{C}$, the samples were monitored for as long as possible $(7-10 \mathrm{~h})$ given limitations of instrument availability, but did not generally reach 2 half-lives of decay.

Procedure 3 (Influence of metallocene additives). A $1.2 \mathrm{mM}$ solution of $\mathrm{Cp}_{2}{ }_{2} \mathrm{Co}^{+} @ 1 \mathrm{a}^{12+}$ was divided into three $0.400 \mathrm{~mL}$ samples that were transferred to three J-Young style air-free NMR tubes, each containing a sealed capillary of ferrocene or $\left[\mathrm{Cp}_{2} \mathrm{Co}\right] \mathrm{PF}_{6}$ in $\mathrm{CD}_{3} \mathrm{CN}$ as an internal standard. $\mathrm{A} 0.215 \mathrm{M}$ stock solution of ferrocene in $\mathrm{CD}_{3} \mathrm{CN}$ was added to one sample to reach a concentration of 6.0 or $14.4 \mathrm{mM}$ (5 or 12 equiv, respectively). A freshly prepared $0.255 \mathrm{M}$ solution of $[\mathrm{Fc}] \mathrm{PF}_{6}$ was added to another sample to reach a concentration of 6.0 or $14.4 \mathrm{mM}$ ( 5 or 12 equiv, respectively). The third sample was left as-is to serve as a control. The ${ }^{1} \mathrm{H}$ NMR spectrum of each sample was then recorded, and additional spectra of the samples with the additives were recorded after $1 \mathrm{~h}$ and $2 \mathrm{~h}$. The spectrum of each sample was then recorded at least once per day until $\geq 3$ half-lives of decay were reached. The samples were stored between measurements as described under Procedure 1 on the previous page.

Procedure 4 (Influence of $\mathrm{AgPF}_{6}$ and $\mathrm{TBAPF}_{6}$ ). Samples were prepared following the procedure described for the influence of metallocene additives (Procedure 3). A $1.98 \mathrm{M}$ stock solution of TBAPF 6 was used to add 24 equiv (28.8 mM) of $\mathrm{TBAPF}_{6}$ to one sample, and a $0.46 \mathrm{M}$ stock solution of $\mathrm{AgPF}_{6}$ was used to add 24 equiv ( $28.8 \mathrm{mM}$ ) of $\mathrm{AgPF}_{6}$ to another sample, with a third sample left without additives to serve as a control. The ${ }^{1} \mathrm{H}$ NMR spectrum of each sample was recorded once per day.

Procedure 5 (Influence of concentration). A $1.2 \mathrm{mM}$ solution of $\mathrm{Cp}_{2}{ }_{2} \mathrm{Co}^{+} @ 1 \mathbf{a}^{12+}$ was divided into 0.400 $\mathrm{mL}, 0.200 \mathrm{~mL}, 0.100 \mathrm{~mL}, 0.050 \mathrm{~mL}$, and $0.025 \mathrm{~mL}$ aliquots, which were transferred to five NMR tubes, each containing a sealed capillary of ferrocene in $\mathrm{CD}_{3} \mathrm{CN}$ as an internal standard. Each sample was diluted to $0.400 \mathrm{~mL}$ using $\mathrm{CD}_{3} \mathrm{CN}$, affording final $\mathrm{Cp}_{2}{ }_{2} \mathrm{Co}^{+} @ 1 \mathrm{a}^{12+}$ concentrations of $1.2 \mathrm{mM}, 0.6 \mathrm{mM}, 0.3 \mathrm{mM}, 0.15$ $\mathrm{mM}$, and $0.075 \mathrm{mM}$. The samples were sealed with a polyethylene cap that was reinforced with PTFE tape before acquiring the ${ }^{1} \mathrm{H}$ NMR spectrum of each sample. Additional spectra were acquired at least once per day, and the samples were stored between measurements as described under Procedure 1 on the previous page. For some of the diluted samples, a low signal-to-noise ratio or inconsistent baselines between spectra prevented effective monitoring to at least 3 half-lives. For these samples, rate constants were determined using only the spectra that could be integrated reliably.

Procedure 6 (Samples reoxidized with [Fc]PF 6 ). A 1.2 mM sample of $\mathrm{Cp}_{2}{ }_{2} \mathrm{Co}^{+} @ 1 \mathrm{a}^{12+}$ was prepared in a Jyoung style air-free NMR tube following a similar procedure to that described under Representative Procedure 1 in section 2.a., except that $\left[\mathrm{Fc}_{\mathrm{PF}} \mathrm{F}_{6}\right.$ was used instead of $\mathrm{AgPF}_{6}$ to reoxidize the host after reduction with 12 equiv of $\mathrm{Cp}_{2}{ }_{2} \mathrm{Co}$. A capillary of $\left[\mathrm{Cp}_{2} \mathrm{Co}\right] \mathrm{PF}_{6}$ in $\mathrm{CD}_{3} \mathrm{CN}$ was added as an internal standard and the sample was sealed with a PTFE stopper. The ${ }^{1} \mathrm{H}$ NMR spectrum of the sample was acquired within $15 \mathrm{~min}$ of preparation and then at intervals of ca. $30 \mathrm{~min}$ until $>3$ half-lives of decay were reached ( $8 \mathrm{~h}$ ). 

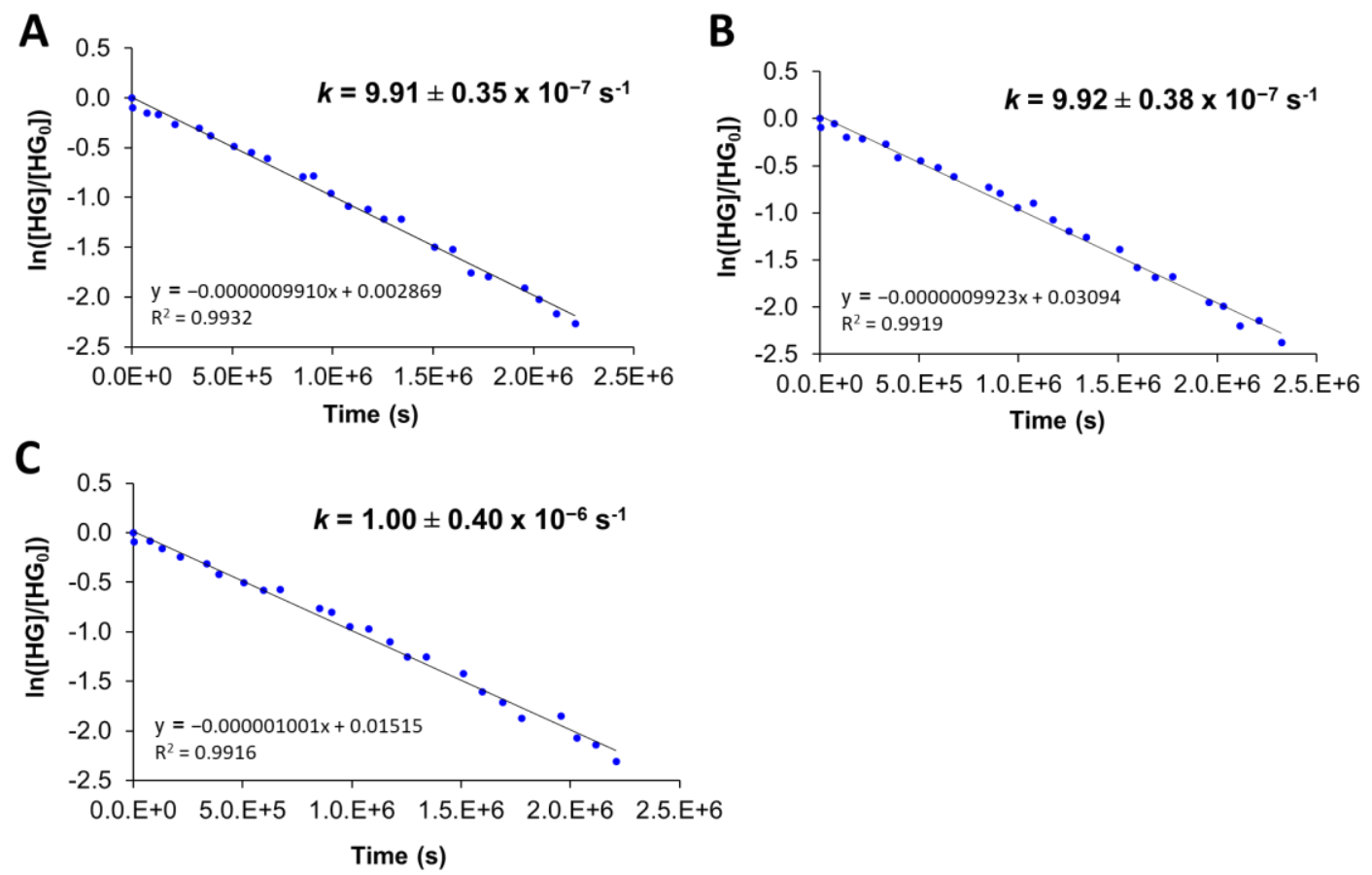

Figure S26. Plots of $\ln \left([\mathrm{HG}] /\left[\mathrm{HG}_{0}\right]\right)$ vs. time $\left(\mathrm{HG}=\mathrm{Cp}^{*}{ }_{2} \mathrm{Co}^{+} @ 1 \mathrm{a}^{12+}\right)$ for $1.2 \mathrm{mM}$ samples of $\mathrm{Cp}^{*}{ }_{2} \mathrm{Co}^{+} @ 1 \mathrm{a}^{12+}$ in $\mathrm{PF}_{6}{ }^{-}$solutions. The host-guest complex was prepared by reducing $1 \mathrm{a} \bullet 12 \mathrm{PF}_{6}$ with 12 equiv of $\mathrm{Cp}_{2}{ }_{2} \mathrm{Co}$ before reoxidizing with $\mathrm{AgPF}_{6}$, followed by dividing into three individual samples following Procedure 1 described above in this section.
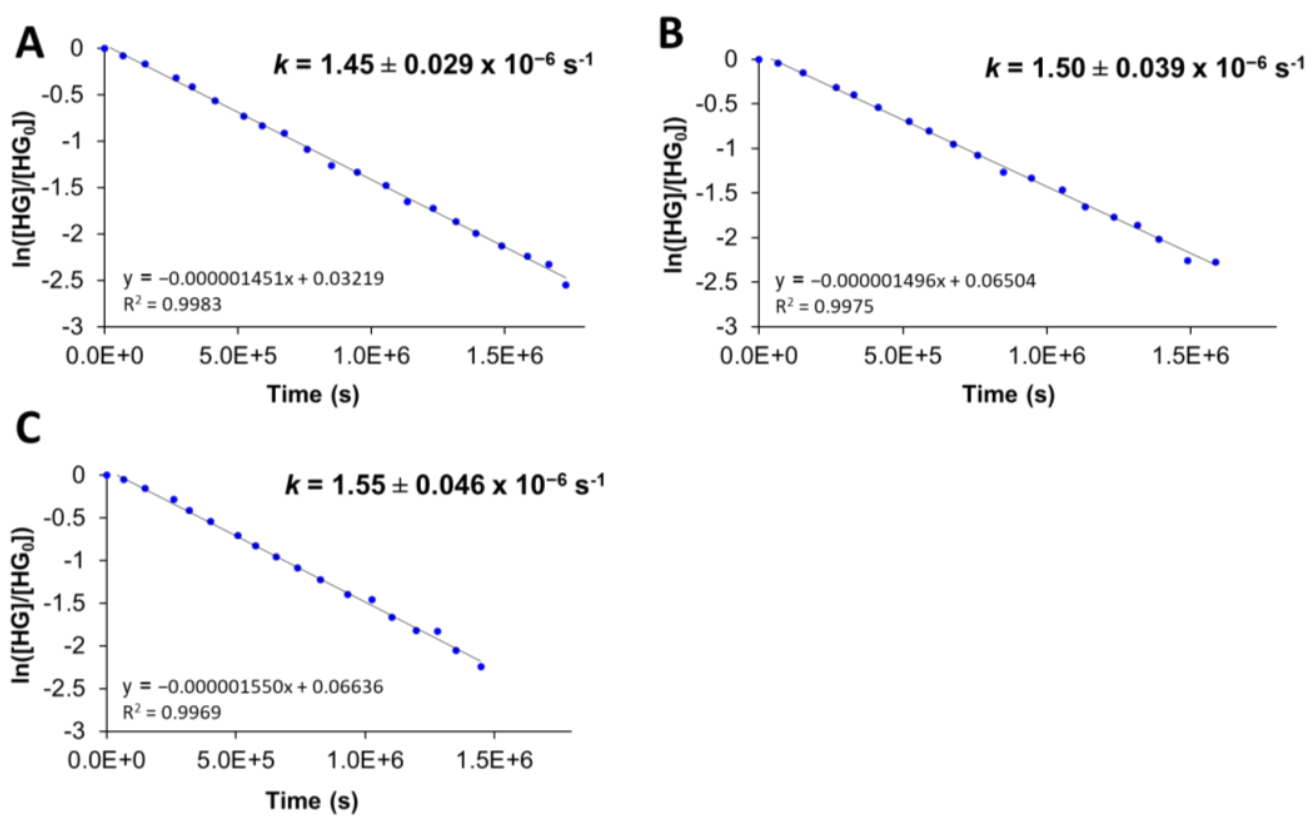

Figure S27. Plots of In([HG]/[HGo]) vs. time $\left(\mathrm{HG}=\mathrm{Cp}_{2}{ }_{2} \mathrm{Co}^{+} @ 1 \mathrm{a}^{12+}\right)$ for $1.2 \mathrm{mM}$ samples of $\mathrm{Cp}_{2}{ }_{2} \mathrm{Co}^{+} @ 1 \mathrm{a}^{12+}$ in $\mathrm{BF}_{4}{ }^{-}$solutions. The host-guest complex was prepared by reducing $1 \mathrm{a} \bullet 12 \mathrm{BF}_{4}$ with 12 equiv of $\mathrm{Cp}^{*}{ }_{2} \mathrm{Co}$ before reoxidizing with $\mathrm{AgBF}_{4}$, followed by dividing into three individual samples following Procedure 1 described above in this section. 

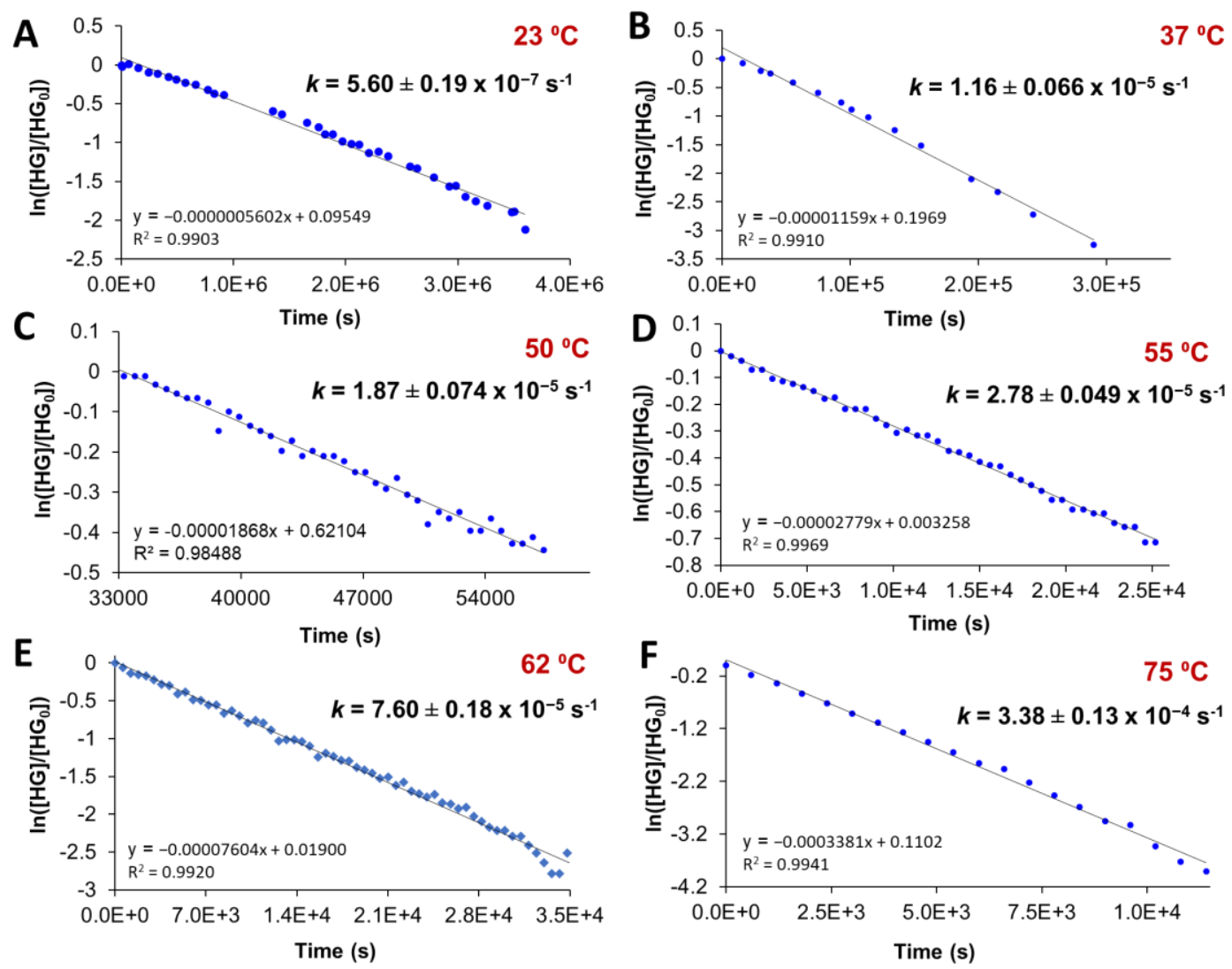

Figure S28. Plots of $\ln \left([\mathrm{HG}] /\left[\mathrm{HG}_{0}\right]\right)$ vs. time $\left(\mathrm{HG}=\mathrm{Cp}^{*}{ }_{2} \mathrm{Co}^{+} @ 1 \mathrm{a}^{12+}\right)$ for $1.2 \mathrm{mM}$ samples of $\mathrm{Cp}^{*}{ }_{2} \mathrm{Co}^{+} @ 1 \mathrm{a}^{12+}$ in $\mathrm{PF}_{6}{ }^{-}$solutions that were monitored at temperatures from $23{ }^{\circ} \mathrm{C}$ to $75^{\circ} \mathrm{C}$. The host-guest complex was prepared by reducing $1 \mathrm{a} \cdot \mathbf{1 2} \mathrm{PF}_{6}$ with 12 equiv of $\mathrm{Cp}_{2}{ }_{2} \mathrm{Co}$ before reoxidizing with $\mathrm{AgPF}_{6}$, followed by dividing into six individual samples and monitoring following Procedure 2 described above in this section.
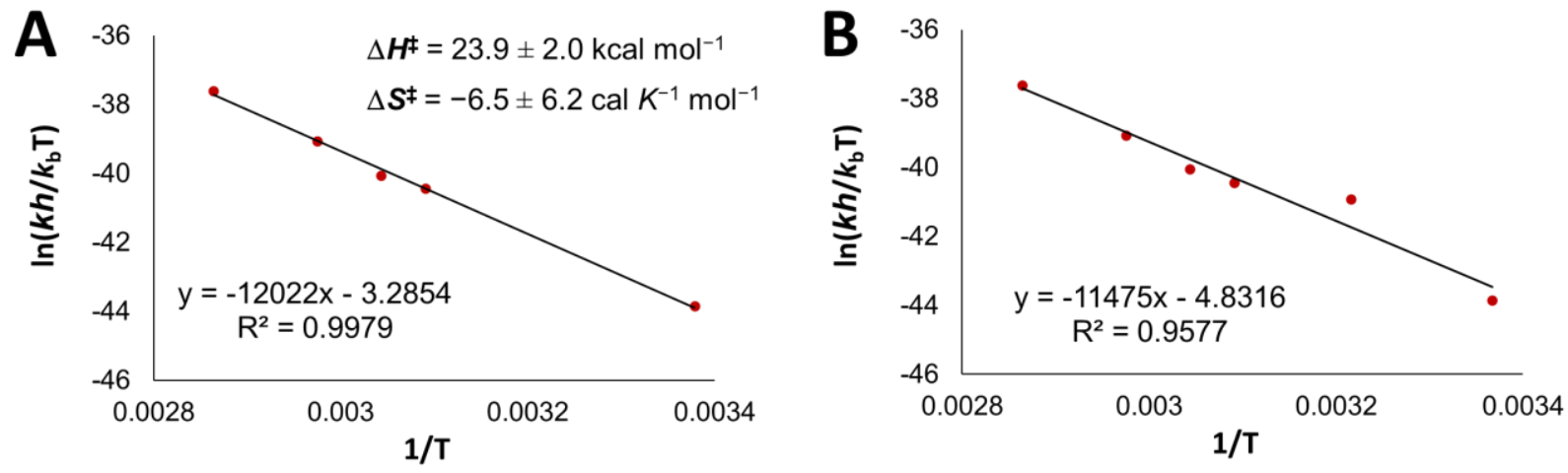

Figure S29. Eyring analyses of the data shown above in Figure S28. (A) Eyring plot produced using the rate constants determined at $23,50,55,62$, and $75^{\circ} \mathrm{C}$, providing activation parameters of $\Delta H^{\ddagger}=23.9 \pm 2.0 \mathrm{kcal}$ $\mathrm{mol}^{-1}$ and $\Delta S^{\ddagger}=-6.5 \pm 6.2 \mathrm{cal} \mathrm{K}^{-1} \mathrm{~mol}^{-1}$. Note that the rate constant determined at $37^{\circ} \mathrm{C}$ was rejected from consideration as a significant outlier. (B) Eyring plot with the $37{ }^{\circ} \mathrm{C}$ data point included, illustrating its significant deviation from the trend produced by the data points obtained at other temperatures. 

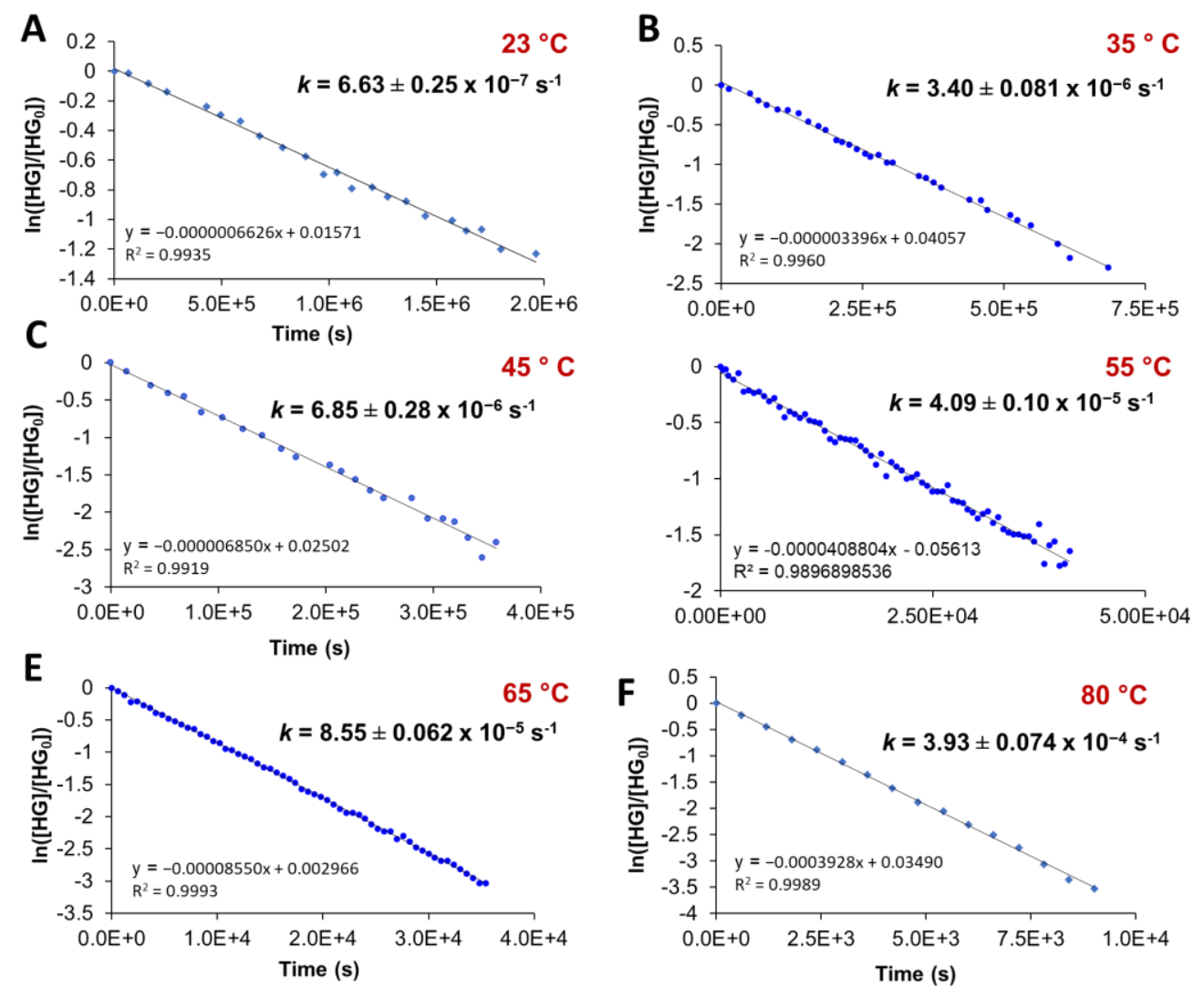

Figure S30. Plots of $\ln \left([\mathrm{HG}] /\left[\mathrm{HG}_{0}\right]\right)$ vs. time $\left(\mathrm{HG}=\mathrm{Cp}^{*}{ }_{2} \mathrm{Co}^{+} @ 1 \mathbf{a}^{12+}\right)$ for $1.2 \mathrm{mM}$ samples of $\mathrm{Cp}^{*}{ }_{2} \mathrm{Co}^{+} @ 1 \mathrm{a}^{12+}$ in $\mathrm{BF}_{4}{ }^{-}$solutions that were monitored at temperatures from $23{ }^{\circ} \mathrm{C}$ to $80^{\circ} \mathrm{C}$. The host-guest complex was prepared by reducing $\mathbf{1 a} \bullet \mathbf{1 2 B F}_{4}$ with 12 equiv of $\mathrm{Cp}_{2}{ }_{2} \mathrm{Co}$ before reoxidizing with $\mathrm{AgBF}_{4}$, followed by dividing into six individual samples and monitoring following Procedure 2 described above in this section.

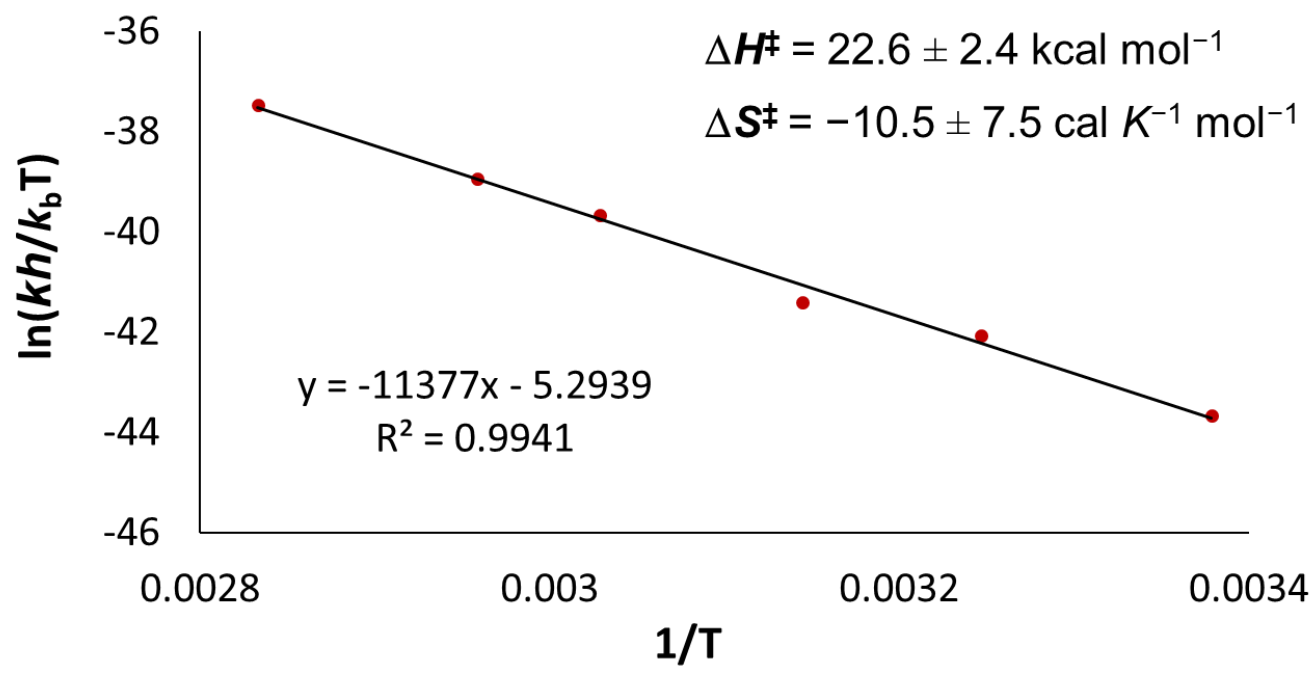

Figure S31. Eyring analyses of the data shown above in Figure S30, providing activation parameters of $\Delta H^{\dagger}=22.6 \pm 2.4 \mathrm{kcal} \mathrm{mol}^{-1}$ and $\Delta S^{\dagger}=-10.5 \pm 7.5 \mathrm{cal} \mathrm{K}^{-1} \mathrm{~mol}^{-1}$. 

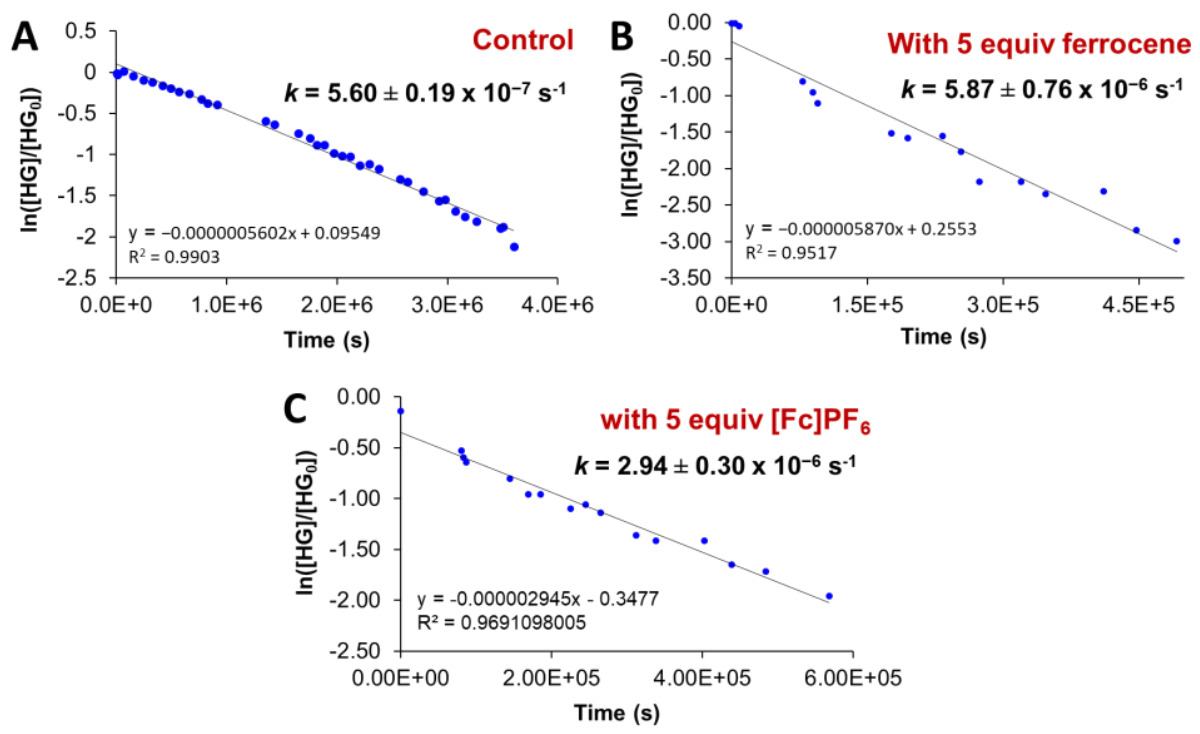

Figure S32. Plots of $\ln \left([\mathrm{HG}] /\left[\mathrm{HG}_{0}\right]\right)$ vs. time $\left(\mathrm{HG}=\mathrm{Cp}^{*}{ }_{2} \mathrm{Co}^{+} @ 1 \mathbf{a}^{12+}\right)$ for $1.2 \mathrm{mM}$ samples of $\mathrm{Cp}_{2}{ }_{2} \mathrm{Co}^{+} @ 1 \mathrm{a}^{12+}$ in $\mathrm{PF}_{6}{ }^{-}$solutions with ferrocene or $\left[\mathrm{Fc}_{\mathrm{P}} \mathrm{PF}_{6}\right.$. The host-guest complex was prepared by reducing $\mathbf{1 a} \bullet \mathbf{1 2}^{2} \mathrm{PF}_{6}$ with 12 equiv of $\mathrm{Cp}_{2}{ }_{2} \mathrm{Co}$ before reoxidizing with $\mathrm{AgPF}_{6}$, followed by dividing into three individual samples and treating with 5 equiv of ferrocene or $\left[\mathrm{Fc}_{\mathrm{P}}\right] \mathrm{PF}_{6}$ as described above in Procedure 3. (A) Control sample without ferrocene or ferrocenium added. (B) Sample with 5 equiv of ferrocene added. (C) Sample with 5 equiv of $\left[\mathrm{Fc}_{\mathrm{C}}\right] \mathrm{PF}_{6}$ added. Note that these samples were prepared from the same batch of $\mathrm{Cp}_{2}{ }_{2} \mathrm{Co}^{+} @ 1 \mathbf{a}^{12+}$ that was used to generate the variable temperature kinetics data presented in Figure S28. The control sample presented here is the same sample used for the $23^{\circ} \mathrm{C}$ kinetics measurement in Figure S28A.
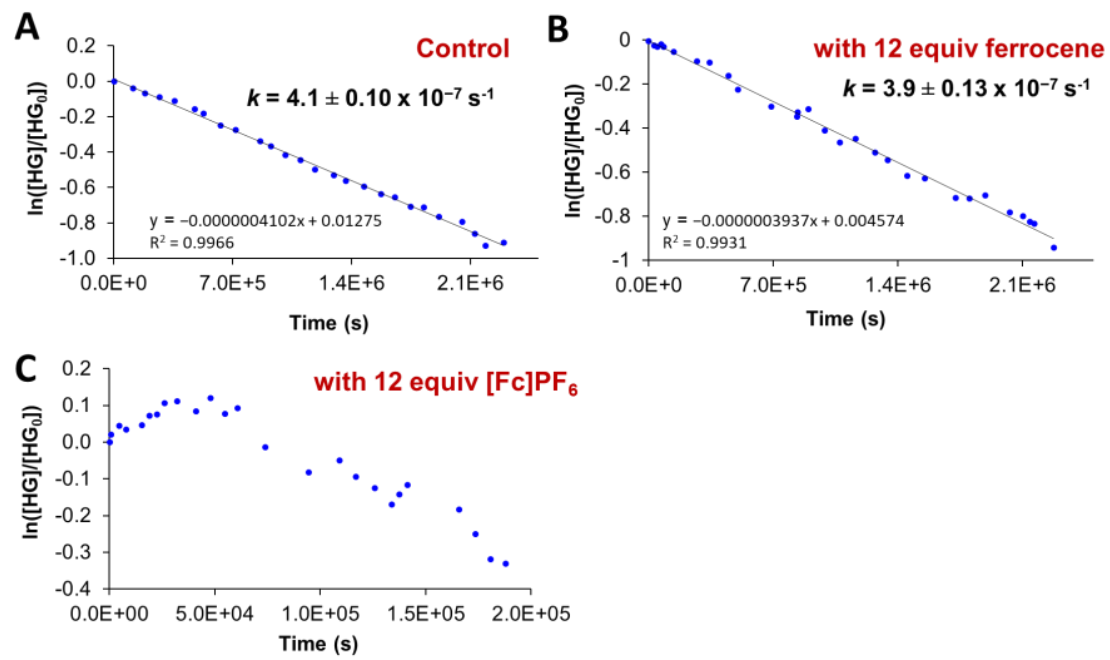

Figure S33. Plots of $\ln \left([\mathrm{HG}] /\left[\mathrm{HG}_{0}\right]\right)$ vs. time $\left(\mathrm{HG}=\mathrm{Cp}^{*}{ }_{2} \mathrm{Co}^{+} @ 1 \mathbf{a}^{12+}\right)$ for $1.2 \mathrm{mM}$ samples of $\mathrm{Cp}^{*}{ }_{2} \mathrm{Co}^{+} @ 1 \mathbf{a}^{12+}$ in $\mathrm{PF}_{6}{ }^{-}$solutions with 12 equiv ferrocene or $\left[\mathrm{Fc}_{\mathrm{P}} \mathrm{PF}_{6}\right.$. Samples were prepared similarly to those in Figure S32. (A) Control sample without additives. (B) Sample with 12 equiv of ferrocene. (C) Sample with 12 equiv of $\left[\mathrm{Fc}_{\mathrm{P}} \mathrm{PF}_{6}\right.$. Sample $\mathrm{C}$ showed similar dissociation of the host-guest complex after $17 \mathrm{~h}$ as was observed for the control, followed by a significantly increased rate. However, accurate integration of the ${ }^{1} \mathrm{H} N M R$ spectra of this sample was prevented by overlap of the signal of the [Cp]PF ${ }_{6}$ standard with that of the broad $\mathrm{Fc}^{+} / \mathrm{Fc}$ resonance. Spectra resulting from this sample are presented below in Figures S34 - S36. 


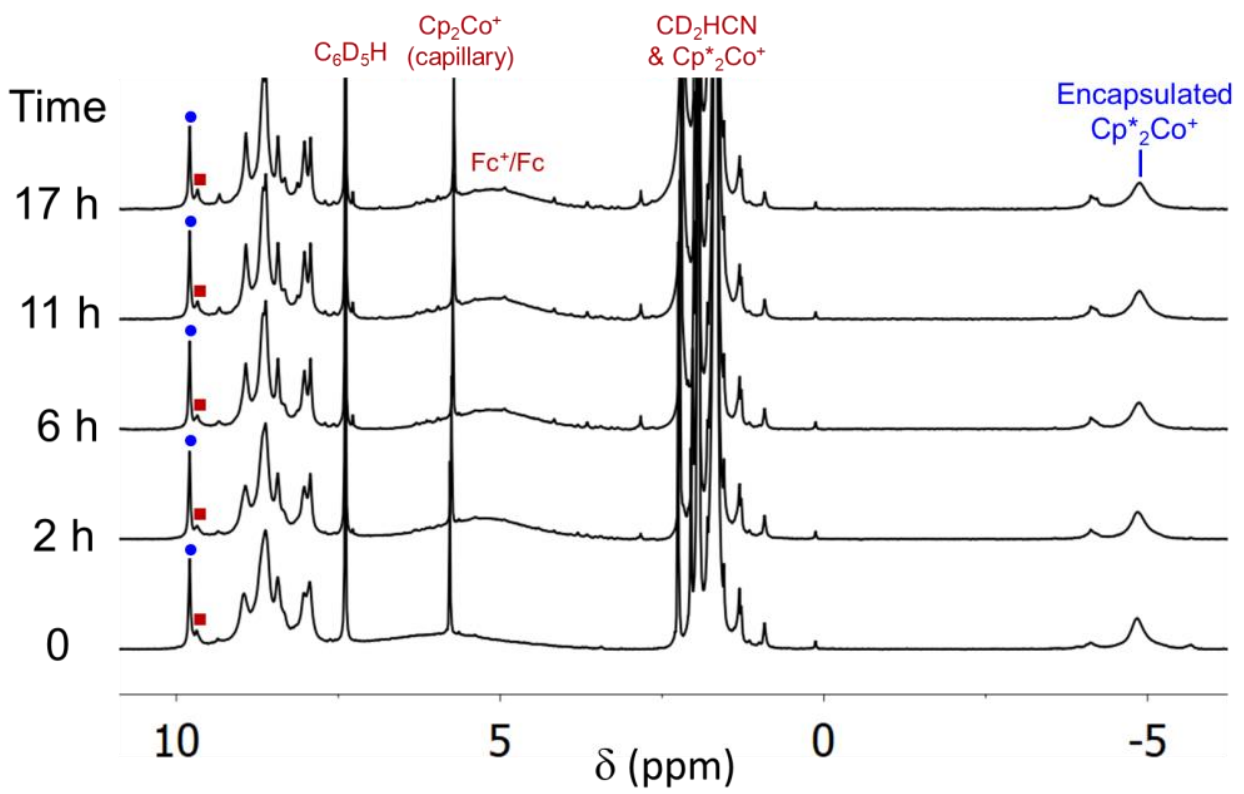

Figure S34. Select ${ }^{1} \mathrm{H}$ NMR spectra recorded from $0-17 \mathrm{~h}$ after adding 12 equiv of [ $\mathrm{Fc}_{\mathrm{P}} \mathrm{PF}_{6}$ to the $1.2 \mathrm{mM}$ sample of $\mathrm{Cp}_{2}{ }_{2} \mathrm{Co}^{+} @ 1 \mathbf{a}^{12+}$ that is plotted in Figure S33C. Blue circles and red squares mark the respective pyridyl 6-position $\mathrm{CH}$ resonances of $\mathrm{Cp}^{*}{ }_{2} \mathrm{Co}^{+} @ 1 \mathrm{a}^{12+}$ and $1 \mathrm{a}^{12+}$, which showed little change in these spectra. Other major resonances not corresponding to the host-guest complex or host are labeled.

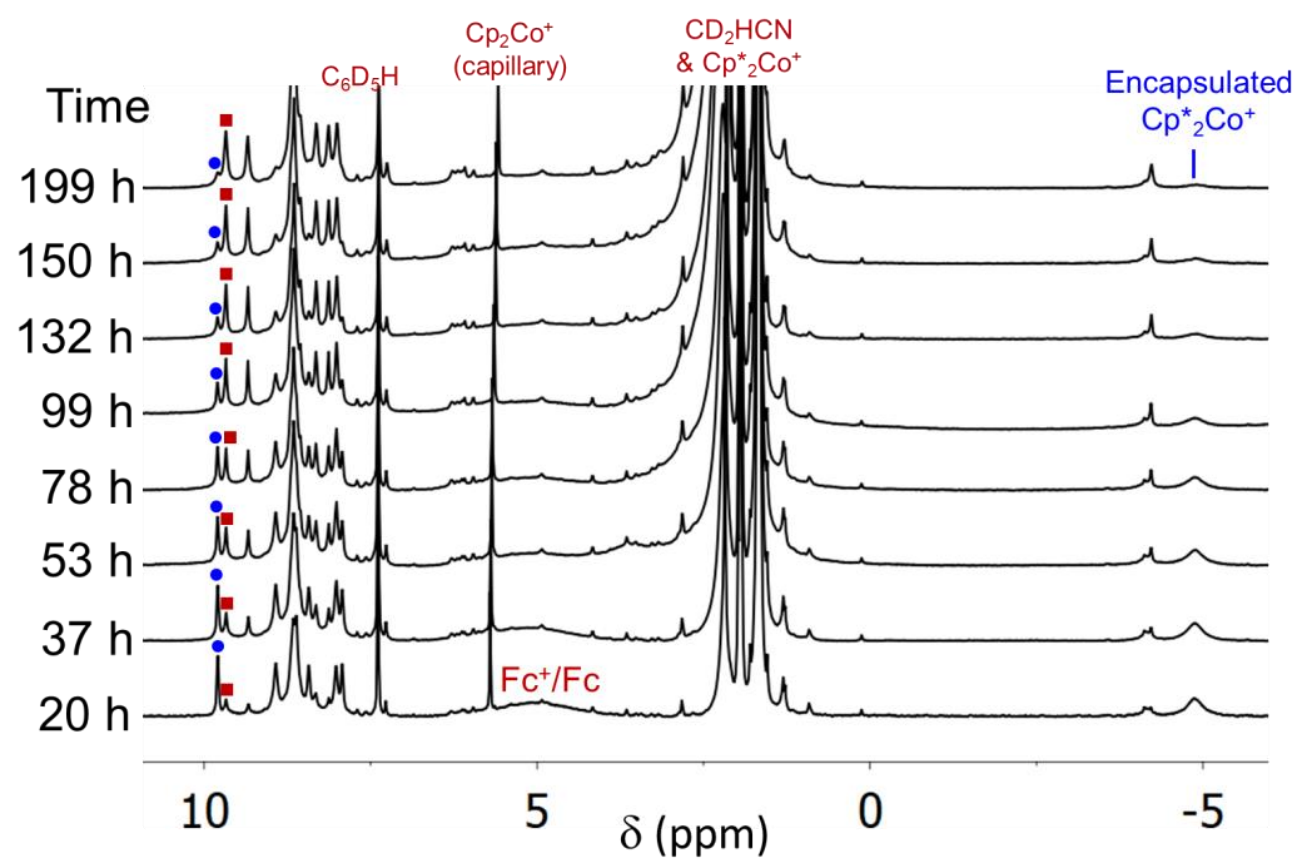

Figure S35. Select ${ }^{1} \mathrm{H}$ NMR spectra recorded from $20-199 \mathrm{~h}$ after adding 12 equiv of [Fc]PF 6 to the 1.2 $\mathrm{mM}$ sample of $\mathrm{Cp}_{2}{ }_{2} \mathrm{Co}^{+} @ 1 \mathrm{a}^{12+}$ that is plotted in Figure S33C. Blue circles and red squares mark the respective pyridyl 6-position $\mathrm{CH}$ resonances of $\mathrm{Cp}_{2}{ }_{2} \mathrm{Co}^{+} @ 1 \mathbf{a}^{12+}$ and $1 \mathrm{a}^{12+}$, which indicate $75 \%$ of the hostguest complex underwent dissociation within this period of monitoring, contrasted with only $\sim 25 \%$ of the corresponding control sample (see Figure S33A). Other major resonances not corresponding to the hostguest complex or host are labeled, including the $\mathrm{Fc}^{+} / \mathrm{Fc}$ resonance that largely disappears within $200 \mathrm{~h}$. 


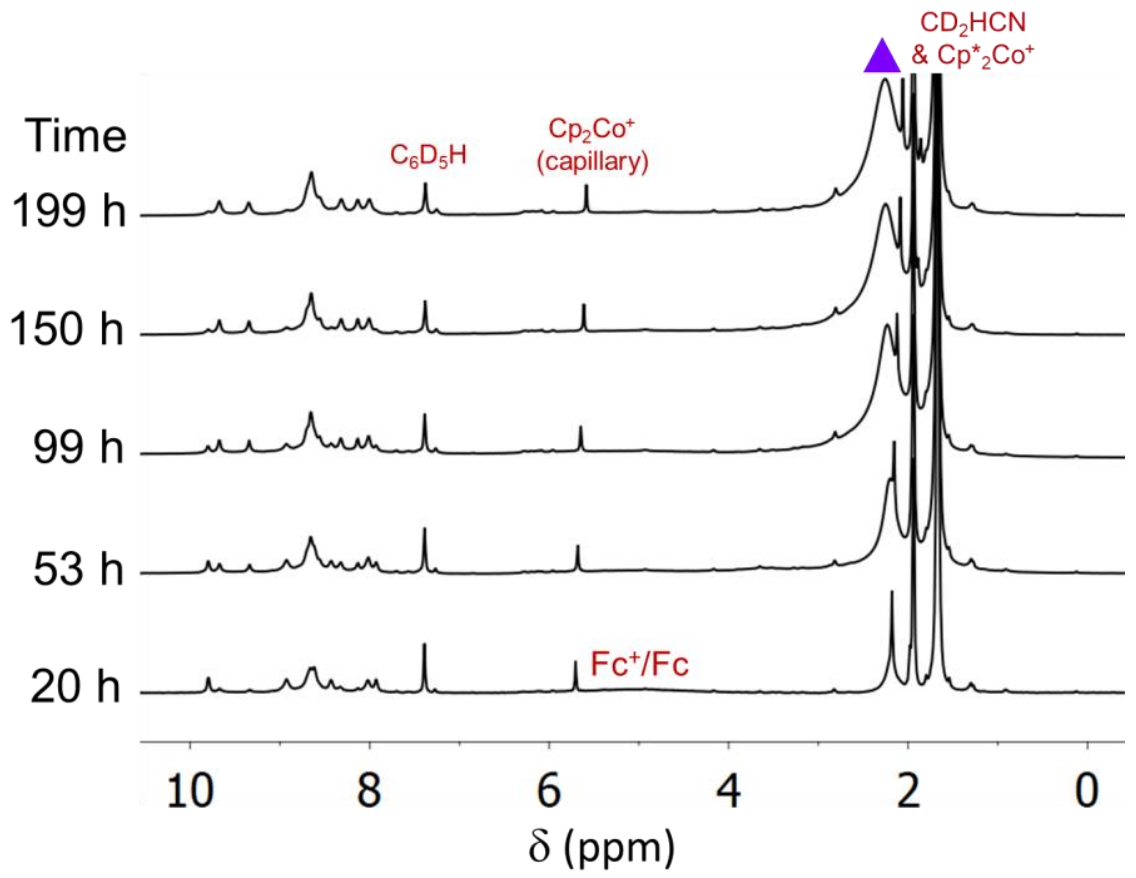

Figure S36. Select ${ }^{1} \mathrm{H}$ NMR spectra recorded from $20-199 \mathrm{~h}$ after adding 12 equiv of [Fc]PF 6 to the 1.2 $\mathrm{mM}$ sample of $\mathrm{Cp}{ }_{2} \mathrm{Co}^{+} @ 1 \mathrm{a}^{12+}$ that is plotted in Figure S33C. A purple triangle is used to mark a large, broad resonance that grows in over time as the $\mathrm{Fc}^{+} / \mathrm{Fc}$ resonance disappears (note that the disappearance of $\mathrm{Fc}^{+} / \mathrm{Fc}$ is more evident in Figure S35). The new resonance could not be identified but suggests that Fc and/or $\mathrm{Fc}^{+}$are converted to a new species over time. Other major resonances not corresponding to the host-guest complex or host are labeled.
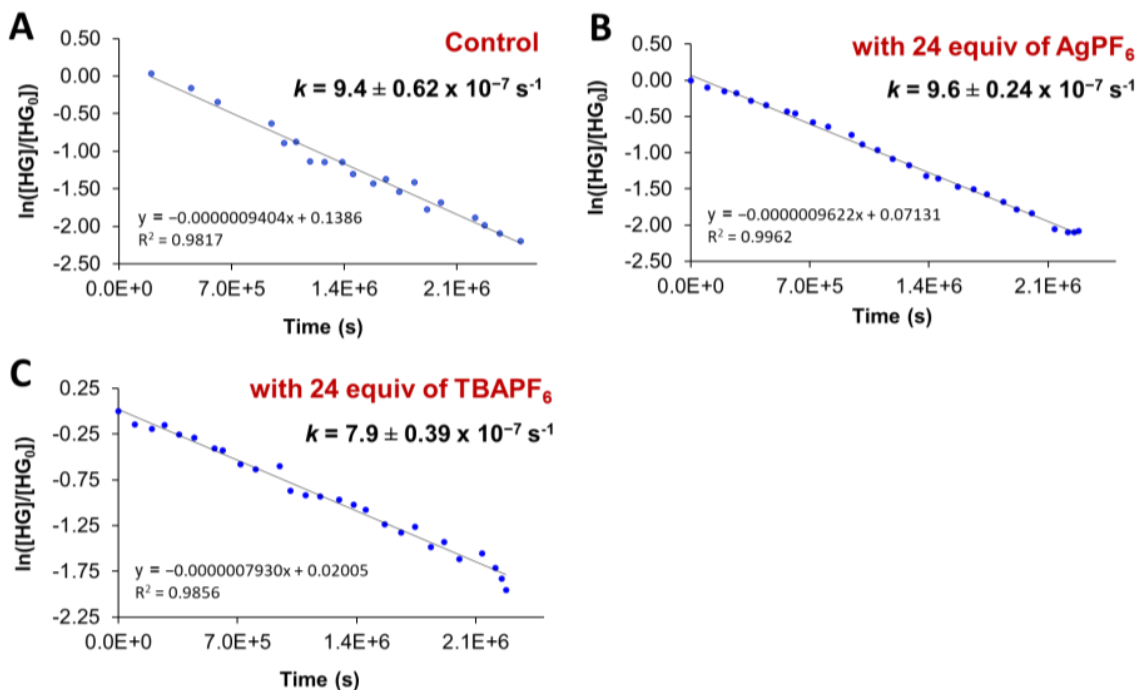

Figure S37. Plots of $\operatorname{In}\left([\mathrm{HG}] /\left[\mathrm{HG}_{0}\right]\right)$ vs. time $\left(\mathrm{HG}=\mathrm{Cp}_{2}{ }_{2} \mathrm{Co}^{+} @ 1 \mathrm{a}^{12+}\right)$ for $1.2 \mathrm{mM}$ samples of $\mathrm{Cp}^{*}{ }_{2} \mathrm{Co}^{+} @ 1 \mathrm{a}^{12+}$ in $\mathrm{PF}_{6}{ }^{-}$solutions with excess $\mathrm{AgPF}_{6}$ or $\mathrm{TBAPF}_{6}$. The host-guest complex was prepared by reducing $1 \mathbf{1 a} \bullet \mathbf{1 2 P F}_{6}$ with 12 equiv of $\mathrm{Cp}_{2}{ }_{2} \mathrm{Co}$ before reoxidizing with $\mathrm{AgPF}_{6}$, followed by dividing into three individual samples and treating with $\mathrm{AgPF}_{6}$ or $\mathrm{TBAPF}_{6}$ as described above in Procedure 4. (A) Control sample without additives. (B) Sample with 24 equiv of excess $\mathrm{AgPF}_{6}$ added. (C) Sample with 24 equiv of $\mathrm{TBAPF}_{6}$ added. 

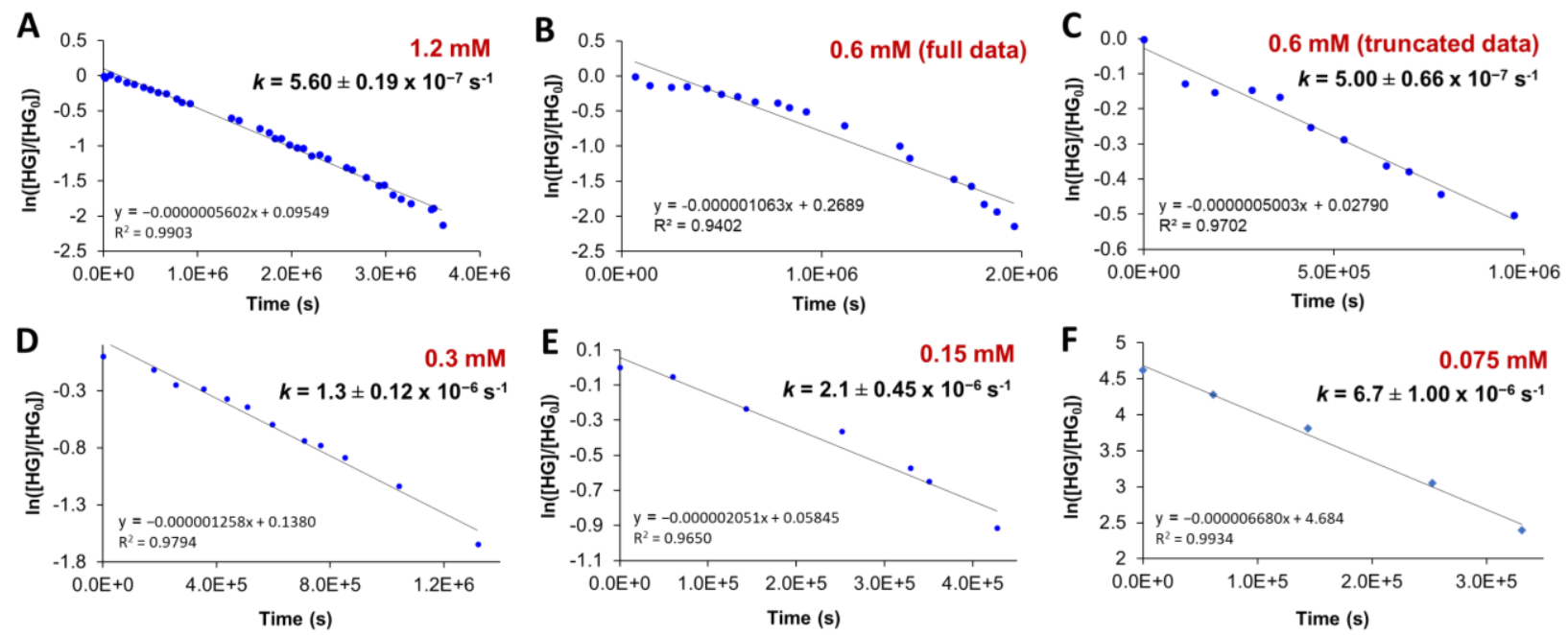

Figure S38. Plots of $\ln \left([\mathrm{HG}] /\left[\mathrm{HG}_{0}\right]\right)$ vs. time $\left(\mathrm{HG}=\mathrm{Cp}^{*}{ }_{2} \mathrm{Co}^{+} @ 1 \mathbf{a}^{12+}\right)$ for different concentration samples of $\mathrm{Cp}^{*}{ }_{2} \mathrm{Co}^{+} @ 1 \mathrm{a}^{12+}$ in $\mathrm{PF}_{6}{ }^{-}$solutions. The host-guest complex was prepared by reducing $\mathbf{1 a} \cdot \mathbf{1 2} \mathrm{PF}_{6}$ with 12 equiv of $\mathrm{Cp}_{2}{ }_{2} \mathrm{Co}$ before reoxidizing with $\mathrm{AgPF}_{6}$, followed by dividing into individual samples and diluting to (A) $1.2 \mathrm{mM},(B, C) 0.6 \mathrm{mM},(D) 0.3 \mathrm{mM},(E) 0.15 \mathrm{mM},(\mathrm{F}) 0.075 \mathrm{mM}$ following Procedure 5 described above. The $0.6 \mathrm{mM}$ sample did not display first-order decay of the host-guest complex over the entire course of monitoring, so a rate constant was estimated from initial data points. Note that these samples were prepared from the same batch of $\mathrm{Cp}^{*}{ }_{2} \mathrm{Co}^{+} @ 1 \mathbf{a}^{12+}$ that was used to generate the data presented in Figures S28 and S32. The $1.2 \mathrm{mM}$ sample presented here is from the same sample used for the $23^{\circ} \mathrm{C}$ kinetics measurement in Figure S28A and as the control sample in Figure S32A.
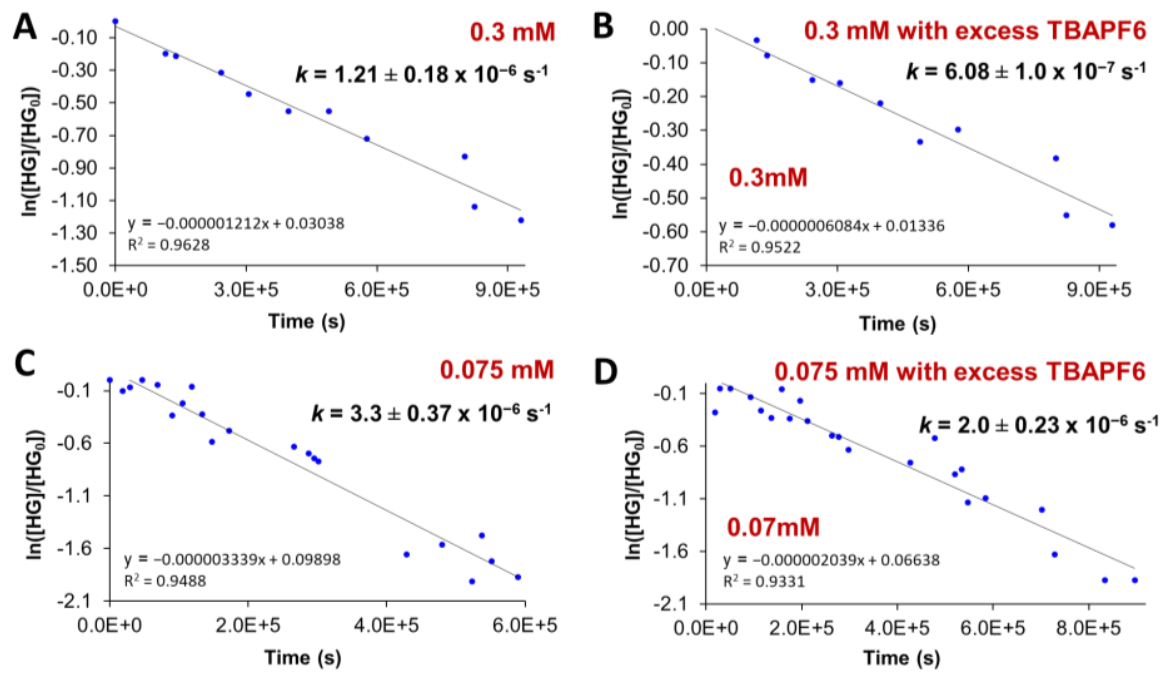

Figure S39. Plots of $\ln \left([\mathrm{HG}] /\left[\mathrm{HG}_{0}\right]\right)$ vs. time $\left(\mathrm{HG}=\mathrm{Cp}^{*}{ }_{2} \mathrm{Co}^{+} @ 1 \mathbf{a}^{12+}\right)$ for different concentration samples of $\mathrm{Cp}_{2}{ }_{2} \mathrm{Co}^{+} @ 1 \mathrm{a}^{12+}$ in $\mathrm{PF}_{6}{ }^{-}$solutions with vs. without excess $\mathrm{TBAPF}_{6}$ added. The host-guest complex was prepared by reducing $1 \mathrm{a} \cdot 12 \mathrm{PF}_{6}$ with 12 equiv of $\mathrm{Cp}_{2}{ }_{2} \mathrm{Co}$ before reoxidizing with $\mathrm{AgPF}_{6}$, followed by dividing into individual samples and diluting to $0.3 \mathrm{mM}$ or $0.075 \mathrm{mM}$ following Procedure 5 described above in this section. To one sample of each concentration was added enough $\mathrm{TBAPF}_{6}$ to reach a total $\mathrm{PF}_{6}{ }^{-}$ concentration of $28.8 \mathrm{M}$. (A) $0.3 \mathrm{mM}$ sample of $\mathrm{Cp}^{*}{ }_{2} \mathrm{Co}^{+} @ 1 \mathbf{a}^{12+}$ without added salt, (B) $0.3 \mathrm{mM}$ sample of $\mathrm{Cp}_{2}{ }_{2} \mathrm{Co}^{+} @ 1 \mathrm{a}^{12+}$ with added TBAPF 6 , (C) $0.075 \mathrm{mM}$ sample of $\mathbf{C p}^{*}{ }_{2} \mathrm{Co}^{+} @ 1 \mathbf{a}^{12+}$ without added salt, (D) 0.075 $\mathrm{mM}$ sample of $\mathrm{Cp}^{*}{ }_{2} \mathrm{Co}^{+} @ 1 \mathbf{a}^{12+}$ with added TBAPF 6 . 
A
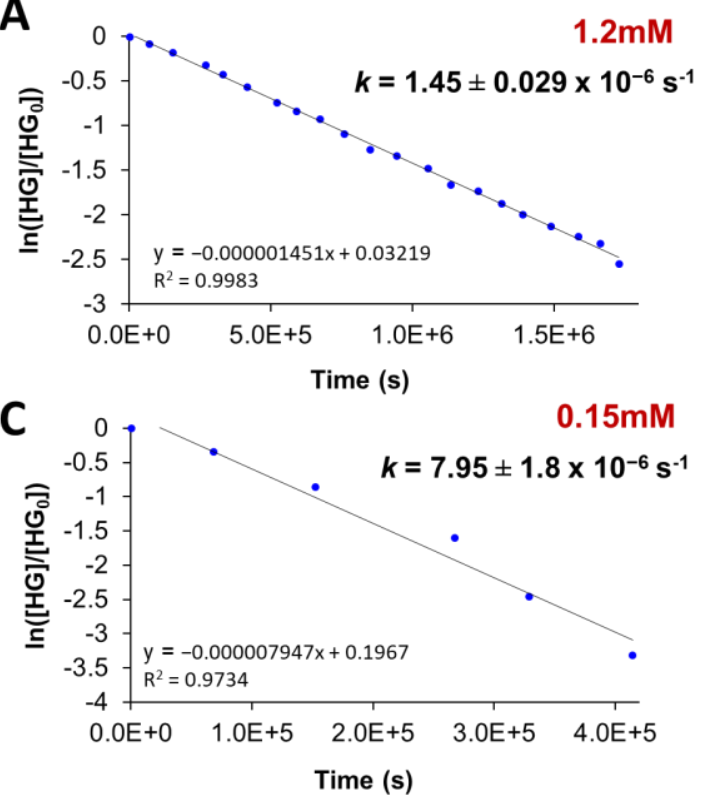

B

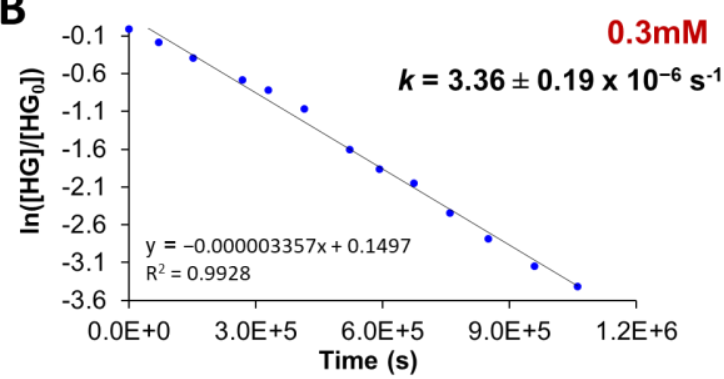

D

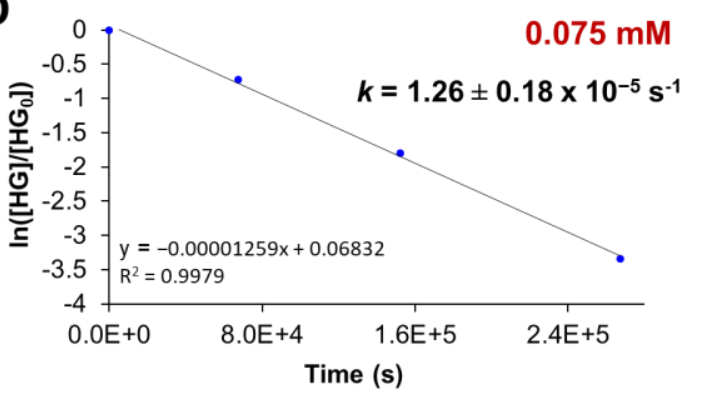

Figure S40. Plots of $\ln \left([\mathrm{HG}] /\left[\mathrm{HG}_{0}\right]\right)$ vs. time $\left(\mathrm{HG}=\mathrm{Cp}^{*}{ }_{2} \mathrm{Co}^{+} @ 1 \mathbf{a}^{12+}\right)$ for different concentration samples of $\mathrm{Cp}^{*}{ }_{2} \mathrm{Co}^{+} @ 1 \mathrm{a}^{12+}$ in $\mathrm{BF}_{4}{ }^{-}$solutions. The host-guest complex was prepared by reducing $\mathbf{1 a} \bullet \mathbf{1 2} \mathrm{BF}_{4}$ with 12 equiv of $\mathrm{Cp}_{2}{ }_{2} \mathrm{Co}$ before reoxidizing with $\mathrm{AgBF}_{4}$, followed by dividing into individual samples and diluting to (A) $1.2 \mathrm{mM}$, (B) $0.3 \mathrm{mM}$, (C) $0.15 \mathrm{mM}$, (D) $0.075 \mathrm{mM}$ following Procedure 5 described above. Note that these samples were prepared from the same batch of $\mathrm{Cp}_{2}{ }_{2} \mathrm{Co}^{+} @ 1 \mathrm{a}^{12+}$ that was used to generate the data in Figures S27. The $1.2 \mathrm{mM}$ sample presented here is the same sample as presented in Figure S27A.

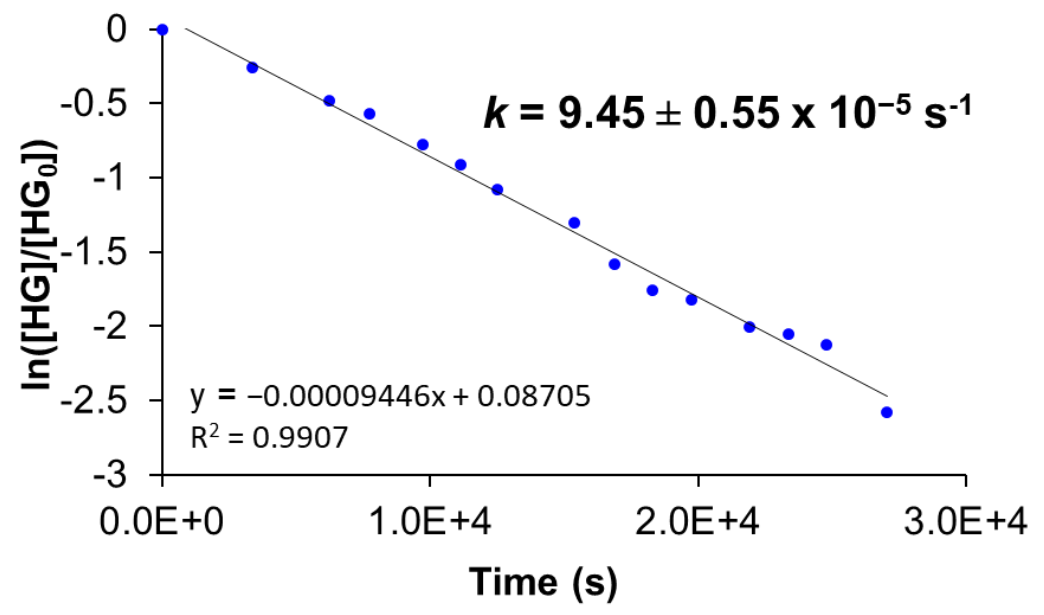

Figure S41. Plot of $\ln \left([\mathrm{HG}] /\left[\mathrm{HG}_{0}\right]\right)$ vs. time $\left(\mathrm{HG}=\mathrm{Cp}^{*}{ }_{2} \mathrm{Co}^{+} @ 1 \mathrm{a}^{12+}\right)$ for a $1.2 \mathrm{mM}$ sample of $\mathrm{Cp}^{*}{ }_{2} \mathrm{Co}^{+} @ 1 \mathbf{a}^{12+}$ that was prepared by reduction of a solution of $1 \mathrm{a} \bullet 12 \mathrm{PF}_{6}$ with 12 equiv of $\mathrm{Cp}_{2}{ }_{2} \mathrm{Co}$ before reoxidizing with slightly greater than 12 equiv of $\left[\mathrm{Fc}_{\mathrm{P}}\right] \mathrm{F}_{6}$ 

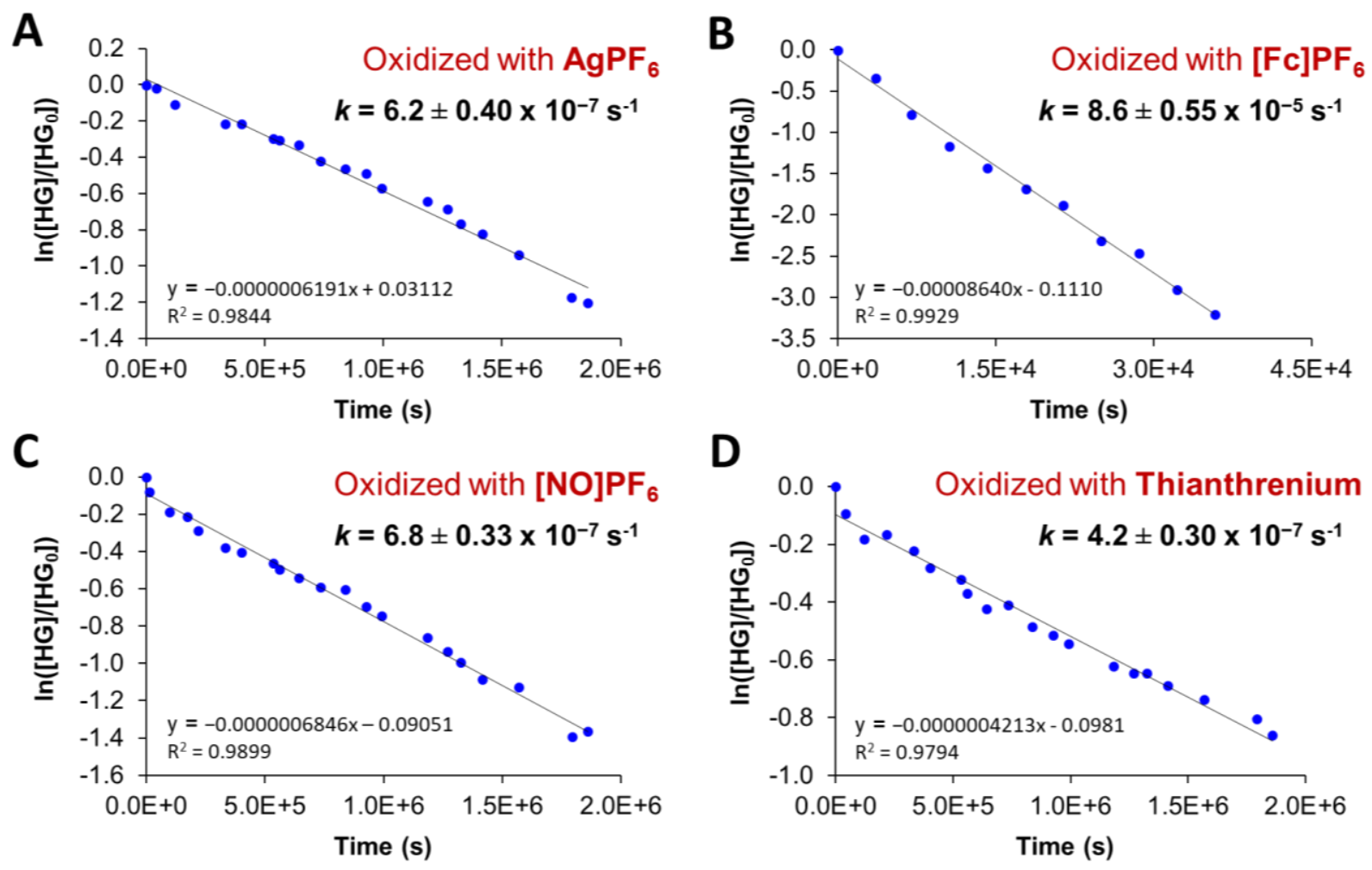

Figure S42. Plots of $\ln \left([\mathrm{HG}] /\left[\mathrm{HG}_{0}\right]\right)$ vs. time $\left(\mathrm{HG}=\mathrm{Cp}^{*}{ }_{2} \mathrm{Co}^{+} @ 1 \mathbf{a}^{12+}\right)$ for $1.2 \mathrm{mM}$ samples of $\mathrm{Cp}^{*}{ }_{2} \mathrm{Co}^{+} @ 1 \mathrm{a}^{12+}$ prepared by reducing $1 \mathrm{1a} \cdot 12 \mathrm{PF}_{6}$ with 12 equiv of $\mathrm{Cp}^{*}{ }_{2} \mathrm{Co}$ before reoxidizing with ca. 12.5 equiv. of the oxidants (A) $\mathrm{AgPF}_{6}$, (B) $\left[\mathrm{Fc}_{\mathrm{P}}\right] \mathrm{PF}_{6}$, (C) $\left[\mathrm{NO}_{\mathrm{P}} \mathrm{PF}_{6}\right.$, or (D) thianthrenium hexafluorophosphate. For the latter sample, a stock solution of thianthrenium hexafluorophosphate in $\mathrm{CD}_{3} \mathrm{CN}$ was prepared from thianthrene and $\left[\mathrm{NO}_{\mathrm{PF}} \mathrm{f}_{6}\right.$ following a reported procedure. ${ }^{4}$
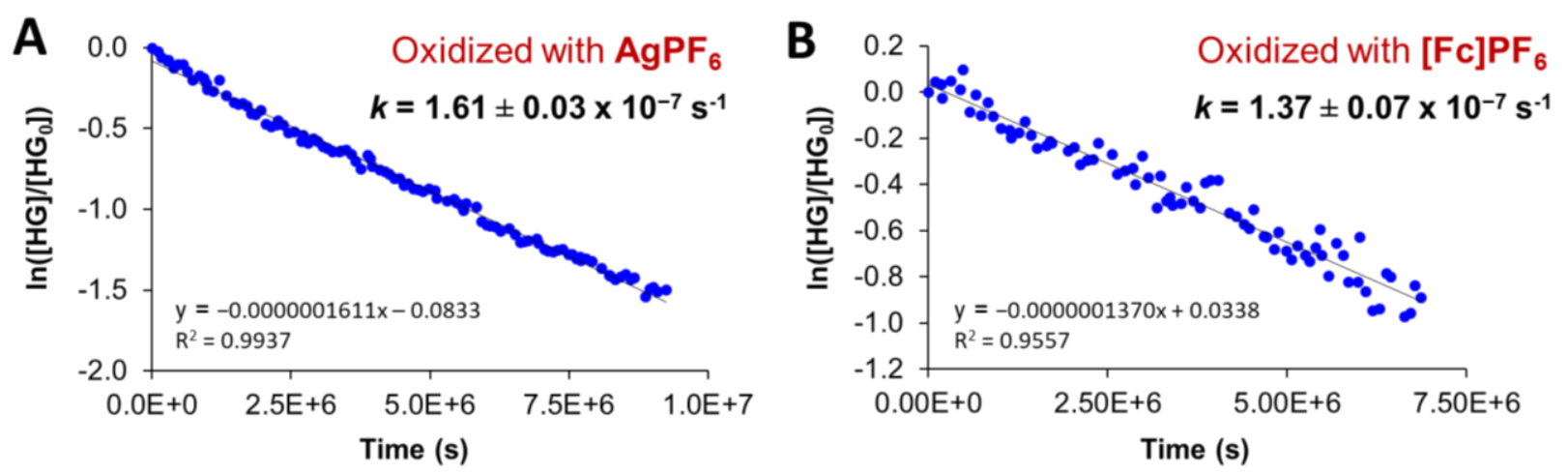

Figure S43. Plots of $\ln \left([\mathrm{HG}] /\left[\mathrm{HG}_{0}\right]\right)$ vs. time $\left(\mathrm{HG}=\mathbf{C p}_{2} \mathbf{C o}^{+} @ \mathbf{1} \mathbf{b}^{12+}\right)$ for $1.2 \mathrm{mM}$ samples of $\mathbf{C p}_{2} \mathbf{C o}^{+} @ \mathbf{1} \mathbf{b}^{12+}$ prepared by reducing $\mathbf{1 b} \cdot \mathbf{1 2} \mathrm{PF}_{6}$ with 3.5 equiv of $\mathrm{Cp}_{2} \mathrm{Co}$ before reoxidizing with ca. 4 equiv. of the oxidants (A) $\mathrm{AgPF}_{6}$, or (B) $\left[\mathrm{Fc}_{\mathrm{C}}\right] \mathrm{PF}_{6}$. 


\section{Van 't Hoff Analyses}

\section{7.a. Conformational changes of $\mathrm{Cp}_{2}{ }_{2} \mathrm{Co}^{+} @ 1 \mathrm{a}^{12+}$ in $\mathrm{PF}_{6}{ }^{-}$solutions.}

Van ' $t$ Hoff analysis was used to determine the enthalpy and entropy changes associated with the two conformations of $\mathrm{Cp}^{*}{ }_{2} \mathrm{Co}^{+} @ 1 \mathbf{a}^{12+}(1.2 \mathrm{mM}$ total concentration) that were observed by variable temperature ${ }^{1} \mathrm{H}$ NMR spectroscopy in $\mathrm{PF}_{6}{ }^{-}$solutions in $\mathrm{CD}_{3} \mathrm{CN}$ (see Figure $\mathrm{S6}$ ). The equilibrium ratio of the two conformations was determined at $233,243,253,263$, and $273 \mathrm{~K}$ by integration of the two distinct resonances (ca. $-4.8 \mathrm{ppm}$ and $-5.4 \mathrm{ppm}$ ) of the $\mathrm{Cp}_{2}{ }_{2} \mathrm{Co}^{+}$guest that could be observed in this temperature range. The equilibrium constant was defined as $K=$ [Integral@-5.4ppm]/[Integral@-4.8ppm], and $\Delta H$ and $\Delta S$ were extracted from a plot of $R \bullet \ln (K)$ vs. $1 / T$. Since the more upfield resonance $(-5.4 \mathrm{ppm})$ is believed to arise from a conformation of the host-guest complex with its apertures opened, the $\Delta H$ and $\Delta S$ values correspond to a structural rearrangement that opens the apertures of the host.

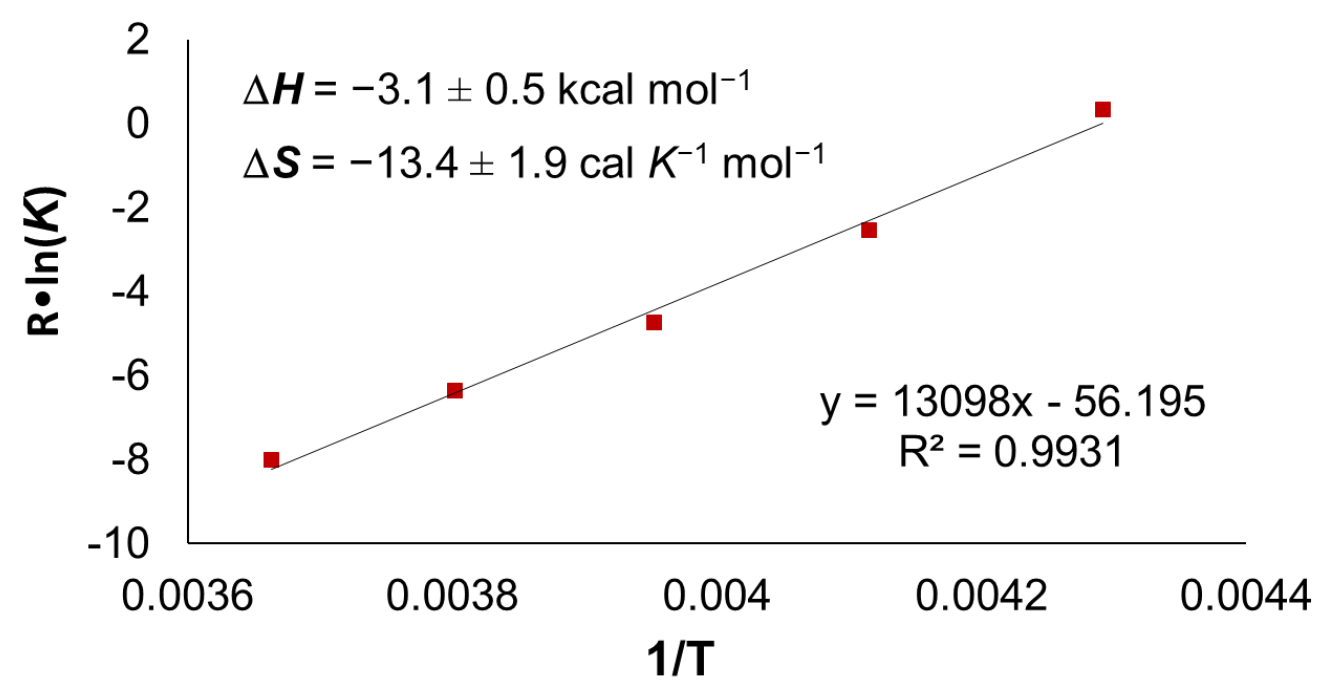

Figure S44. Van 't Hoff plot for the conformational changes of $\mathrm{Cp}_{2}{ }_{2} \mathrm{Co}^{+} @ 1 \mathrm{a}^{12+}$ observed in $\mathrm{PF}_{6}{ }^{-}$solutions by ${ }^{1} \mathrm{H}$ NMR spectroscopy from $233-273 \mathrm{~K}$. The equilibrium constant for this analysis was defined as $K=[$ Integral@-5.4ppm]/[Integral@-4.8ppm].

\section{7.b. Association of $\mathrm{PF}_{6}{ }^{-}$in $1 a^{12+}$.}

Van 't Hoff analysis was used to determine the enthalpy and entropy changes associated with the association of $\mathrm{PF}_{6}{ }^{-}$anions in the host $1 \mathrm{a}^{12+}$ based on estimated association constants determined from ${ }^{19} \mathrm{~F}$ NMR spectra of 0.03 to $3.0 \mathrm{mM}$ solutions of $1 \mathbf{1 a} \cdot 12 \mathbf{P F}_{6}$ over the temperature range $233 \mathrm{~K}$ to $353 \mathrm{~K}$. Estimation of the association constants made use of several assumptions, some which are well-justified while others are simplifications made for practical reasons. These assumptions limit the accuracy of the 
estimated association constants, and thus, of the Van ' $t$ Hoff analysis as well. Nevertheless, the data make it clear that $\mathrm{PF}_{6}{ }^{-}$association in $1 \mathrm{a}^{12+}$ is strong $\left(K_{\mathrm{a}} \geq 10^{3} \mathrm{M}^{-1}\right.$ per binding site) and varies little with temperature, both of which can only be true if anion association is entropically favorable.

Determination of $K_{\mathrm{a}}$ for $\mathrm{PF}_{6}{ }^{-}$association in $1 \mathrm{a}^{12+}$. Solutions of $1 \mathrm{a} \cdot 12 \mathrm{PF}_{6}$ in $\mathrm{CD}_{3} \mathrm{CN}$ were prepared at concentrations of 3.0, 0.77, 0.1, and $0.03 \mathrm{mM}$. The ${ }^{19} \mathrm{~F}$ NMR spectra of these samples and of a sample of TBAPF $_{6}$ were recorded at $298 \mathrm{~K}$ (Figure S44) and then at $10 \mathrm{~K}$ intervals from $233-353 \mathrm{~K}$. A sealed capillary of fluorobenzene was used as an internal standard for comparing the samples. The difference $(\Delta \delta)$ of the ${ }^{19} \mathrm{~F}$ chemical shift of the samples of $\mathbf{1 a} \cdot \mathbf{1 2}^{2} \mathbf{P F}_{6}$ relative to the chemical shift of the $\mathrm{TBAPF}_{6}$ reference were then determined at each temperature and are shown in Table S1. This data was then fit to a 1:1 binding model using an Excel Macro created by Christopher Hunter, providing the association constants listed in Table S1. Assumptions and limitations of this approach are described:

(1) The chemical shift measured for the reference sample of $\mathrm{TBAPF}_{6}$ was taken to represent free $\mathrm{PF}_{6}{ }^{-}$ in solution (i.e., weak interactions with $\mathrm{TBA}^{+}$). This assumption is well-founded since the ${ }^{19} \mathrm{~F} \mathrm{NMR}$ spectrum of $\mathrm{TBAPF}_{6}$ was found to exhibit little concentration dependence.

(2) Changes to the ${ }^{1} \mathrm{H}$ NMR chemical shifts of the host were small and difficult to measure for the most dilute solutions, so the relative $\delta \Delta$ of the signals of the host were assumed to be proportional to the changes observed in the ${ }^{19} \mathrm{~F}$ NMR spectra of the anions. This is a well-founded assumption since all samples maintain a constant ratio of $1 \mathrm{a}^{12+}$ to $\mathrm{PF}_{6}{ }^{-}$, so relative changes to the ${ }^{19} \mathrm{~F}$ chemical shift caused by anion binding must be proportional to changes that would be observed for the host.

(3) Only a small number of concentrations of $1 \mathrm{a}^{12+}(3.0,0.77,0.1$, and $0.03 \mathrm{mM})$ were examined to reduce the time required to collect data since measurements were performed over a wide range of temperatures.

(4) The use of a 1:1 binding model assumes independent behavior of the anion binding sites of $1 \mathbf{a}^{12+}$. This assumption allowed the data to be analyzed with limited data points, but is likely a simplification considering that DFT results suggest the host may undergo conformational changes in response to association/dissociation of anions.

(5) Changes to the ${ }^{1} \mathrm{H}$ NMR chemical shifts of the host were small and difficult to measure for the most dilute solutions, so the relative $\delta \Delta$ of the signals of the host were assumed to be proportional to the changes observed in the ${ }^{19} \mathrm{~F}$ NMR spectra for the anions. This is a well-founded assumption since all samples maintain a constant ratio of $1 \mathrm{a}^{12+}$ to $\mathrm{PF}_{6}{ }^{-}$.

Van ' $\mathrm{t}$ Hoff analysis of $\mathrm{PF}_{6}{ }^{-}$association in $1 \mathbf{a}^{12+}$. The association constants determined from $233 \mathrm{~K}$ to 353 $K$ were used to create a plot of $\mathrm{R} \bullet \ln (K)$ vs. $1 / T$. A poor linear fit was obtained for this data, but even allowing for considerable error in the determined $\Delta \mathrm{H}$ and $\Delta \mathrm{S}$, it appears that anion association in $1 \mathrm{a}^{12+}$ is driven primarily by a favorable entropy. 


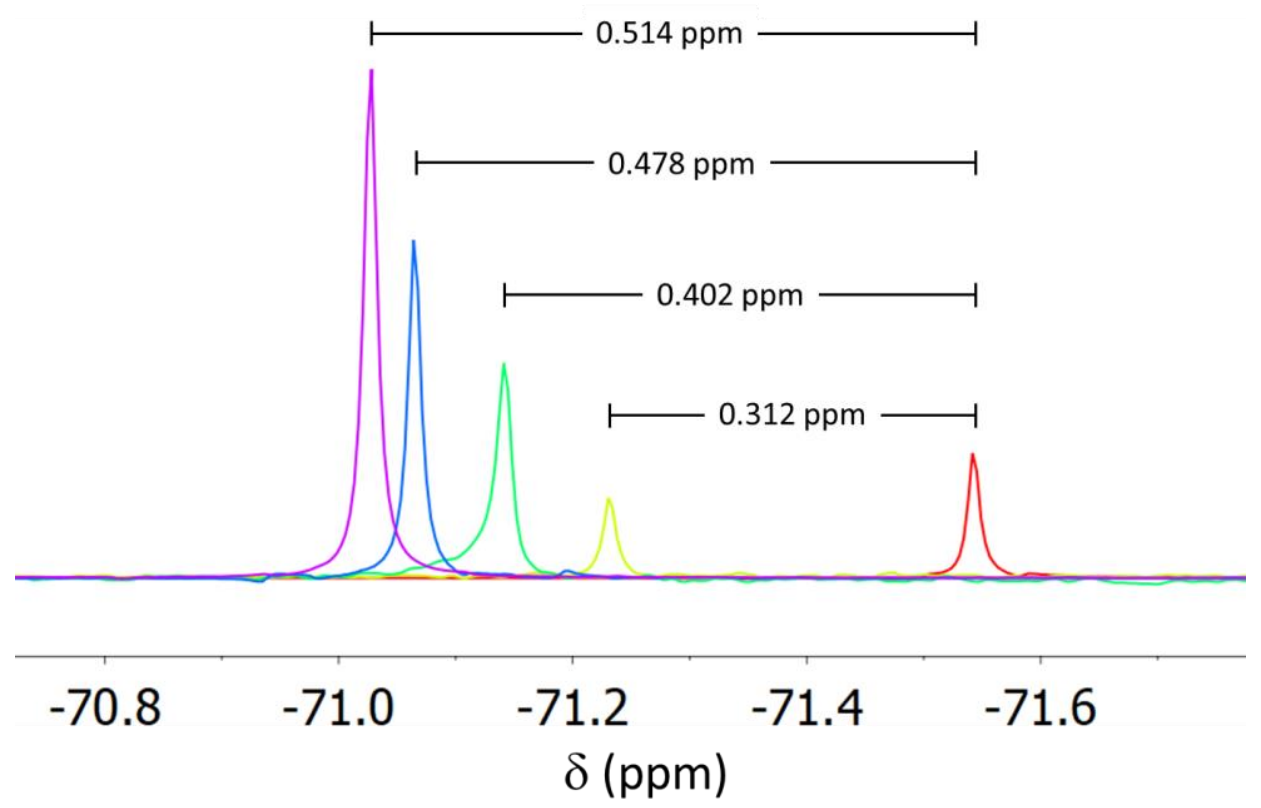

Figure S45. Partial overlaid ${ }^{19} \mathrm{~F}$ NMR spectra of $\mathrm{CD}_{3} \mathrm{CN}$ solutions of $\mathrm{TBAPF}_{6}\left(1.2 \mathrm{mM}\right.$, red) and $\mathrm{CD}_{3} \mathrm{CN}$ solutions of $1 \mathrm{a} \cdot 12 \mathrm{PF}_{6}$ at concentrations of $3.0 \mathrm{mM}$ (purple), $0.77 \mathrm{mM}$ (blue), $0.1 \mathrm{mM}$ (green), and 0.03 $\mathrm{mM}$ (yellow). Spectra were recorded at $298 \mathrm{~K}$ and only the more upfield half of the doublet resulting from $\mathrm{P}-\mathrm{F}$ coupling in the $\mathrm{PF}_{6}{ }^{-}$anions is shown.

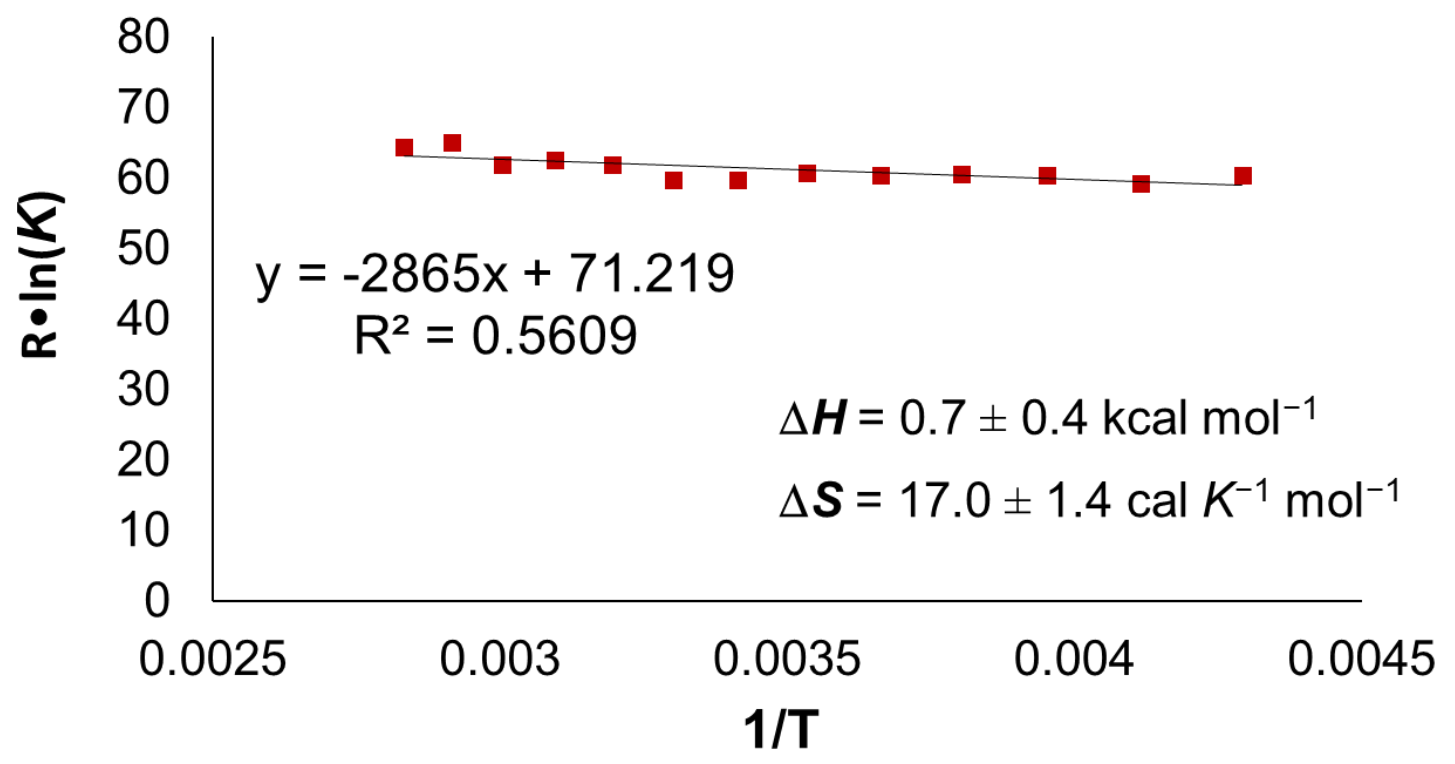

Figure S46. van 't Hoff plot for the association of $\mathrm{PF}_{6}{ }^{-}$in the host $1 \mathrm{a}^{12+}$ measured across the temperature range $233-353 \mathrm{~K}$. The association constants were determined as described above in this section. 
Table S1. Summary of the data used in the van 't Hoff analysis plotted in Figure S46.

\begin{tabular}{|c|c|c|c|c|c|c|c|c|c|}
\hline \multirow[b]{2}{*}{$\mathrm{T}\left({ }^{\circ} \mathrm{C}\right)$} & \multicolumn{2}{|c|}{$3.0 \mathrm{mM}^{\mathrm{a}}$} & \multicolumn{2}{|c|}{$0.77 \mathrm{mM}^{\mathrm{a}}$} & \multicolumn{2}{|c|}{$0.1 \mathrm{mM}^{\mathrm{a}}$} & \multicolumn{2}{|c|}{$0.03 \mathrm{mM}^{\mathrm{a}}$} & \multirow[b]{2}{*}{$K_{\mathrm{a}}\left(\times 10^{3} \mathrm{M}^{-1}\right)^{\mathrm{d}}$} \\
\hline & $\Delta \delta^{\mathrm{a}}$ & $\begin{array}{c}\text { Relative } \\
\text { Shift }^{\mathrm{c}}\end{array}$ & $\Delta \delta^{\mathrm{a}}$ & $\begin{array}{c}\text { Relative } \\
\text { shift }^{\mathrm{c}}\end{array}$ & $\Delta \delta^{\mathrm{a}}$ & $\begin{array}{c}\text { Relative } \\
\text { shift }^{c}\end{array}$ & $\Delta \delta^{\mathrm{a}}$ & $\begin{array}{c}\text { Relative } \\
\text { shift }^{\mathrm{c}}\end{array}$ & \\
\hline 80 & 0.692 & 1 & 0.622 & 0.899 & 0.537 & 0.776 & 0.389 & 0.561 & 2.30 \\
\hline 70 & 0.650 & 1 & 0.594 & 0.915 & 0.516 & 0.794 & 0.382 & 0.588 & 2.51 \\
\hline 60 & 0.618 & 1 & 0.563 & 0.911 & 0.486 & 0.787 & 0.376 & 0.608 & 1.69 \\
\hline 50 & 0.584 & 1 & 0.537 & 0.920 & 0.463 & 0.793 & 0.357 & 0.611 & 1.86 \\
\hline 40 & 0.558 & 1 & 0.514 & 0.920 & 0.440 & 0.787 & 0.340 & 0.608 & 1.69 \\
\hline 30 & 0.539 & 1 & 0.490 & 0.909 & 0.414 & 0.768 & 0.321 & 0.594 & 1.32 \\
\hline 20 & 0.505 & 1 & 0.465 & 0.920 & 0.391 & 0.773 & 0.306 & 0.605 & 1.32 \\
\hline 10 & 0.476 & 1 & 0.442 & 0.929 & 0.369 & 0.777 & 0.287 & 0.603 & 1.47 \\
\hline 0 & 0.450 & 1 & 0.418 & 0.929 & 0.350 & 0.778 & 0.274 & 0.608 & 1.42 \\
\hline-10 & 0.429 & 1 & 0.397 & 0.926 & 0.333 & 0.777 & 0.259 & 0.604 & 1.46 \\
\hline-20 & 0.410 & 1 & 0.382 & 0.933 & 0.318 & 0.777 & 0.248 & 0.606 & 1.43 \\
\hline-30 & 0.391 & 1 & 0.363 & 0.929 & 0.303 & 0.774 & 0.240 & 0.614 & 1.23 \\
\hline-40 & 0.374 & 1 & 0.350 & 0.938 & 0.293 & 0.784 & 0.231 & 0.619 & 1.42 \\
\hline
\end{tabular}

(a) Concentration of $1 \mathbf{1 a} \mathbf{1 2}^{2} \mathrm{PF}_{6}$. (b) Difference between the ${ }^{19} \mathrm{~F}$ chemical shift observed for the $\mathrm{PF}_{6}{ }^{-}$anions in solutions of $1 \mathbf{1 a} \cdot \mathbf{1 2 P F}_{6}$ relative to that observed for a solution of TBAPF 6 at each temperature. (c) Fraction of $\Delta \delta$ observed at each concentration relative to that observed for $3.0 \mathrm{mM}$ solutions at each temperature. (d) Association constants determined by fitting the $\Delta \delta$ at each temperature to a $1: 1$ binding model using a concentration of anion-binding sites $2 x$ that of the concentration of the host. 


\section{DFT Calculations}

Geometry optimization and energy calculations were performed using Quickstep within the CP2K software package. ${ }^{5}$ Electrostatic energies were evaluated using the wavelet solver within a cubic simulation cell of side length $40 \AA$, and used a plane-wave cutoff of 400 Ry. We employed the PerdewBurke-Ernzerhof (PBE) generalized gradient approximation (GGA) within the density functional theory (DFT) calculations. All calculations employed double- $\zeta$ valence polarization basis sets optimized for molecules (DZVP-MOLOPT-SR-GTH) ${ }^{6}$ and Goedecker-Teter-Hutter (GTH) pseudopotentials. ${ }^{7}$ For both Co and $\mathrm{Pt}$, pseudopotentials accounted for the $1 s^{2} 2 s^{2} 2 p^{6}$ electrons, with all others treated explicitly in the DFT calculations. The calculations were performed with the net charge appropriate for each cationic state by modifying the total number of electrons in the system as needed.

Geometry optimizations were performed using the limited memory Broyden-Fletcher-Goldfarb-Shanno (LBFGS) optimization algorithm with convergence criteria of a maximum geometry change (MAX_DR) of $3 \times 10^{-3}$ Bohr, a maximum force (MAX_FORCE) of $4.5 \times 10^{-4}$ Hartree/Bohr, a root mean square geometry change (RMS_DR) of $1.5 \times 10^{-3} \mathrm{Bohr}$, and a root mean square force per configuration (RMS_FORCE) of $3 \mathrm{x}$ $10^{-4}$ Hartree/Bohr. Initial configurations of $\mathrm{Cp}_{2}{ }_{2} \mathrm{Co}^{+} @ 1 \mathrm{a}^{12+}$ were approximated using the crystal structure reported for a closely related $\mathrm{Pd}$-linked metal-organic nanoprism, ${ }^{8}$ including the initial placement of two internally bound $\mathrm{PF}_{6}{ }^{-}$anions, which were removed as appropriate for examining their influence on the structure. The effects of replacing the $\mathrm{PF}_{6}{ }^{-}$anions with $\mathrm{BF}_{4}{ }^{-}$anions were evaluating by substituting $\mathrm{BF}_{4}{ }^{-}$ anions at the original location of the $\mathrm{PF}_{6}{ }^{-}$anions, then performing a geometry optimization as described above. Lastly, the open conformation of $\left[\left(\mathrm{Cp}_{2}{ }_{2} \mathrm{Co}^{+} \cdot 2 \mathrm{PF}_{6}{ }^{-}\right) @ 1 \mathrm{a}^{12+}\right]^{11+}$ was optimized using the methods described above starting from an initial geometry that was located using molecular dynamics simulations:

Molecular dynamics (MD) simulations were performed using the CP2K software package starting from the same initial geometry used for geometry optimization of the closed state of $\left[\left(\mathrm{Cp}^{*}{ }_{2} \mathrm{Co}^{+} \cdot 2 \mathrm{PF}_{6}{ }^{-}\right) @ 1 \mathrm{a}^{12+}\right]^{11+}$. The simulations were carried out in the canonical (NVT) ensemble, with constant number of particles, volume, and temperature. A constant temperature of $100 \mathrm{~K}$ was maintained using a canonical velocity rescaling thermostat, ${ }^{9}$ and the equations of motion were integrated using a timestep of $1 \mathrm{fs}$. After locating an open conformation of $\left[\left(\mathrm{Cp}^{*}{ }_{2} \mathrm{Co}^{+} \cdot 2 \mathrm{PF}_{6}{ }^{-}\right) @ 1 \mathbf{a}^{12+}\right]^{11+}$, DFT geometry optimization was performed as described above.
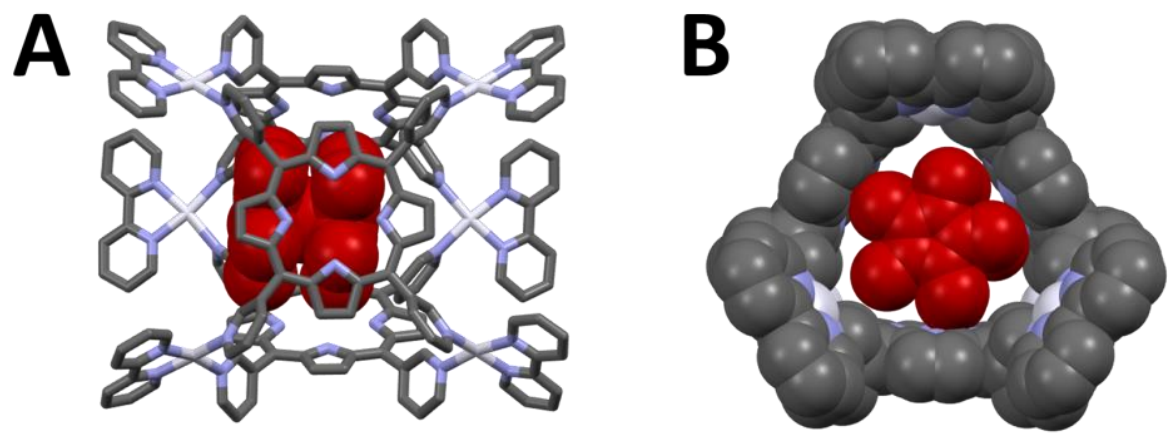

Figure S47. Computationally optimized structure of the $\left[\mathrm{Cp}_{2}{ }_{2} \mathrm{Co}^{+} @ 1 \mathbf{a}^{12+}\right]^{13+}$ form of $\mathrm{Cp}^{*}{ }_{2} \mathrm{Co}^{+} @ 1 \mathbf{a}^{12+}$. The $\mathrm{Cp}_{2}{ }_{2} \mathrm{Co}^{+}$guest is depicted in red, carbon atoms of the host in gray, $\mathrm{N}$ in light blue, and $\mathrm{Pt}$ in white. (A) View facing a porphyrin wall of $\left[\mathrm{Cp}^{*}{ }_{2} \mathrm{Co}^{+} @ 1 \mathrm{a}^{12+}\right]^{13+}$. (B) View of a triangular face of $\left[\mathrm{Cp}^{*}{ }_{2} \mathrm{Co}^{+} @ 1 \mathrm{a}^{12+}\right]^{13+}$. 

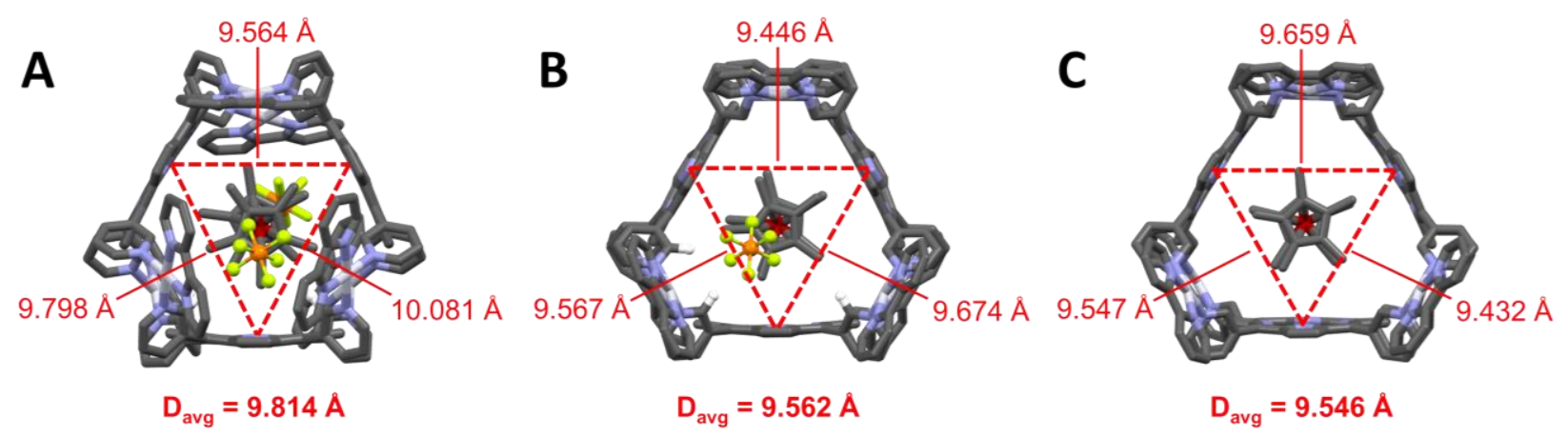

Figure S48. Comparison of computationally optimized structures of the $(\mathrm{A})\left[\left(\mathrm{Cp}^{*}{ }_{2} \mathrm{Co}^{+} \cdot 2 \mathrm{PF}_{6}{ }^{-}\right) @ 1 \mathrm{a}^{12+}\right]^{11+},(\mathrm{B})$ $\left[\left(\mathrm{Cp}_{2}{ }_{2} \mathrm{Co}^{+} \bullet \mathrm{PF}_{6}{ }^{-}\right) @ 1 \mathrm{a}^{12+}\right]^{12+}$, and (C) $\left[\mathrm{Cp}_{2}{ }_{2} \mathrm{Co}^{+} @ 1 \mathbf{a}^{12+}\right]^{13+}$ forms of $\mathrm{Cp}_{2}{ }_{2} \mathrm{Co}^{+} @ 1 \mathbf{a}^{12+}$. Views facing a triangular face of the host-guest complex are presented with the centroid-to-centroid distances between the porphyrin walls labeled. Centroids of each porphyrin are defined by the four central nitrogen atoms of these units. The average centroid-to-centroid distances show a compression of the central cavity of the host in $\left[\left(\mathrm{Cp}^{*}{ }_{2} \mathrm{Co}^{+} \cdot \mathrm{PF}_{6}{ }^{-}\right) @ 1 \mathrm{a}^{12+}\right]^{12+}$ and $\left[\mathrm{Cp}^{*}{ }_{2} \mathrm{Co}^{+} @ 1 \mathrm{a}^{12+}\right]^{13+}$ relative to that in $\left[\left(\mathrm{Cp}^{*}{ }_{2} \mathrm{Co}^{+} \cdot 2 \mathrm{PF}_{6}{ }^{-}\right) @ 1 \mathrm{a}^{12+}\right]^{11+}$.
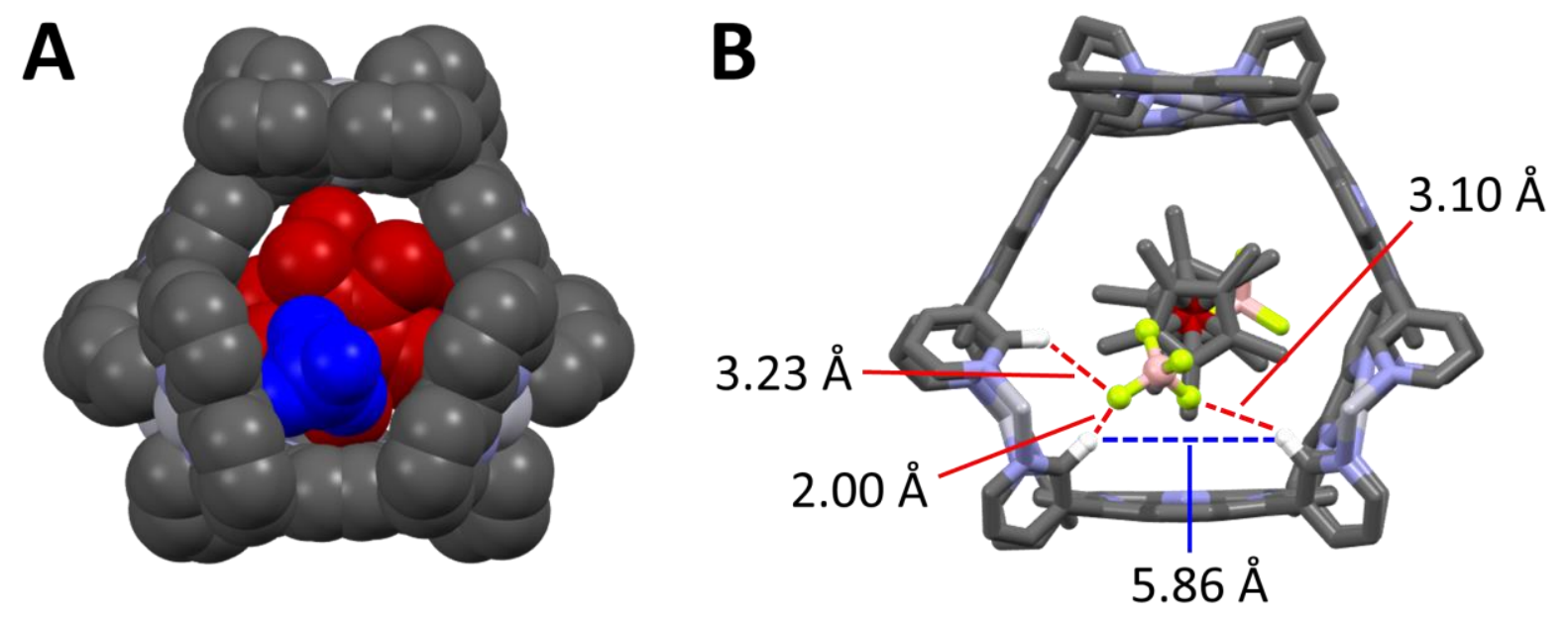

Figure S49. Computationally optimized structure of $\left[\left(\mathrm{Cp}_{2}{ }_{2} \mathrm{Co}^{+} \cdot 2 \mathrm{BF}_{4}^{-}\right) @ 1 \mathrm{a}^{12+}\right]^{11+}$. (A) Space-filling view of a triangular face the complex with the cationic guest shown in red and $\mathrm{BF}_{4}{ }^{-}$anions in blue. (B) View of the same triangular face with selected $\mathrm{CH}---\mathrm{F}$ and $\mathrm{CH}---\mathrm{HC}$ distances illustrated. Two bipy ligands are omitted for clarity. 


\section{References}

1. Dutton, K.G.; Rothschild, D. A.; Pastore, D. B.; Emge, T. J.; Lipke, M. C., The Influence of RedoxActive Linkers on the Stability and Physical Properties of a Highly Electroactive Porphyrin Nanoprism. Inorg. Chem. 2020, 59, 12616 - 12624.

2. Dolbier, W. R., Guide to Fluorine NMR for Organic Chemists. Wiley: Hoboken, NJ, 2008.

3. Allouche, L.; Marquis, A.; Lehn, J.-M., Discrimination of Metallosupramolecular Architectures in Solution by Using Diffusion Ordered Spectroscopy (DOSY) Experiments: Double-Stranded Helicates of Different Lengths. Chem. Eur. J. 2006, 12, 7520 - 7525.

4. Bandlish, B. K.; Shine, H. J. Ion radicals. 37. Preparation and isolation of cation radical tetrafluoroborates by the use of nitrosonium tetrafluoroborate. J. Org. Chem. 1977, 42, 561 - 563.

5. Kühne, T. D.; lannuzzi, M.; Del Ben, M.; Rybkin, V. V.; Seewald, P.; Stein, F.; Laino, T.; Khaliullin, R. Z.; Schütt, O.; Schiffmann, F. CP2K: An electronic structure and molecular dynamics software package-Quickstep: Efficient and accurate electronic structure calculations. J. Chem. Phys. 2020, 152, 194103.

6. VandeVondele, J.; Hutter, J. Gaussian basis sets for accurate calculations on molecular systems in gas and condensed phases. J. Chem. Phys. 2007, 127, 114105.

7. Goedecker, S.; Teter, M.; Hutter, J. Separable dual-space Gaussian pseudopotentials. Phys. Rev. B 1996, 54, 1703.

8. Bar, A. K.; Mohapatra, S.; Zangrando, E.; Mukherjee, P. S. A Series of Trifacial Pd 6 Molecular Barrels with Porphyrin Walls. Chem. Eur. J. 2012, 18, 9571-9579.

9. Bussi, G.; Donadio, D.; Parrinello, M. Canonical sampling through velocity rescaling. J. Chem. Phys. 2007, 126, 014101. 